\title{
Fungal diversity in the tropics: Entoloma spp. in Panama
}

\author{
Kai Reschke ${ }^{1}$ (1) Machiel E. Noordeloos ${ }^{2} \cdot$ Cathrin Manz ${ }^{1} \cdot$ Tina A. Hofmann ${ }^{3}$. José Rodríguez-Cedeño ${ }^{3}$. \\ Bálint Dima ${ }^{4} \cdot$ Meike Piepenbring $^{1}$
}

Received: 30 August 2021 / Revised: 9 October 2021 / Accepted: 12 October 2021 / Published online: 4 March 2022

(c) The Author(s) 2022, corrected publication 2022

\begin{abstract}
Entoloma (Agaricales, Basidiomycota) is a species-rich genus with approximately 2000 species known worldwide. In Central America, however, information about the species of this genus is sparse, despite the generally high biodiversity in this region. Recently, 124 specimens of Entoloma were collected in Panama, Chiriquí Province. In the present publication, the morphology of 20 species represented by more than one specimen is described and depicted with photographs, line drawings, and scanning electron micrographs. Molecular phylograms based on ITS or concatenated ITS and partial nc LSU rDNA sequences are provided. The taxonomic status of these species is evaluated and 17 species of Entoloma are described as new to science. Only one species could be assigned to an already known species, viz. Entoloma belouvense. Nolanea albertinae, described from Brazil, appeared similar and is combined in E. belouvense on varietal level. The identifications of two further species are uncertain. At least 30 other species, including potentially new species, cannot formally be described due to insufficient material. A preliminary key to the species of the genus Entoloma in Panama is provided. The spatial shape of the polyhedroid basidiospores of Entoloma spp. is discussed based on literature and the micrographs generated for the present study. Our re-evaluations indicate that the type of polyhedroid basidiospore and the structure of its base are not reliable as diagnostic characters for the delimitation of subgenera in Entoloma.
\end{abstract}

Keywords Neotropic $\cdot$ Entolomataceae $\cdot$ Taxonomy $\cdot$ Phylogeny $\cdot$ New species

\section{Introduction}

\section{The genus Entoloma in Central America}

The genus Entoloma (Agaricales, Basidiomycota) includes species with almost exclusively polyhedroid, faceted

Section editor: Zhu-Liang Yang

Kai Reschke

Reschke@em.uni-frankfurt.de

1 Mycology Research Group, Faculty of Biological Sciences, Goethe University Frankfurt Am Main, Max-von-Laue Straße 13, 60438 Frankfurt am Main, Germany

2 Naturalis Biodiversity Center, P.O. Box 9517 , 2300 RA Leiden, The Netherlands

3 Centro de Investigaciones Micológicas (CIMi), Herbario UCH, Universidad Autónoma de Chiriquí, 0427 David, Chiriquí Province, Panama

4 Department of Plant Anatomy, Institute of Biology, Eötvös Loránd University, Pázmány Péter sétány 1/c, 1117 Budapest, Hungary basidiospores, which are angled in outline and pinkish as seen with a light microscope. It comprises mainly species with agaricoid basidiocarps; few species develop secotioid or gasteroid basidiocarps (Co-David et al. 2009; Kinoshita et al. 2012; Vidal et al. 2016). Currently, approximately 2000 species of Entoloma are known to science (Noordeloos et al. 2018). Two monographic treatments of the genus exist for two regions of North America (Hesler 1967; Largent 1994). Such monographs are not available for South America, but some preliminary and regionally comprehensive treatments have been published (Horak 1978, 1982; Coimbra et al. 2013; Karstedt and Capelari 2013). Coimbra (2014) published a checklist including 271 species of Entolomataceae recorded for Central and South America. However, almost nothing is known about Entoloma species in Panama. Only one species, Entoloma cylindrocapitatum (T.J. Baroni \& Ovrebo) Noordel. \& Co-David, has been reported until now (Ovrebo and Baroni 2007; Hofmann and Piepenbring 2021). Few Entoloma species are reported from the other Central American countries, Belize, Costa Rica, El Salvador, Guatemala, Honduras, and Nicaragua: six species are reported 
from Costa Rica (Baroni and Halling 2000; Halling and Mueller 2005), a single record exists for Belize (Largent et al. 2008a), and no species are known for El Salvador, Guatemala, Honduras, and Nicaragua (Coimbra 2014). From Colombia, the South American neighbouring country of Panama, six species of Entoloma spp. are reported (FrancoMolano and Uribe-Calle 2000; Vasco-Palacios and FrancoMolano 2013; Osorio and Osorio 2016).

\section{Description of the study region}

The province of Chiriquí is located between $8^{\circ}$ and $9^{\circ}$ north in the western part of Panama at the border to Costa Rica (Fig. 1). It forms part of the Mesoamerican biodiversity hotspot, one of the 25 biodiversity hotspots of the world recognised by Myers et al. (2000). There are several important protected areas in Chiriquí including the "Parque Nacional Volcán Barú" (PNVB) in the northern part of Chiriquí, which includes the highest mountain in Panama (Volcán Barú, $3475 \mathrm{~m}$ asl.), and the "Parque Internacional La Amistad" (PILA), which is listed as a UNESCO World Heritage Site and spans from Costa Rica to Panama. These two parks are mainly covered by montane mixed forests with Quercus spp. as the dominant trees, while at some locations Alnus acuminata Kunth is dominant. The "Reserva Forestal de Fortuna" is a mountainous forest reserve in the northeastern part of Chiriquí. It includes forests dominated by Oreomunnea mexicana (Standl.) J.-F.Leroy in lower montane sites, while the higher montane forest is dominated by Quercus spp. South of David, the capital of Chiriquí, there are extensive mangroves and numerous small islands. The island of Parida is located about $10 \mathrm{~km}$ south of the coast and forms the centre of the "Parque Nacional Marino Golfo de Chiriquí". The lowlands of Chiriquí are mainly covered by cattle pastures and teak plantations. Chiriquí has a tropical climate, with a rainy season from April/May to December and a dry season from January to April. The annual rainfall in David (49 $\mathrm{m}$ asl.) is approximately $3900 \mathrm{~mm}$ and the average temperature $25.2^{\circ} \mathrm{C}$, in Boquete $(1096 \mathrm{~m}$ asl.) $3810 \mathrm{~mm}$ and $18.4^{\circ} \mathrm{C}$, and in Volcán (1412 $\mathrm{m}$ asl.) $4400 \mathrm{~mm}$ and $16.9^{\circ} \mathrm{C}$, respectively (https://en.climate-data.org accessed 10 -june-2021). The dry season is less pronounced in the mountains, with an average precipitation of approximately 60 and $70 \mathrm{~mm}$ in the driest month, February, in Volcán and Boquete, respectively, compared to $36 \mathrm{~mm}$ in David.

\section{Material and methods}

\section{Fieldwork}

Specimens of Entoloma spp. were collected by the authors and collaborators from 2014 to 2018, mainly in montane forests at 1600-2400 m asl. dominated by Quercus spp., sometimes by Alnus acuminata. Some collections were made in a forest dominated by Oreomunnea mexicana at $1200 \mathrm{~m}$ asl., a forest dominated by Calophyllum longifolium Willd. at $40 \mathrm{~m}$ asl. on Isla Parida, and close to a path in disturbed secondary vegetation at $120 \mathrm{~m}$ asl. in Los Algarrobos. Most of the specimens were photographed in the field. Further
Fig. 1 Study locations in Chiriquí Province, Panama

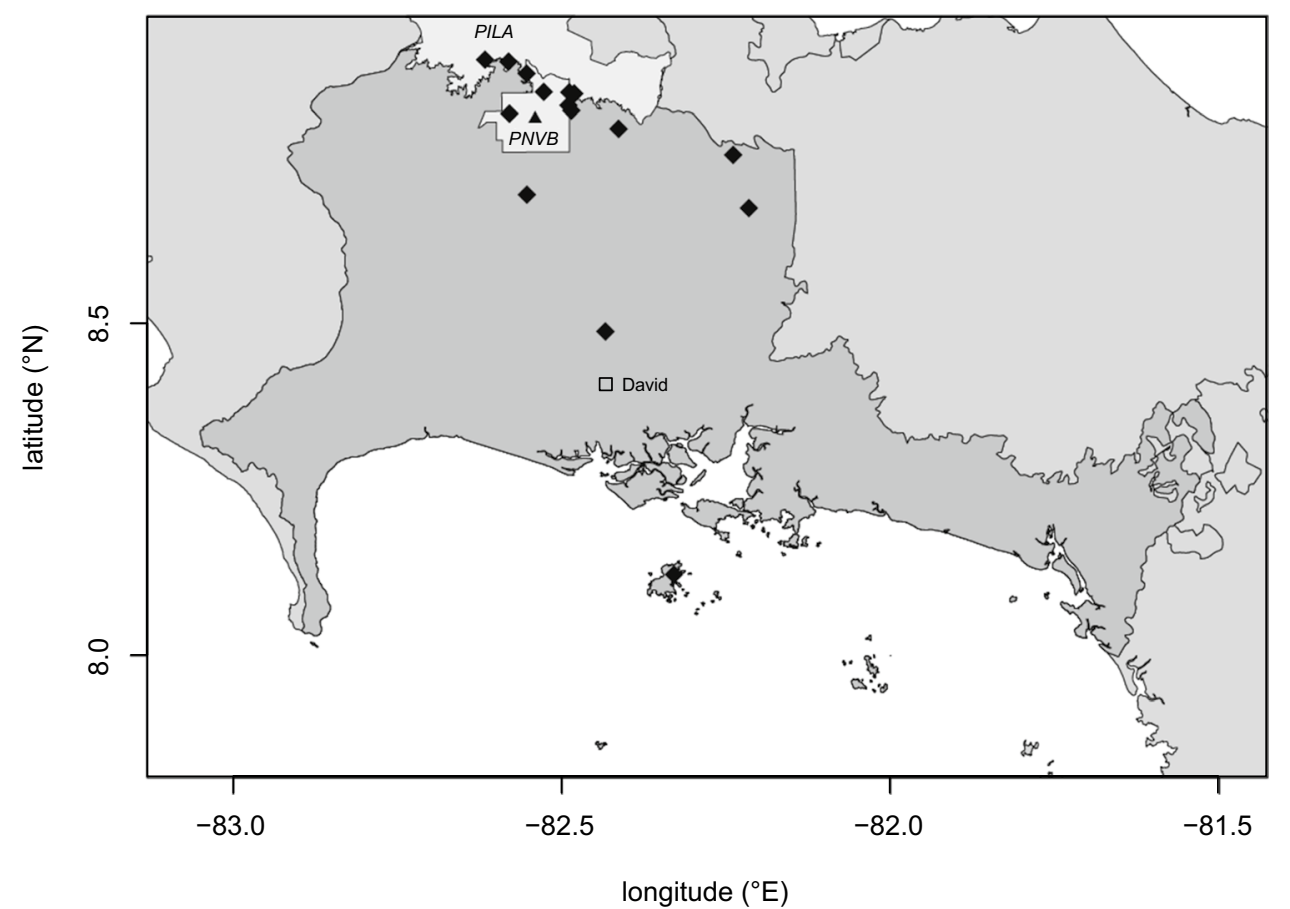


photos were taken in the laboratory and ephemeral characters as colour, smell, and taste were registered. Colour terms and codes were determined using Kornerup and Wanscher (1967). Coordinates of the locations were recorded using a Garmin GPSmap 62 (Garmin Deutschland, Garching, Germany). The basidiocarps were dried at $40-45{ }^{\circ} \mathrm{C}$ on an electric food dehydrator and frozen for several days before storage in herbaria. Mainly specimens of species represented by at least two collections were studied in detail.

\section{Light microscopy}

Micromorphological characters of the basidiocarps were analysed by light microscopy on dried material. The size of the basidiospores, hymenial structures, and features of the pileipellis were investigated in hand-cut sections mounted in tap water or in 5-10\% KOH. To measure the long cells of the hymenophoral trama and stipe surface, sections were soaked in $\mathrm{KOH}$ for $5 \mathrm{~min}$, rinsed with deionised water, and stained with Congo Red. At least 20 basidiospores were measured from lamellae squash preparations for each collection. For some specimens, the presence or absence of clamp connections at the base of basidia was additionally examined using phase contrast. Spore sizes and $Q$-values are given in 5th percentile-mean-95th percentile. Spore sizes are rounded to the nearest $0.5 \mu \mathrm{m}, Q$-values to the nearest 0.05 . Other values of measurements were less strictly rounded off to avoid pseudo-exact indication of sizes.

\section{Scanning electron microscopy (SEM)}

Fragments of basidiocarps were prepared for SEM following a protocol including the use of dioctyl sodium sulfosuccinate (DSS), based on Koch et al. (2021) and Erbar (1995) with several modifications. Small pieces of lamellae were soaked in a solution of 5\% (w/v) DSS in 4:1 water:ethanol for $24 \mathrm{~h}$. The samples were then rinsed three times in 4:1 water:ethanol and two times in $0.1 \mathrm{M}$ sodium cacodylate buffer and thereafter fixed in $4 \%$ glutaraldehyde in $0.1 \mathrm{M}$ sodium cacodylate buffer for 20-24 h. After fixation, the samples were rinsed two times in the cadodylate buffer and then dehydrated in a graded ethanol series of 30, 50, 70, 90, 100 , and $100 \%$ for $10-20$ min each. The dehydrated samples were stored in $100 \%$ ethanol until critical point drying using liquid $\mathrm{CO}_{2}$. Dried samples were sputtered with gold and studied in a Hitachi (S 4500) scanning electron microscope. The description of basidiospore structures follows Pegler and Young (1979), except that polyhedron terminology is used instead of their spore types. The earlier term "dièdre basal" (Kühner and Boursier 1929) is used instead of "dihedral base" to avoid confusion with mathematical terms.

\section{DNA extraction and PCR}

Pieces of lamellae of 3-10 $\mathrm{mm}^{2}$ were taken from dry basidiocarps and ground in a MM301 Mixer Mill (Retsch GmbH, Haan, Germany). DNA was extracted from the resulting powder using the peqGOLD fungal DNA mini kit (VWR, Darmstadt, Germany) or the innuPREP Plant DNA Kit (analytikjena, Jena, Germany) according to the instruction manuals. The ITS region was amplified by PCR in a peqSTAR gradient thermal cycler (PEQLAB, Erlangen, Germany) using the VWR Taq DNA polymerase (VWR, Darmstadt, Germany). To obtain the ITS sequences, the forward primer ITS1 or ITS1F and the reverse primer ITS4 or ITS4B (White et al. 1990; Gardes and Bruns 1993) were used. Further ITS sequences were obtained as described by Papp and Dima (2018). To obtain the D1/D2 region of the nc LSU rDNA, the primers LR0R together with LR5 (Vilgalys and Hester 1990) or NL1 together with NL4 (O'Donnell 1992) were used. Both rDNA regions were amplified using the same PCR protocol: denaturation at $98^{\circ} \mathrm{C}$ for 4 min followed by 35 cycles of $95{ }^{\circ} \mathrm{C}$ for $45 \mathrm{~s}, 53{ }^{\circ} \mathrm{C}$ for $30 \mathrm{~s}$, and $72{ }^{\circ} \mathrm{C}$ for $60 \mathrm{~s}$, with a final elongation step at $72{ }^{\circ} \mathrm{C}$ for $5 \mathrm{~min}$. A partial sequence of the second largest subunit of RNA polymerase II ( $R P B 2)$ was obtained using the primers rpb2-6F and rpb2-7.1R (Matheny 2005) with a touchdown PCR protocol: denaturation at $95^{\circ} \mathrm{C}$ for 4 min followed by 14 cycles of $94{ }^{\circ} \mathrm{C}$ for $45 \mathrm{~s}, 56^{\circ} \mathrm{C}\left(-0.5{ }^{\circ} \mathrm{C} / \mathrm{cyc}\right)$ for $60 \mathrm{~s}$, and $72{ }^{\circ} \mathrm{C}$ for $60 \mathrm{~s}$, thereafter 40 cycles of $94{ }^{\circ} \mathrm{C}$ for $30 \mathrm{~s}, 53{ }^{\circ} \mathrm{C}$ for $40 \mathrm{~s}$, and $72{ }^{\circ} \mathrm{C}$ for $60 \mathrm{~s}$, with a final elongation step at $72{ }^{\circ} \mathrm{C}$ for $10 \mathrm{~min}$. Success of amplification was checked by gel electrophoresis using a 1\% (w/v) agarose gel. Successfully amplified products were sent to Microsynth Seqlab (Göttingen, Germany) for purification and Sanger sequencing.

\section{Phylogenetic analyses}

Sequences were edited with Geneious 2019.2.1 (Biomatters Ltd., Auckland, New Zealand) and aligned with Mafft (Katoh and Standley 2013) using the E-INS-i algorithm. The ends of the resulting alignments as well as unreliable terminal parts of sequences were manually pruned in AliView (Larsson 2014). For the phylogenetic analysis of sequences of subg. Cyanula, aligned ITS and LSU sequences were concatenated and a piece of 61 nucleotides at the $5^{\prime}$ end of the LSU, which was not available for many sequences, excluded from the final alignment. Maximum likelihood trees were built using RAxML 8.2.11 (Stamatakis 2014). The GTRGAMMA model was used for alignments of less than 50 sequences, the GTRCAT model with 45 per site rate categories for 50 sequences, and more, along with a bootstrap analysis (Felsenstein 1985) with 500 repetitions. Resultant phylogenetic trees were visualised using FigTree 
(Rambaut 2014). All sequences generated are deposited in GenBank (Table 1).

\section{Results}

A total of 124 specimens of Entoloma spp. were collected. These specimens represent more than 50 species, with at least 22 species being represented by more than one specimen. Twenty of these species were studied in detail and are described below. Only one species could be assigned to an already described species and two species were identified with considerable uncertainty. Seventeen species are unknown to science and are described as new species below. The most frequently represented subclade was the subgenus Cyanula, with 35 specimens belonging to 18 species. Specimens of the subgenera Alboleptonia, Cubospora Entoloma, and Nolanea were frequently found as well (Table 2).

In 2017 and 2018, most specimens were collected in montane forests with abundant to dominating trees of Quercus spp. The highest number of Entoloma specimens for a single location, i.e. 22 specimens found during three visits, was collected in the PILA, in a montane forest dominated by Alnus acuminata, with some Quercus spp. and at least one individual of Podocarpus sp. On the contrary, only two specimens, both of subg. Cyanula, were collected in lowland habitats, one in a forest close to mangrove forest on Island Parida and the other one at a path in disturbed secondary vegetation (Table 3). This path in Los Algarrobos was the most often visited location in these years. The specimens collected in the years before 2017 were mainly collected during a local inventory project and are thus less informative for comparisons of diversity of habitats.

\section{Shape of basidiospores}

Polyhedroid basidiospores of 17 species of Entoloma from Panama were analysed by SEM. The basidiospores displayed a considerable degree of variability, increasing with the number of facets. Apart from the cuboid basidiospores, the number of angles of the respective facets was often variable and thus not determined. The adaxial facet is always a single facet and consistent in its position above the apiculus. The spatial formation of facets can abaxially be variable. The basal facet can either be next to the abaxial facet or separated from it by lateral facets (Fig. 2e). When two abaxial facets are formed, they can be next to each other or separated by lateral facets (Figs. 2i, 26d). Shape and a consistent base type of the basidiospores of two species of subg. Entoloma (E. nuboocculatum and E. mediorobustum, described below) could not be determined because of considerable variability of these characters. Five species have hendecahedroid spores, three of subg. Cyanula and two of subg.
Nolanea. Two species each have heptahedroid, octahedroid, or decahedroid basidiospores, respectively, while one species each presents cuboid, enneahedroid, dodecahedroid, or tetrahedroid basidiospores. Reduced forms frequently occur, mainly concerning reduction or lack of the apical facet and/ or reduction of the pair of adaxial facets to a single adaxial facet. Basidiospore shapes in subgenera are not consistent. The largest variability was observed in subg. Alboleptonia, including one species with mainly octahedroid, one species with enneahedroid, and another species with tetradecahedroid basidiospores. A simple base is formed in four species, two in subg. Entoloma and two in subg. Nolanea, while basidiospores with a dièdre basal are present in all subgenera, exclusively so in Alboleptonia, Cubospora, and Cyanula. A base built by three facets was found in the newly described species E. mediorobustum (Fig. 21).

\section{Taxonomy}

The traditional infrageneric classification of Entoloma is based on morphological characters, viz., habit, lamellae attachment, pileipellis structure, and basidiospore shape (Romagnesi 1974; Romagnesi and Gilles 1979). This classification has been continuously revised and emended (Noordeloos 1981, 1992, 2004; Largent 1994). Co-David et al. (2009) demonstrated that a high number of subgroups in this classification were not monophyletic based on molecular phylogenetic results. With the incorporation of DNA sequence data, several subgenera have since been revised, viz., Pouzarella by He et al. (2013), Leptonia by Morozova et al. (2014a), Entoloma (as "Rhodopolia") by Kokkonen (2015), and Claudopus by He et al. (2019). The section Cyanula was elevated to the rank of subgenus by Noordeloos and Gates (2012) and two new subgenera, Cubospora and Cuboeccilia, were described by Karstedt et al. (2019). He et al. (2019) recognised 10 major clades, largely referring to the studies just cited. Baroni et al. (2011) described the genus Entocybe for a few aberrant species of the large, basal clade of Entoloma. This new genus, however, causes the basal clade to be paraphyletic and was, therefore, not recognised by He et al. (2019).

\section{Subgenus Entoloma Fig. 3}

As in most other subgenera, species of subgenus Entoloma are hard to identify on macroscopical characters in the field, as they are pretty uniform in colour and stature. Kühner and Romagnesi $(1953,1954)$ first considered the structure and pigmentation of the covering layer of the pileus as potential tools to distinguish species, besides size and shape of basidiospores. Noordeloos $(1981,1992,2004)$ expanded the concept, resulting in an overview of sect. Rhodopolia in Europe 
Table 1 Data corresponding to the sequences used for phylogenetic analyses, including GenBank accessions, if not stated otherwise

\begin{tabular}{|c|c|c|c|c|c|}
\hline \multirow[t]{2}{*}{ Species (annotation) } & \multirow[t]{2}{*}{ Specimen voucher } & \multirow[t]{2}{*}{ Origin } & \multicolumn{2}{|l|}{ Accession } & \multirow[t]{2}{*}{ Reference } \\
\hline & & & ITS & LSU & \\
\hline \multicolumn{6}{|l|}{ subgenus Alboleptonia } \\
\hline Alboleptonia sericella & Lueck1 & Germany & KP965765 & & Karich et al. 2015 \\
\hline Entoloma amistadosericellum & KaiR490 & Panama & MZ611648 & & This study \\
\hline Entoloma amistadosericellum & KaiR492 & Panama & MZ611649 & & This study \\
\hline Entoloma amistadosericellum & KaiR495 & Panama & MZ611650 & & This study \\
\hline Entoloma amistadosericellum & KaiR501 & Panama & MZ611651 & & This study \\
\hline Entoloma amistadosericellum & KaiR502 & Panama & MZ611652 & & This study \\
\hline Entoloma amistadosericellum & KaiR612, holotype & Panama & MZ611663 & & This study \\
\hline Entoloma amistadosericellum & KaiR672 & Panama & MZ611673 & & This study \\
\hline Entoloma amistadosericellum & KaiR675 & Panama & MZ611674 & & This study \\
\hline Entoloma confusissimum & KaiR489 & Panama & MZ611647 & & This study \\
\hline Entoloma confusissimum & KaiR670 & Panama & MZ611672 & & This study \\
\hline Entoloma niveum & PDD104142 & New Zealand & MZ611695 & & This study \\
\hline Entoloma nubilosilvae & KaiR429 & Panama & MZ611643 & & This study \\
\hline Entoloma nubilosilvae & KaiR430 & Panama & MZ611644 & & This study \\
\hline Entoloma nubilosilvae & KaiR465, holotype & Panama & MZ611645 & & This study \\
\hline Entoloma nubilosilvae & KaiR474 & Panama & MZ611646 & & This study \\
\hline Entoloma sericellum & KaiR1203 & Sweden & MZ611636 & & This study \\
\hline Entoloma sericellum & KaiR1214 & Sweden & MZ611637 & & This study \\
\hline Entoloma sericellum & LE254362 & Russia & KC898453 & & Morozova et al. 2014a \\
\hline Entoloma serrulatum & LE254361 & Russia & KC898447 & & Morozova et al. 2014a \\
\hline \multicolumn{6}{|l|}{ Subgenus Cubospora } \\
\hline Entoloma aurantiovirescens & KaiR623, holotype & Panama & MZ611665 & & This study \\
\hline Entoloma aurantiovirescens & PAN419 & Panama & MZ611691 & & This study \\
\hline Entoloma luteum & GDGM27698 & China & JQ281486 & & He et al. 2012 \\
\hline Entoloma murrayi & MHHNU30602 & China & MK250917 & & $\begin{array}{l}\text { Zhang and Chen, } \\
\text { unpublished }\end{array}$ \\
\hline Entoloma murrayi & QI1001 & China & KJ658967 & & He et al. $2015 b$ \\
\hline Entoloma murrayi & QI1002 & China & KJ658968 & & He et al. $2015 b$ \\
\hline Entoloma murrayi & SDR NAMA 2017-160 & USA, Wisconsin & MK575459 & & Russell, unpublished \\
\hline Entoloma quadratum & LE254355 & Russia & KC898452 & & Morozova et al. $2014 \mathrm{a}$ \\
\hline Entoloma quadratum & MHHNU30632 & China & MK250921 & & $\begin{array}{l}\text { Zhang and Chen, } \\
\text { unpublished }\end{array}$ \\
\hline Entoloma quadratum & MHHNU82 & China & KU518319 & & $\begin{array}{l}\text { He and Chen, unpub- } \\
\text { lished }\end{array}$ \\
\hline Entoloma quadratum & PAN241 & Panama & MZ611690 & & This study \\
\hline Entoloma semilanceatum & NS2283 & Cameroon & MN069544 & & Largent et al. 2019 \\
\hline Entoloma virescens & MHHNU30619 & China & MK250919 & & $\begin{array}{l}\text { Zhang and Chen, } \\
\text { unpublished }\end{array}$ \\
\hline Inocephalus murrayi & ECO-TA-HO 7874 & Mexico & MF156254 & & $\begin{array}{l}\text { Arias-Hernandez } \\
\text { et al., unpublished }\end{array}$ \\
\hline \multicolumn{6}{|l|}{ Subgenus Cyanula } \\
\hline Entoloma aff. griseocyaneum & NL5097 & USA & MZ869020 & MK277993 & $\begin{array}{l}\text { This study/Varga et al. } \\
2019\end{array}$ \\
\hline Entoloma aff. griseocyaneum & PO6 & Canada, Ontario & KY706188 & & Hay et al. 2018 \\
\hline Entoloma aff. necopinatum & KaiR646 & Panama & MZ611670 & MZ678748 & This study \\
\hline Entoloma arcanum & KaiR614 & Panama & & & This study \\
\hline \multirow[t]{2}{*}{ Entoloma arcanum } & KaiR488, holotype & Panama & & MZ678738 & This study \\
\hline & & & \multicolumn{3}{|c|}{$+R P B 2: \mathrm{MZ605445}$} \\
\hline
\end{tabular}


Table 1 (continued)

\begin{tabular}{|c|c|c|c|c|c|}
\hline Entoloma caeruleomarginatum & CME3 & Panama & \multicolumn{2}{|l|}{ MZ611627 } & This study \\
\hline Entoloma caeruleomarginatum & KaiR535, holotype & Panama & \multicolumn{2}{|l|}{ MZ611658 } & This study \\
\hline Entoloma caeruleomarginatum & CME11 & Panama & \multicolumn{2}{|l|}{ MZ611622 } & This study \\
\hline Entoloma cf. catalaunicum & E163 & Estonia & \multicolumn{2}{|c|}{ Unite: UDB011680 } & Liiv, unpublished \\
\hline Entoloma cf. indutoides & TU106924 & Estonia & \multicolumn{2}{|l|}{$\begin{array}{l}\text { Unite: } \\
\text { UDB015261 }\end{array}$} & Liiv, unpublished \\
\hline Entoloma cf. largentii & OSC144006 & USA & \multicolumn{2}{|l|}{ KX574458 } & Gordon, unpublished \\
\hline Entoloma cf. pseudoturci & Cro16 & Croatia & \multicolumn{2}{|l|}{ MZ611633 } & This study \\
\hline Entoloma cf. unicolor & PBM3995 & USA & \multicolumn{2}{|l|}{ KY777373 } & $\begin{array}{c}\text { Matheny et al., } \\
\text { unpublished }\end{array}$ \\
\hline Entoloma $\mathrm{cf}$. violaceobrunneum & KaiR632 & Panama & \multicolumn{2}{|l|}{ MZ678740 } & This study \\
\hline Entoloma cf. violaceobrunneum & CME2 & Panama & & & This study \\
\hline Entoloma coracis & O-F-256850, holotype & Norway & MW934571 & MW934251 & Crous et al. 2021 \\
\hline Entoloma fuscosquamosum & KY744158 & USA & KY744158 & & $\begin{array}{c}\text { Matheny et al., } \\
\text { unpublished }\end{array}$ \\
\hline Entoloma glaucobasis & Roth 16-6-95/NL-2704 & Germany/Sweden & MZ869021 & MK277991 & $\begin{array}{l}\text { This study/Varga et al. } \\
2019\end{array}$ \\
\hline Entoloma griseocaeruleum & CME8 & Panama & MZ611631 & & This study \\
\hline Entoloma griseocaeruleum & CME13 & Panama & MZ611624 & & This study \\
\hline Entoloma griseocaeruleum & KaiR536 & Panama & MZ611659 & & This study \\
\hline Entoloma griseocaeruleum & KaiR534, holotype & Panama & MZ611657 & & This study \\
\hline Entoloma griseocyaneum & KaiR997 & Germany & MZ611684 & & This study \\
\hline Entoloma holmvassdalenense & O-F-304575 & Norway & MZ869018 & MZ678746 & This study \\
\hline Entoloma holmvassdalenense & O-F75311, holotype & Norway & KM610321 & & Weholt et al. 2014 \\
\hline Entoloma incanum & KaiR990 & Germany & MZ611683 & & This study \\
\hline Entoloma indutoides & WU19603 & Austria & MZ869022 & & $\begin{array}{l}\text { This study/Varga } \\
\text { et al. } 2019\end{array}$ \\
\hline Entoloma inocephalum & LE262922 & Vietnam & KC898449 & MH259311 & $\begin{array}{l}\text { Morozova et al. } \\
\text { 2014a/Karstedt } \\
\text { et al. } 2019\end{array}$ \\
\hline Entoloma isborscianum & KaiR1004 & Germany & MW934565 & & $\begin{array}{l}\text { Crous et al. 2021/This } \\
\text { study }\end{array}$ \\
\hline Entoloma longistriatum & PBM4018 & USA & KY744164 & & $\begin{array}{c}\text { Matheny et al., } \\
\text { unpublished }\end{array}$ \\
\hline Entoloma mediterraneense & Cro26 & Croatia & MZ611634 & & This study \\
\hline Entoloma melleosquamulosum & KaiR638 & Panama & MZ611669 & & This study \\
\hline Entoloma melleosquamulosum & CME16, holotype & Panama & MZ611626 & & This study \\
\hline Entoloma microserrulatum & KaiR413, holotype & Panama & MZ611642 & & This study \\
\hline Entoloma microserrulatum & KaiR664 & Panama & MZ611671 & & This study \\
\hline Entoloma montanum & O-F-293389/N03-09-2010 & Norway/Norway & MW340878 & MZ678747 & $\begin{array}{l}\text { Noordeloos et al. } \\
\text { 2021/This study }\end{array}$ \\
\hline Entoloma montanum & GB191635, holotype & Sweden & MW340896 & & $\begin{array}{l}\text { Noordeloos et al. } \\
2021\end{array}$ \\
\hline Entoloma mougeotii & LE254352 & Russia, Caucasus & KC898446 & & Morozova et al. 2014a \\
\hline Entoloma nigrovelutinum & LE295077, holotype & Vietnam & MF898426 & MF898427 & Crous et al. 2017 \\
\hline Entoloma nipponicum & TNS-F70747 & Japan & MK693223 & MK696392 & Crous et al. 2019 \\
\hline Entoloma norlandicum & O-F-76176, holotype & Norway & MW340899 & & $\begin{array}{l}\text { Noordeloos et al. } \\
2021\end{array}$ \\
\hline Entoloma ochromicaceum & TUF120040/DMS-9201008 & Estonia/Denmark & $\begin{array}{l}\text { Unite: } \\
\text { UDB023715 }\end{array}$ & MZ678743 & $\begin{array}{l}\text { Liiv, unpublished/ } \\
\text { This study }\end{array}$ \\
\hline Entoloma odoratum & DMS-166826 & Denmark & MZ869017 & MZ678745 & This study \\
\hline Entoloma querquedula & TUR & Finland & LN850627 & & Kokkonen 2015 \\
\hline Entoloma roseotinctum & JL-26-19 & Norway & MZ869019 & & This study \\
\hline
\end{tabular}


Table 1 (continued)

\begin{tabular}{|c|c|c|c|c|c|}
\hline Entoloma sarcitulum & K378, holotype & Great Britain & LN850561 & & Kokkonen 2015 \\
\hline Entoloma serrulatum & O-F-158208/DMS-730296 & Norway/Denmark & MZ869016 & & This study \\
\hline Entoloma sp. & $\mathrm{PO} 2$ & Canada, Ontario & KY706185 & & Hay et al. 2018 \\
\hline Entoloma sp. & CM13_233 & New Caledonia & KY774214 & & $\begin{array}{l}\text { Carriconde et al., } \\
\text { unpublished }\end{array}$ \\
\hline Entoloma sp. & MES-534 & Chile & KY462681 & & Truong et al. 2017 \\
\hline Entoloma sp. & KaiR511 & Panama & MZ611655 & & This study \\
\hline Entoloma sp. & OTA61944 & New Zealand & KP191935 & & $\begin{array}{l}\text { Lebel and Cooper, } \\
\text { unpublished }\end{array}$ \\
\hline Entoloma sp. & CY13_140_1 & New Caledonia & KY774215 & & $\begin{array}{l}\text { Carriconde et al., } \\
\text { unpublished }\end{array}$ \\
\hline Entoloma subcaesiocinctum & GDGM31059 & China & KY972699 & & He et al. 2017 \\
\hline Entoloma subcoracis & LE312483, holotype & Russia & MW934593 & MW934255 & Crous et al. 2021 \\
\hline Entoloma subfarinaceum & SAT1518702 & USA & KY777374 & & $\begin{array}{c}\text { Matheny et al., } \\
\text { unpublished }\end{array}$ \\
\hline Entoloma subserrulatum & MGW1490 & USA & KY744177 & & $\begin{array}{c}\text { Matheny et al., } \\
\text { unpublished }\end{array}$ \\
\hline Entoloma subserrulatum & EL9 & Canada & KY706167 & & Hay et al. 2018 \\
\hline Entoloma turci & WPR004 & Germany & MZ611693 & & This study \\
\hline Entoloma viiduense & G1602 & Estonia & UDB015211 & MK278008 & $\begin{array}{l}\text { Liiv, unpublished/ } \\
\text { Varga et al. } 2019\end{array}$ \\
\hline Entoloma violaceoserrulatum & TUR JV 8329F, isotype & Finland & MF476913 & MF487803 & Morozova et al. 2017 \\
\hline Entoloma yanacolor & QCAM6312, holotype & Ecuador & MG947210 & & Crous et al. 2018 \\
\hline \multicolumn{6}{|l|}{ Subgenus Entoloma } \\
\hline Entoloma aff. alpicola & O:F7195 & Norway & MZ868961 & & This study \\
\hline Entoloma aff. rhodopolium & $68-88$ & Finland & LN850500 & & Kokkonen 2015 \\
\hline Entoloma aff. sinuatum & TRTC156546 & Canada & JN021019 & & Dentinger et al. 2011 \\
\hline Entoloma aff. sordidulum & PGL110817 & Norway & MZ869007 & & This study \\
\hline Entoloma alnobetulae & $\begin{array}{l}\text { K53-59, G262083, } \\
\text { holotype }\end{array}$ & France & LN850537 & & Kokkonen 2015 \\
\hline Entoloma alpicola & O:F-61507 & Norway & MZ868967 & & This study \\
\hline Entoloma atrosericeum & GG160811 & Sweden & MZ868968 & & This study \\
\hline Entoloma atrosericeum & $\begin{array}{l}\text { K69-310, G262084, } \\
\text { holotype }\end{array}$ & France & LN850607 & & Kokkonen 2015 \\
\hline Entoloma aurorae-borealis & O-F-254651, holotype & Norway & MH234486 & & Noordeloos et al. 2021 \\
\hline Entoloma baeosporum & holotype & France & MZ868973 & & This study \\
\hline Entoloma bisporigerum & 2047, K108895, holotype & United Kingdom & LN850536 & & Kokkonen 2015 \\
\hline Entoloma bisporigerum & OW-E20-14 & Norway & MZ868976 & & This study \\
\hline Entoloma boreale & 106/09, TUR, holotype & Finland & LN850624 & & Kokkonen 2015 \\
\hline Entoloma borgenii & TB79.120, C5933 & Greenland & LN850524 & & Kokkonen 2015 \\
\hline Entoloma brunneipes & TENN9029, holotype & USA & LN850621 & & Kokkonen 2015 \\
\hline Entoloma brunneocinereum & TENN12881, holotype & USA & LN850615 & & Kokkonen 2015 \\
\hline Entoloma brunneorugulosum & KaiR583 & Panama & MZ611660 & & This study \\
\hline Entoloma brunneorugulosum & KaiR691, holotype & Panama & MZ611676 & & This study \\
\hline Entoloma brunneorugulosum & KaiR692 & Panama & MZ611677 & & This study \\
\hline Entoloma brunneorugulosum & KaiR695 & Panama & MZ611679 & & This study \\
\hline Entoloma brunneorugulosum & PAN532 & Panama & MZ611692 & & This study \\
\hline Entoloma bryorum & $117 / 07$ & Finland & LN850539 & & Kokkonen 2015 \\
\hline Entoloma bryorum & O:F-303879 & Norway & MZ868978 & & This study \\
\hline Entoloma caccabus & "Podoba", G262081 & France & LN850540 & & Kokkonen 2015 \\
\hline Entoloma caccabus & $\mathrm{C} 157,4226$ & The Netherlands & MZ868979 & & This study \\
\hline Entoloma caccabus & $\mathrm{C} 158,4001$ & The Netherlands & MZ868981 & & This study \\
\hline
\end{tabular}


Table 1 (continued)

\begin{tabular}{|c|c|c|c|c|}
\hline Entoloma carolinianum & TENN21855, holotype & USA & LN850617 & Kokkonen 2015 \\
\hline Entoloma cf. alpicola & 23, N1F31, 2 & NA & HQ445607 & $\begin{array}{l}\text { Bjorbækmo et al. } \\
2010\end{array}$ \\
\hline Entoloma cf. alpicola & O:F-260165 & Norway & MZ869001 & This study \\
\hline Entoloma cf. bryorum & O:TEB 395-18 & Norway & MZ868985 & This study \\
\hline Entoloma cf. carolinianum & IBUG:Montanez222 & Mexico & MZ869010 & This study \\
\hline Entoloma cf. rhodopolium & DB03-06-2018-3 & Hungary & MZ868960 & This study \\
\hline Entoloma cf. spadiceum & TENN070791 & USA, Tennessee & MF686497 & $\begin{array}{l}\text { Matheny and } \\
\text { Sanchez-Garcia, } \\
\text { unpublished }\end{array}$ \\
\hline Entoloma cf. venosum & WU19672 & & MZ868991 & This study \\
\hline Entoloma cistophilum & Trim2006, isotype & France & MZ868999 & This study \\
\hline Entoloma dulciodorans & IBUG:LGD7580 & Mexico & MZ869011 & This study \\
\hline Entoloma dulciodorans & $\begin{array}{l}\text { IBUG:Rodriguez322, } \\
\text { paratype }\end{array}$ & Mexico & MZ869012 & This study \\
\hline Entoloma eminens & 417/12, TUR, holotype & Finland & LN850584 & Kokkonen 2015 \\
\hline Entoloma eminens & O:F-248409 & Norway & MZ868982 & This study \\
\hline Entoloma eminens & TEB699-17 & Norway & MZ868983 & This study \\
\hline Entoloma fasciculatum & TENN29376, holotype & USA & LN850614 & Kokkonen 2015 \\
\hline Entoloma festivum & holotype & The Netherlands & MZ869009 & This study \\
\hline Entoloma gerriae & holotype & The Netherlands & MZ868980 & This study \\
\hline Entoloma gerriae & WU28035 & Austria & MZ868990 & This study \\
\hline Entoloma griseopruinatum & JLC_030924-8, holotype & France & MZ868984 & This study \\
\hline Entoloma griseopruinatum & JLC030924-8, isotype & France & LN850556 & Kokkonen 2015 \\
\hline Entoloma griseorugulosum & RFS-020921-01, isotype & Spain & LN850591 & Kokkonen 2015 \\
\hline Entoloma indutoides & 1617, K108968, holotype & United Kingdom & LN850608 & Kokkonen 2015 \\
\hline Entoloma inusitatum & holotype & Germany & MZ868969 & This study \\
\hline Entoloma jubatum & PAM13-26 & Sweden & MZ868975 & This study \\
\hline Entoloma lactarioides & Liiv217, holotype & Russia, Karelia & MZ869000 & This study \\
\hline Entoloma lacus & KUB110, holotype & Japan & LC088049 & Kondo et al. 2017 \\
\hline Entoloma leucocarpum & MEN701, holotype & The Netherlands & MZ868970 & This study \\
\hline Entoloma lividoalbum & GE12-025 & France & MZ868957 & This study \\
\hline Entoloma lividomurinum & TENN28208, holotype & USA & LN850616 & Kokkonen 2015 \\
\hline Entoloma lupinum & 13/14, TUR, holotype & Finland & LN850570 & Kokkonen 2015 \\
\hline Entoloma majaloides & 1168, K69959, holotype & United Kingdom & LN850489 & Kokkonen 2015 \\
\hline Entoloma majaloides & GG160812 & Sweden & MZ868966 & This study \\
\hline Entoloma mediorobustum & JR064, holotype & Panama & MZ611635 & This study \\
\hline Entoloma mediorobustum & PA728 & Panama & MZ611688 & This study \\
\hline Entoloma melenosmum & $\begin{array}{l}\text { JHP-338, C6229, holo- } \\
\text { type }\end{array}$ & Greenland & LN850508 & Kokkonen 2015 \\
\hline Entoloma myriadophyllum & $366 \mathrm{VN} 10$ & & MZ869004 & This study \\
\hline Entoloma myrmecophilum & IBUG:Quezada 1 & Mexico & MZ869014 & This study \\
\hline Entoloma myrmecophilum & IBUG:SantosBarba 5 & Mexico & MZ869013 & This study \\
\hline $\begin{array}{l}\text { Entoloma myrmecophilum var. } \\
\text { coalescens }\end{array}$ & holotype & Germany & MZ868958 & This study \\
\hline Entoloma nidorosum & GG160815 & Sweden & MZ868997 & This study \\
\hline Entoloma nidorosum $\mathrm{s}$. MEN & FR2016708 & France & MZ868995 & This study \\
\hline Entoloma nidorosum $\mathrm{s}$. MEN & MEN2012111 & The Netherlands & MZ868996 & This study \\
\hline Entoloma nigrobrunneum & TENN9100, holotype & USA & LN850618 & Kokkonen 2015 \\
\hline Entoloma noordeloosii & WU18780, holotype & Austria & MZ868962 & This study \\
\hline Entoloma noordeloosii & WU39739 & & MZ868963 & This study \\
\hline Entoloma nuboocculatatum & KaiR588 & Panama & MZ611661 & This study \\
\hline
\end{tabular}


Table 1 (continued)

\begin{tabular}{|c|c|c|c|c|}
\hline Entoloma nuboocculatatum & KaiR687, holotype & Panama & MZ611675 & This study \\
\hline Entoloma nubooccultatum & PA165 & Panama & MZ611685 & This study \\
\hline Entoloma nubooccultatum & PA696 & Panama & MZ611686 & This study \\
\hline Entoloma nubooccultatum & PA727 & Panama & MZ611687 & This study \\
\hline Entoloma nubooccultatum & PA864 & Panama & MZ611689 & This study \\
\hline Entoloma olorinum & G:00,126,192, holotype & France & MZ868998 & This study \\
\hline Entoloma paludicola & K178125, holotype & United Kingdom & LN850517 & Kokkonen 2015 \\
\hline Entoloma palustre & 101/14, TUR, holotype & Finland & LN850592 & Kokkonen 2015 \\
\hline Entoloma paragaudatum & 383/08, TUR, holotype & Finland & LN850530 & Kokkonen 2015 \\
\hline Entoloma philocistus & WU18871, paratype & Portugal & LN850600 & Kokkonen 2015 \\
\hline Entoloma platophylloides & MD2017-10 & Italy & MZ868959 & This study \\
\hline Entoloma politum & $289 / 09$ & Finland & LN850511 & Kokkonen 2015 \\
\hline Entoloma politum & O:F61875 & Norway & MZ869002 & This study \\
\hline Entoloma politum $\mathrm{s}$. Gulden & O:F-73841 & Norway & MZ869006 & This study \\
\hline Entoloma pruinosum & CME12 & Panama & MZ611623 & This study \\
\hline Entoloma pruinosum & CME14 & Panama & MZ611625 & This study \\
\hline Entoloma pruinosum & KaiR533, holotype & Panama & MZ611656 & This study \\
\hline Entoloma pseudorhodopolium & KUB102, holotype & Japan & LC088042 & Kondo et al. 2017 \\
\hline Entoloma pusillulum & C-F-5917 & Greenland & MZ611694 & This study \\
\hline Entoloma radicipes & 42/14, TUR, holotype & Finland & LN850585 & Kokkonen 2015 \\
\hline Entoloma rhodopolium & 213/14, TUR, neotype & Sweden & LN850494 & Kokkonen 2015 \\
\hline Entoloma rhodopolium & Montanez149-150 & Mexico & MZ869015 & This study \\
\hline Entoloma rhodopolium & O:F-254019 & Norway & MZ868993 & This study \\
\hline Entoloma rhodopolium & OF254444 & Norway & MZ868992 & This study \\
\hline Entoloma rigidulum & PRM153709, holotype & Czech Republic & LN850629 & Kokkonen 2015 \\
\hline Entoloma rivulare & 703/12, TUR, holotype & Finland & LN850544 & Kokkonen 2015 \\
\hline Entoloma roseoalbum & ARN6209, holotype & The Netherlands & MZ868972 & This study \\
\hline Entoloma rubrobasis & 24,101, TURA & Finland & LN850580 & Kokkonen 2015 \\
\hline Entoloma rubrobasis & O:F-304601 & Norway & MZ868987 & This study \\
\hline Entoloma sarcopum & KUB205 & Japan & LC088067 & Kondo et al. 2017 \\
\hline Entoloma saussetiense & PC0085778, holotype & France & LN850594 & Kokkonen 2015 \\
\hline Entoloma sericatum & $237 / 11$ & Finland & LN850445 & Kokkonen 2015 \\
\hline Entoloma sericatum & $358 / 08$ & Finland & LN850444 & Kokkonen 2015 \\
\hline Entoloma serpens & 410/09, TUR, holotype & Finland & LN850526 & Kokkonen 2015 \\
\hline Entoloma silvae-frondosae & L-DB6568 & $\begin{array}{l}\text { Hungary: Vas, Apatist- } \\
\text { vanfalva }\end{array}$ & MH790432 & Crous et al. 2018 \\
\hline Entoloma sinuatum & J.Vauras $8181 \mathrm{~F}$ & Finland & KC710116 & Morgado et al. 2013 \\
\hline Entoloma sinuatum & J.Wisman, 2003-09-19 & NA & KC710109 & Morgado et al. 2013 \\
\hline Entoloma sordidulum & Co-David 2003 & NA & KC710062 & Morgado et al. 2013 \\
\hline Entoloma sordidulum $\mathrm{s}$. MEN & ALV8406 & Norway & MZ869008 & This study \\
\hline Entoloma sp. & $46-18 \mathrm{~A}$ & & MZ868994 & This study \\
\hline Entoloma sp. & EL145-18 & Sweden & MZ869005 & This study \\
\hline Entoloma sp. & JO160811 & Sweden & MZ868971 & This study \\
\hline Entoloma sp. & KBEB83, 17 & Norway & MZ868988 & This study \\
\hline Entoloma sp. & MEN2012125 & The Netherlands & MZ868977 & This study \\
\hline Entoloma sp. & N128 Irmgard6540 & USA & MZ868964 & This study \\
\hline Entoloma sp. & O:F304982 & Norway & MZ869003 & This study \\
\hline Entoloma sp. & UBC, F-32218 & Canada, BC & MF955123 & $\begin{array}{l}\text { Berbee et al., unpub- } \\
\text { lished }\end{array}$ \\
\hline Entoloma subarcticum & JHP-392, isotype & Greenland & MZ868974 & This study \\
\hline
\end{tabular}


Table 1 (continued)

\begin{tabular}{|c|c|c|c|c|}
\hline Entoloma subradiatum & $\begin{array}{l}\text { "rhosse", G262076, } \\
\text { lectotype }\end{array}$ & France & LN850596 & Kokkonen 2015 \\
\hline Entoloma subrhodopolium & KUB1, holotype & Japan & LC088033 & Kondo et al. 2017 \\
\hline Entoloma svalbardense & $\begin{array}{l}\text { GG310/86, O74756, } \\
\text { holotype }\end{array}$ & Svalbard & LN850610 & Kokkonen 2015 \\
\hline Entoloma svalbardense & MENJG228 & Norway, Svalbard & JF304386 & Geml et al. 2012 \\
\hline Entoloma tiliae & LE254179 & Russia, Saint Petersburg & MH790420 & Crous et al. 2018 \\
\hline Entoloma tiliae & O:F-251963 & Norway & MZ868986 & This study \\
\hline Entoloma transvenosum & MEN1215, holotype & Denmark & MZ868965 & This study \\
\hline Entoloma venosum & MD2012-15 & Germany & MZ868989 & This study \\
\hline Rhodophyllus myrmecophilus & holotype & France & LN850462 & Kokkonen 2015 \\
\hline uncultured Entoloma & NA & Mexico & KY574307 & $\begin{array}{l}\text { Garibay-Orijel and } \\
\text { Garcia-Guzman, } \\
\text { unpublished }\end{array}$ \\
\hline uncultured fungus & NA & USA & EU807287 & $\begin{array}{l}\text { Hanson et al., unpub- } \\
\text { lished }\end{array}$ \\
\hline \multicolumn{5}{|l|}{ subgenus Nolanea } \\
\hline $\begin{array}{l}\text { Entoloma belouvense var. bel- } \\
\text { ouvense }\end{array}$ & WU27132, holotype & France, Reunion & MZ611698 & This study \\
\hline $\begin{array}{l}\text { Entoloma belouvense var. } \\
\text { albertinae }\end{array}$ & CME5 & Panama & MZ611628 & This study \\
\hline $\begin{array}{l}\text { Entoloma belouvense var. } \\
\text { albertinae }\end{array}$ & KaiR630 & Panama & MZ611668 & This study \\
\hline Entoloma cetratum & LE235480 & Russia & KC898450 & Morozova et al. 2014a \\
\hline Entoloma clandestinum & KaiR1282 & Sweden & MZ611639 & This study \\
\hline Entoloma conferendum & KaiR1342 & Austria & MZ611640 & This study \\
\hline Entoloma conferendum & KaiR1358 & Germany & MZ611641 & This study \\
\hline Entoloma conferendum & KaiR978 & Germany & MZ611680 & This study \\
\hline Entoloma cremeostriatum & CME10 & Panama & MZ611621 & This study \\
\hline Entoloma cremeostriatum & KaiR508 & Panama & MZ611654 & This study \\
\hline Entoloma cremeostriatum & KaiR613, holotype & Panama & MZ611664 & This study \\
\hline Entoloma euchroum & KR-M-0032474 & Germany & KC898421 & Morozova et al. 2014a \\
\hline Entoloma flavoconicum & KaiR609 & Panama & MZ611662 & This study \\
\hline Entoloma flavoconicum & KaiR628, holotype & Panama & MZ611667 & This study \\
\hline Entoloma infula & KaiR988 & Germany & MZ611681 & This study \\
\hline Entoloma infula & KaiR989 & Germany & MZ611682 & This study \\
\hline Entoloma luteofuscum & K-M-188309, holotype & India & KF698730 & Raj et al. 2014 \\
\hline Entoloma olivaceohebes & WU17841, holotype & Italy & JX454804 & Vila et al. 2013 \\
\hline Entoloma olivaceohebes & WU20798 & Italy & JX454803 & Vila et al. 2013 \\
\hline Entoloma paraconferendum & CME6, holotype & Panama & MZ611629 & This study \\
\hline Entoloma paraconferendum & CME7 & Panama & MZ611630 & This study \\
\hline Entoloma piceinum & LE254131, holotype & Russia & KM262035 & Morozova et al. 2014b \\
\hline Entoloma pulchellum & HMLD1300 & China & KC257436 & $\begin{array}{l}\text { Wang and Bau, unpub- } \\
\text { lished }\end{array}$ \\
\hline Entoloma pulchellum & KA12-1242 & South Korea & KR673495 & Kim et al. 2015 \\
\hline Entoloma readiae & PDD71294 & New Zealand & MZ611696 & This study \\
\hline Entoloma readiae & PDD87270 & New Zealand & MZ611697 & This study \\
\hline Entoloma sericeum & KaiR1267 & Sweden & MZ611638 & This study \\
\hline Entoloma sp. & KaiR626 & Panama & MZ611666 & This study \\
\hline Entoloma sp. & KaiR693 & Panama & MZ611678 & This study \\
\hline Entoloma subelegans & WU32902, holotype & Mauritius & MZ611699 & This study \\
\hline Entoloma transitionisporum & CME9 & Panama & MZ611632 & This study \\
\hline
\end{tabular}


Table 1 (continued)

\begin{tabular}{|c|c|c|c|c|}
\hline Entoloma transitionisporum & KaiR503, holotype & Panama & MZ611653 & This study \\
\hline Entoloma vernum & LE312418 & Russia & MF476911 & Morozova et al. 2017 \\
\hline Nolanea albertinae & FK0912 & Brazil & KF679349 & Karstedt et al. 2020 \\
\hline Nolanea albertinae & FK0935, holotype & Brazil & KF679348 & Karstedt et al. 2020 \\
\hline Nolanea albertinae & FK1731 & Brazil & KF679350 & Karstedt et al. 2020 \\
\hline Nolanea albertinae & FK1732 & Brazil & KF679351 & Karstedt et al. 2020 \\
\hline Nolanea atropapillata & FK0898, holotype & Brazil & KF679354 & Karstedt et al. 2020 \\
\hline Nolanea pallidosalmonea & FK0891 & Brazil & KF738923 & Karstedt et al. 2020 \\
\hline Nolanea parvispora & FK1140 & Brazil & KF679353 & Karstedt et al. 2020 \\
\hline Nolanea sp. & FLAS-F-61537 & USA & MH211959 & $\begin{array}{c}\text { Kaminsky et al., } \\
\text { unpublished }\end{array}$ \\
\hline Nolanea tricholomatoidea & FK1049, holotype & Brazil & KF679352 & Karstedt et al. 2020 \\
\hline
\end{tabular}

Table 2 Infrageneric positions of the specimens collected between 2014 and 2018

\begin{tabular}{lll}
\hline Subclade & Specimens & $\begin{array}{l}\text { Number } \\
\text { of spe- } \\
\text { cies }\end{array}$ \\
\hline Subg. Cyanula & 35 & 18 \\
Subg. Entoloma & 23 & 5 \\
Subg. Alboleptonia & 17 & 3 \\
Subg. Nolanea & 15 & 7 \\
Subg. Cubospora & 11 & 6 \\
Subg. Pouzarella & 5 & 5 \\
Subg. Inocephalus & 3 & 3 \\
Sect. Calliderma & 3 & 1 \\
Subg. Claudopus & 1 & 1 \\
Not determined & 11 & $>5$ \\
\hline
\end{tabular}

with species distinguished by a combination of macro- and microscopical characters. Since an ectomycorrhizal lifestyle was discovered for species of subg. Entoloma (Antibus et al. 1981; Loree et al. 1989; Agerer 1997), ecological characters are also considered to delimit species. Kokkonen (2015) used ITS sequence data as a new tool to tackle concepts of species in subg. Entoloma in Northern Europe. New species were defined based on a combination of morphological and ecological characteristics combined with an ITS phylogeny. As a result, nine species were described as new to science and many species were synonymised. Ongoing studies in Europe (Brandrud et al. 2018; Noordeloos et al. 2018) show that there are still many questions as how to interpret classical species, as well as how to deal with apparently cryptic speciation in this clade. Montañez et al. (2016) presented six species of subg. Entoloma collected in Quercus-Pinus forests in central Mexico. Also, Largent (1994) described species of subg. Entoloma from Quercus-dominated habitats. As Quercus spp. migrated from North America southwards and reached Central America approximately 10 million years ago (Kappelle et al. 1992; Hooghiemstra 2006), there should be links to species described from Mexico or southern USA. Unfortunately, hardly any molecular data of the species described from these regions are available for comparison and we must rely on morphological comparisons for several species.

Entoloma brunneorugulosum Reschke, Noordel. \& Lotz-Winter, sp. nov., Figs. 4 and 5

Mycobank number: MB840935.

Typification: PANAMA. CHIRIQUÍ: near Volcán, Paso Ancho, PNVB, forest trail towards summit of volcano,
Table 3 Specimens per habitat in the years 2017 and 2018

\begin{tabular}{ll}
\hline Habitat & Specimens \\
\hline Montane forest with abundant to dominant Quercus spp. & 47 \\
Montane forest dominated by Alnus acuminata & 22 \\
Montane forest with abundant Quercus spp. and Comarostaphylis arbutoides & 9 \\
Transition of submontane tropical forest dominated by Oreomunnea mexicana to montane & 2 \\
Quercus-dominated forest & 1 \\
Montane tropical forest & 1 \\
Disturbed lower montane forest with Quercus spp. and Alnus acuminata & 1 \\
Lowland forest close to mangrove & 1 \\
Lowland, path in disturbed secondary vegetation & 84 \\
Total & 1 \\
\hline
\end{tabular}


Fig. 2 Basidiospore shapes of Entoloma spp. as seen by SEM a cuboid with dièdre basal (KaiR623), b heptahedroid with simple base (CME6), c octahedroid with dièdre basal (KaiR465), d enneahedroid with dièdre basal (KaiR612), e decahedroid with simple base (KaiR691), f hendecahedroid with dièdre basal (KaiR628), $\mathbf{g}$ hendecahedroid with dièdre basal (KaiR534), h dodecahedroid with dièdre basal (CME16), i tetradecahedroid with dièdre basal (KaiR670), $\mathbf{j}$, $\mathbf{k}$ indetermined shape with frequent small intercalary facets and more than two apicoadaxial facets (KaiR687), l indetermined shape with different base types, including a base formed by three facets, upper right (JR64); D: adaxial facet, $\mathrm{AD}$ : apico-adaxial facets, $\mathrm{sAD}$ : single apico-adaxial facet, A: apical facet, Ba: basal facet, B: abaxial facet, L: lateral facets; bars $=5 \mu \mathrm{m}$
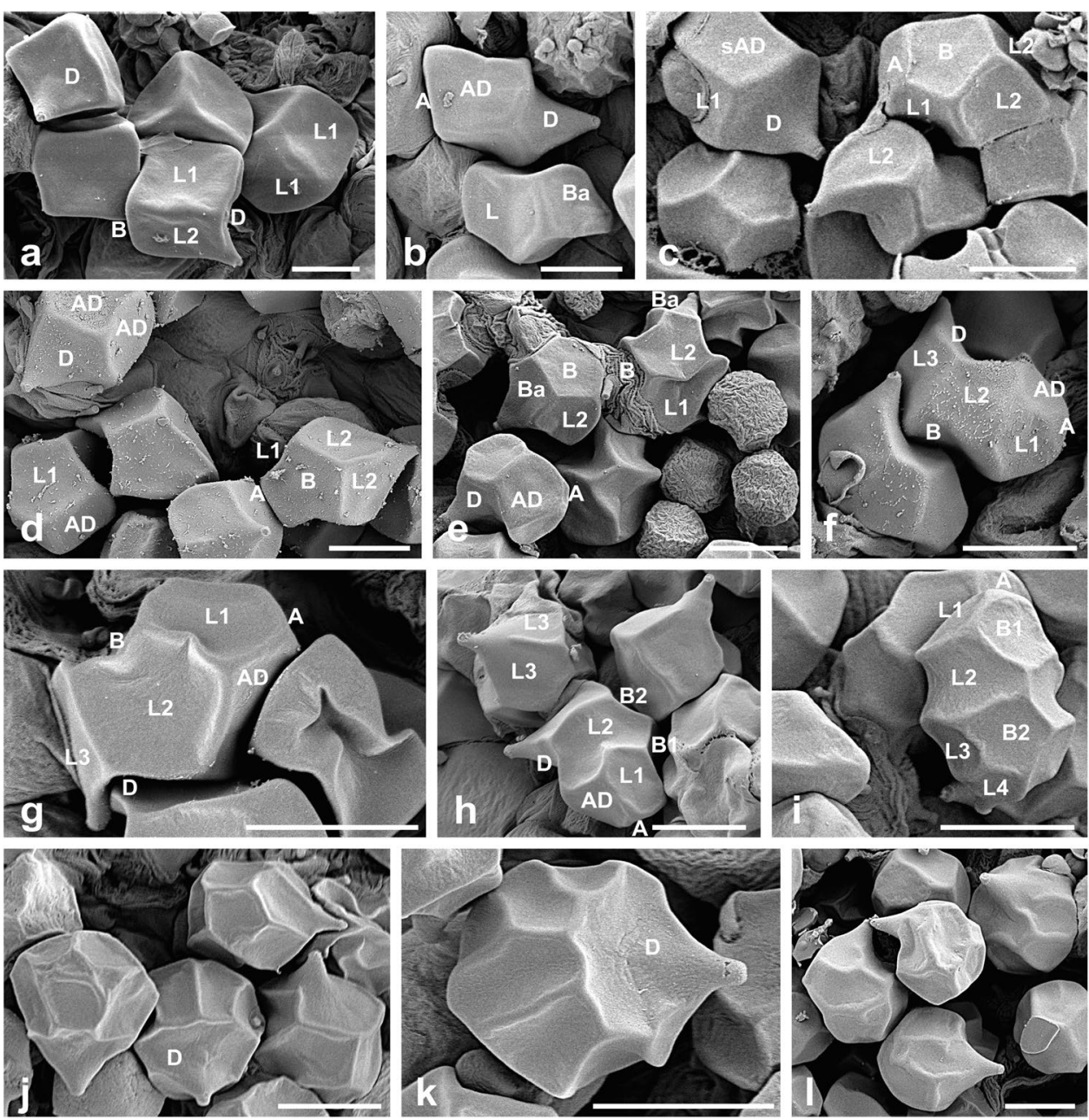

approximately $2000 \mathrm{~m}$ asl., montane forest with abundant Quercus spp. and Comarostaphylis arbutoides, 28 June 2017, B. Wergen, KaiR691, holotype (M).

Etymology: brunneus $($ Latin $)=$ brown, rugosus $($ Latin $)=$ rugose; refers to colour and structure of the pileal surface.

Description: Basidiocarps tricholomatoid. Pileus $3.0-5.0 \mathrm{~cm}$ diameter, convex when young, becoming plane to depressed in old basidiocarps, usually with an obtuse umbo, margin initially deflexed, then straight, blackish brown to dark yellowish brown $(5 \mathrm{~F} 8)$ in the centre, dark brown to light brown $(6 \mathrm{D} 7,6 \mathrm{E} 7,6 \mathrm{~F} 7,6 \mathrm{~F} 8)$, olive brown $(4 \mathrm{~F} 8)$, yellowish brown $(5 \mathrm{E} 7,5 \mathrm{E} 8)$ to greyish yellow $(4 \mathrm{C} 6,4 \mathrm{C} 7)$ towards the margin, pileal surface glabrous, with a waxy appearance, rugulose, slightly translucently striate at the margin up to a quarter of the radius in fresh basidiocarps. Lamellae adnate to sinuate, segmentiform to ventricose, rather distant, relatively thick and broad, initially whitish with greyish to cream tinge, later greyish pink, with smooth, concolorous edges. Stipe $3.5-4.0 \times 0.6-0.9 \mathrm{~cm}$, cylindrical, solid in young basidiocarps, becoming hollow, basically yellowish brown (5E5,
5E6, 5E7) to olive brown (4E6, 4E7, 4E8, 4F6, 4F7), overlaid by whitish fibrils, paler, almost white, towards base, whitish fibrillose-flocculose at the apex when young. Basal mycelium white. Odour and taste farinaceous to farinaceous rancid.

Basidiospores $8.5-9.5-11.0 \times 7.0-7.9-9.0 \mu \mathrm{m}$, $Q=1.05-1.20-1.35$ ( $n=85$ spores of 4 specimens), decahedroid, composed of an adaxial facet (D), a pair of apicoadaxial facets (AD), an apical facet (A), an abaxial facet (B), two pairs of lateral facets (L1-L2), and a basal facet (Ba) forming a simple base, mainly subisodiametrical to broadly heterodiametrical, with $5-7$, predominantly 6 , pronounced angles in outline, weakly pigmented yellowish pink, somewhat thick-walled. Basidia 43-61 × 12-15 $\mu \mathrm{m}$, clavate, hyaline, predominantly 4 -spored, with up to $6 \mu \mathrm{m}$ long sterigmata, rarely 2 -spored. Lamellar edge fertile, hymenial cystidia absent. Hymenophoral trama regular, formed by cylindrical to fusiform cells, $55-135 \times 6-25 \mu \mathrm{m}$. Pileipellis a cutis formed by rather long, narrow, and cylindrical cells, $55-190 \times 6.0-12.0 \mu \mathrm{m}$, with some cylindrical to clavate terminal cells, cells shorter and wider downwards, gradually passing into the pileitrama, composed of 


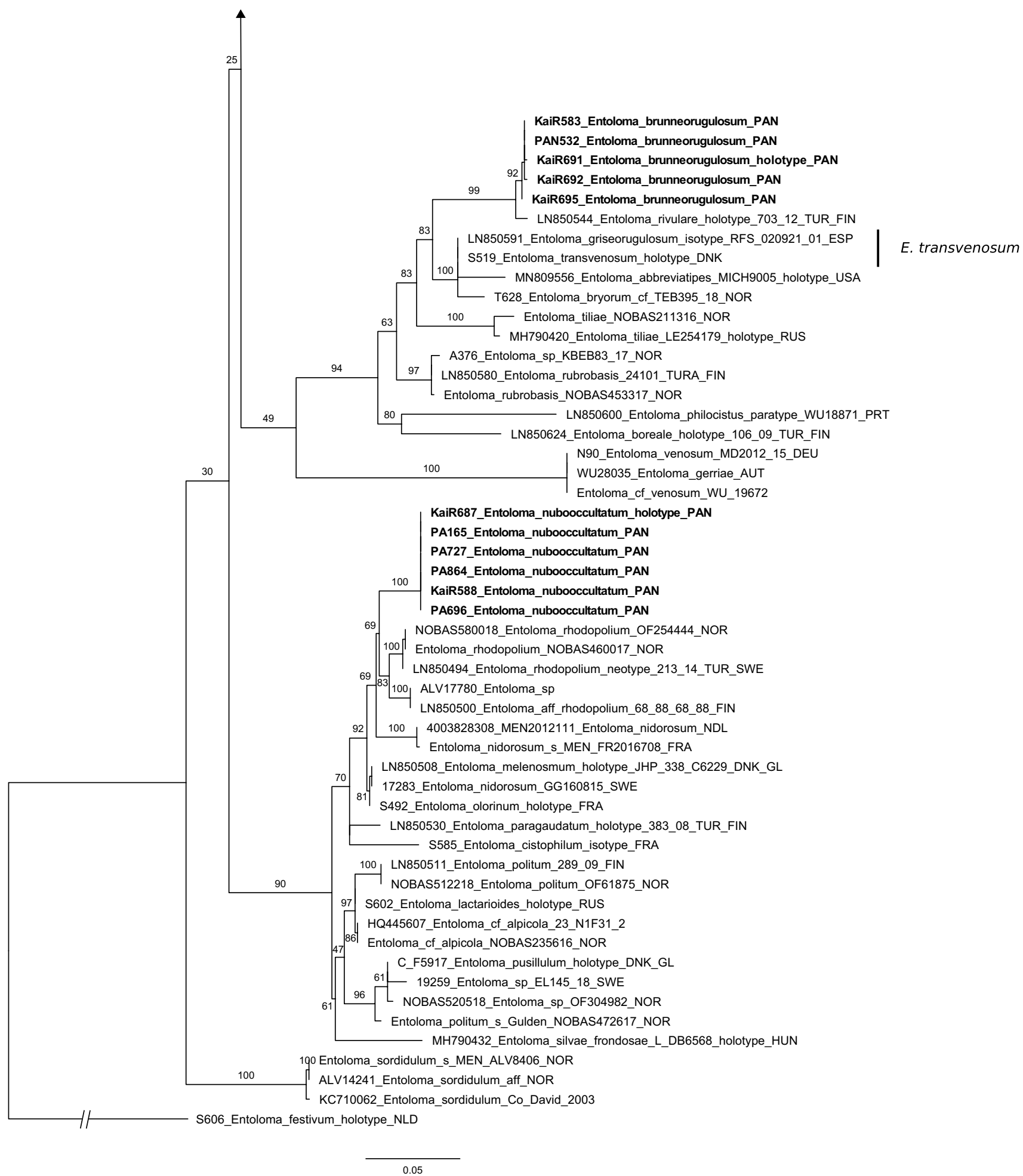

Fig. 3 Maximum Likelihood phylogram of species of subg. Entoloma based on ITS, rooted to E. festivum, bootstrap values above or below branches, bar = estimated changes/nucleotide

inflated to fusiform cells, up to $22 \mu \mathrm{m}$ wide. Pigment intracellular, brown, mainly in dense clusters of brown granules in the upper pileipellis. Stipitipellis a cutis composed of cylindrical cells, $75-300 \times 3.0-9.5 \mu \mathrm{m}$, with intracellular, brown, mainly granular pigment, like the pigment of the pileipellis. Caulocystidia absent. Oleiferous hyphae present in the trama. Clamp connections abundant in all parts of the basidiocarp. 


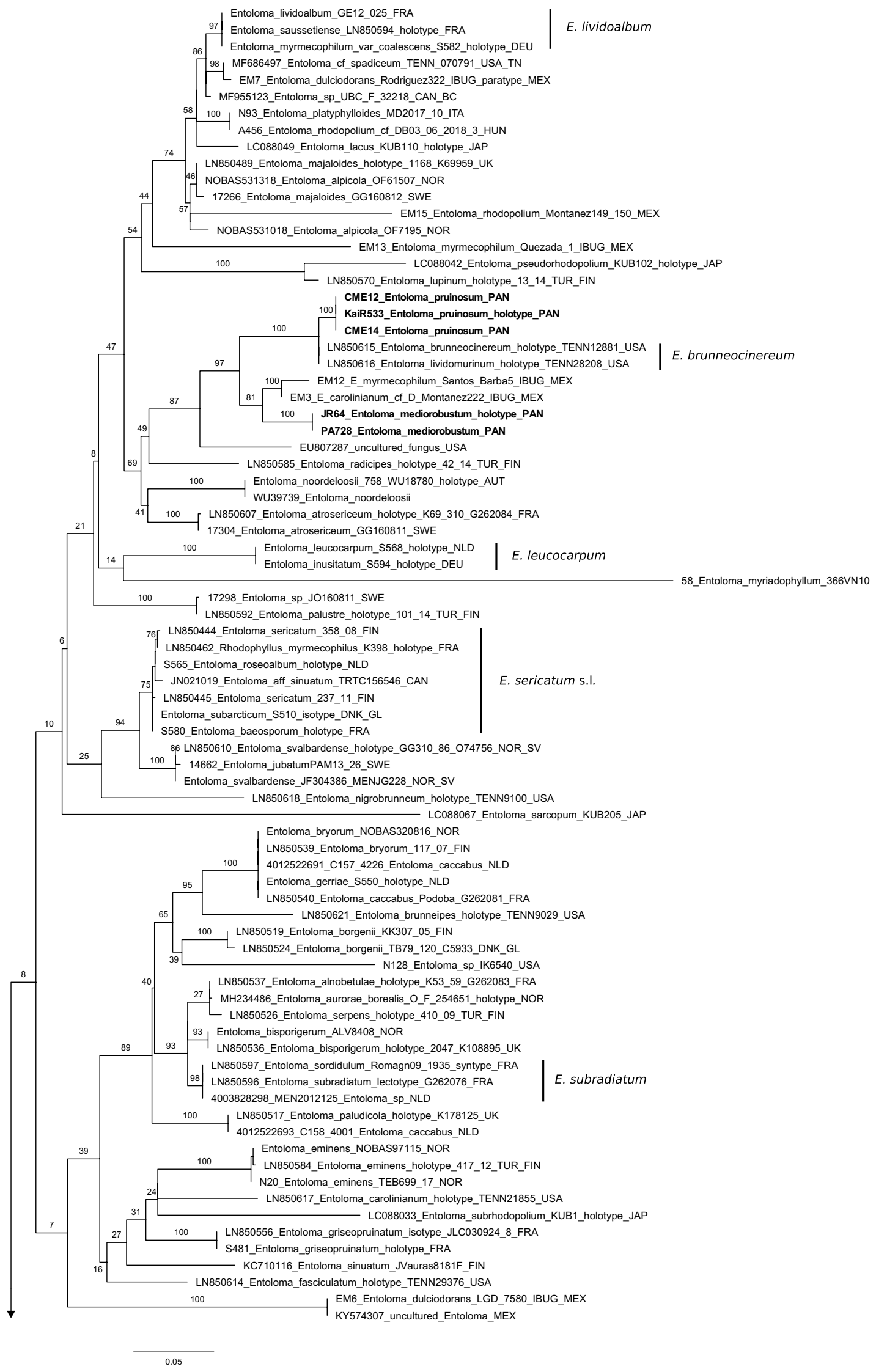

Fig. 3 (continued) 
Fig. 4 Basidiocarps, and basidiospores as seen by SEM of Entoloma brunneorugulosum a (KaiR583) b, c, d (KaiR691, holotype) bars $=10 \mu \mathrm{m}$
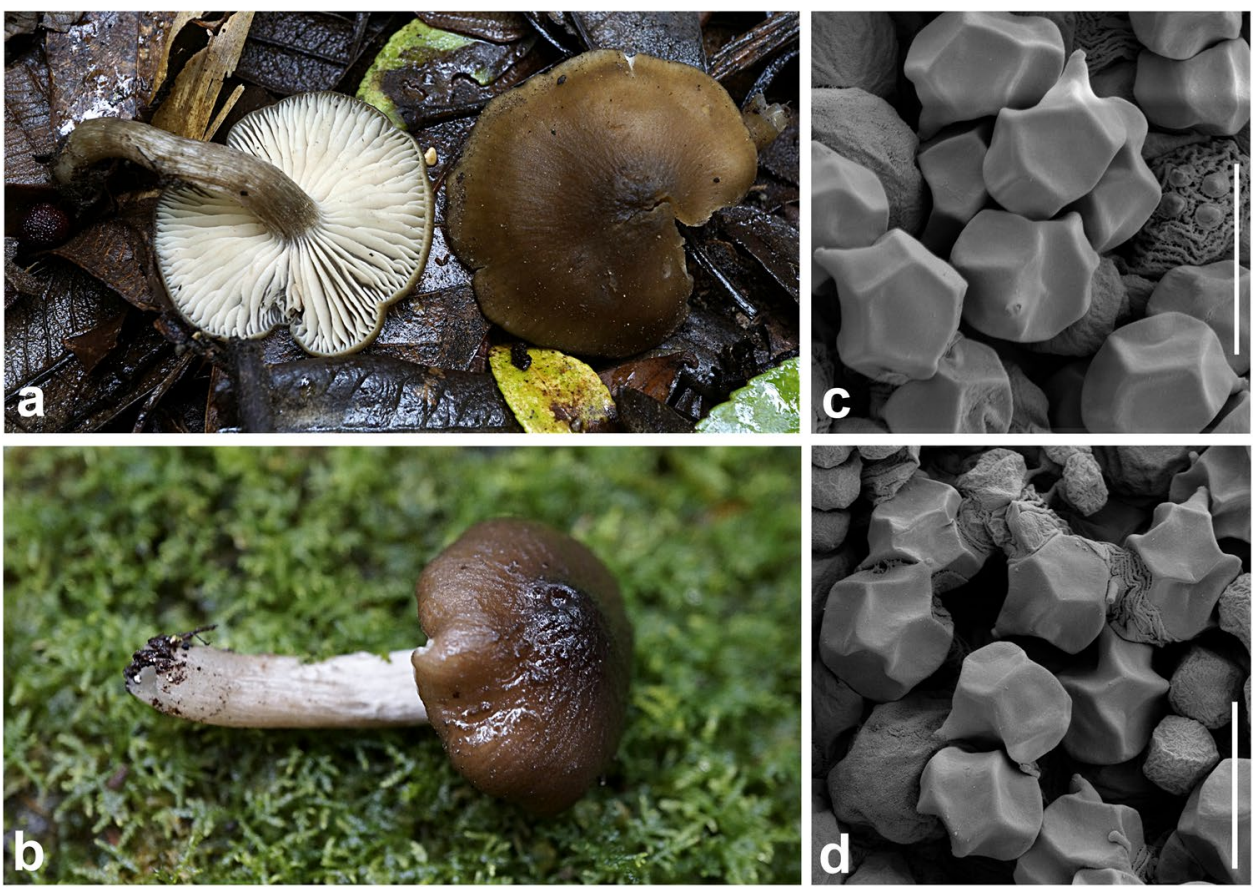

Fig. 5 Microscopic structures of Entoloma brunneorugulosum a pileipellis with intracellular pigment (KaiR691, holotype), bar $=20 \mu \mathrm{m}$ b basidiospores (KaiR583), bar $=10 \mu \mathrm{m}$
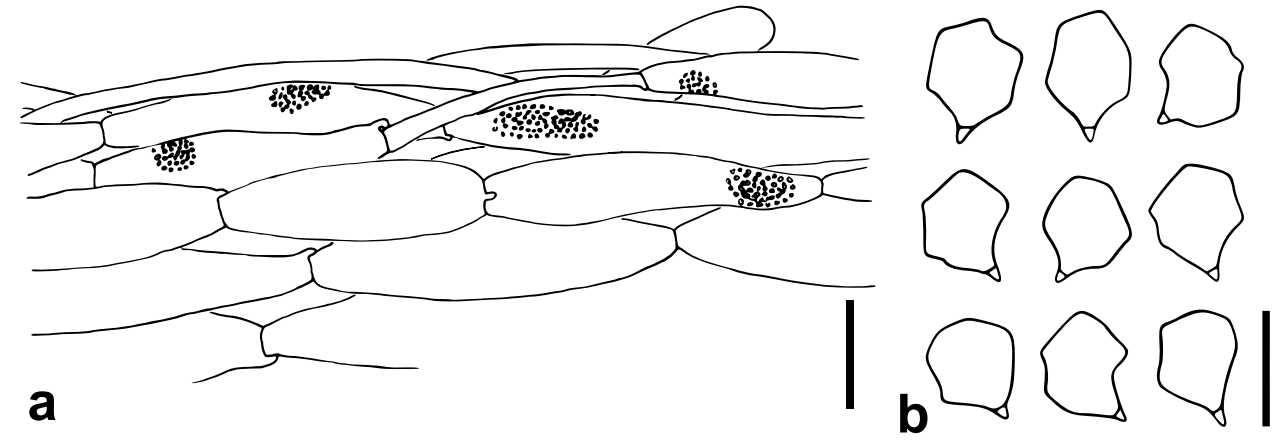

Fig. 6 Basidiocarp, and basidiospores as seen by SEM of Entoloma mediorobustum (JR64, holotype)
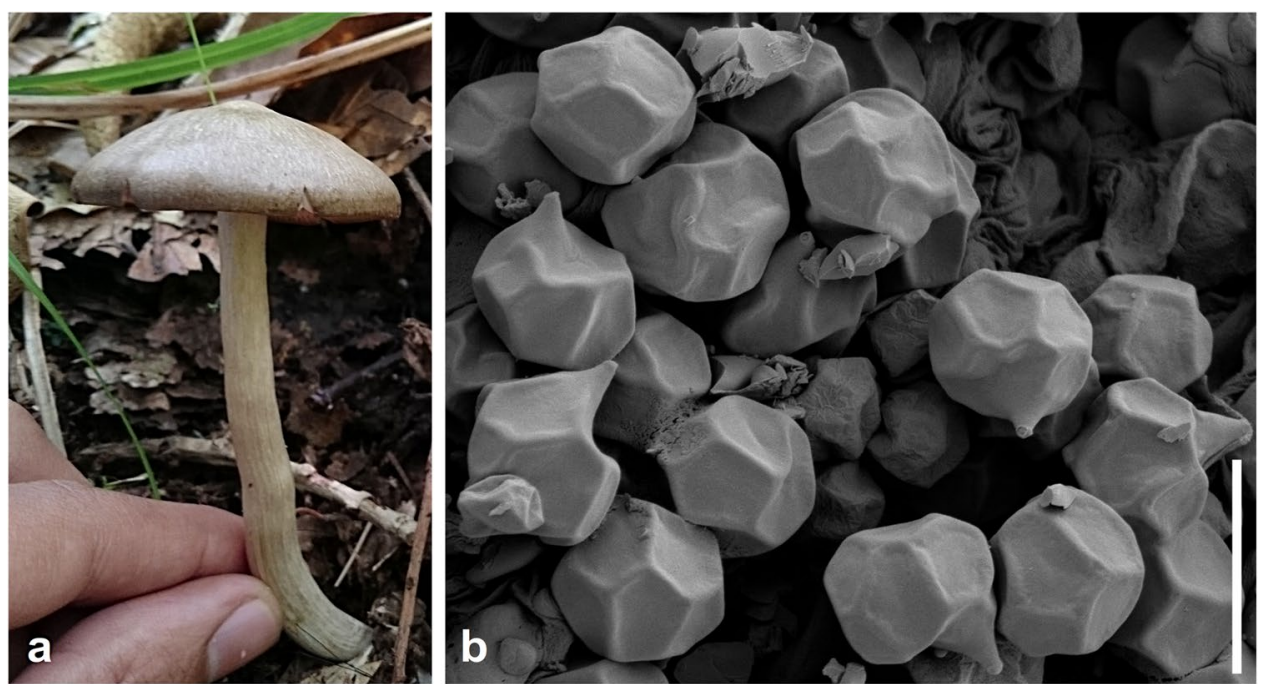
Fig. 7 Microscopic structures of Entoloma mediorobustum (JR64, holotype): a pileipellis with incrusting pigment indicated on the right hand side, bar $=20 \mu \mathrm{m} ; \mathbf{b}$ basidiospores, bar $=10 \mu \mathrm{m}$

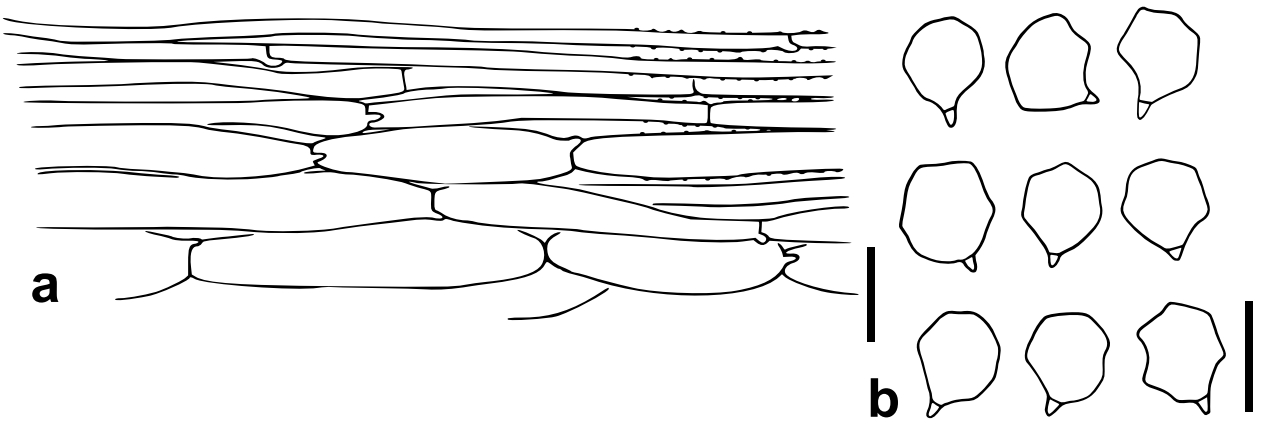

Habitat: Basidiocarps solitary to scattered in a group, in Quercus-dominated montane forest at around $2000 \mathrm{~m}$ asl. in Chiriquí, Panama. Probably ectomycorrhizal with Quercus spp. or Comarostaphylis arbutoides.

Additional specimens examined: PANAMA. CHIRIQUÍ: near Volcán, Paso Ancho, PNVB, approx. 2000 m asl., montane forest with abundant Quercus spp. and Comarostaphylis arbutoides, 10 July 2016, H. Lotz-Winter, PAN532 (M); ibid., 17 June 2017, E. Heinemann, KaiR583 (M); ibid., 28 June 2017, K. Reschke and T.A. Hofmann, KaiR692 (M); ibid., 28 June 2017, K. Reschke and T.A. Hofmann, KaiR695 (UCH9247, M).

Notes: Entoloma brunneorugulosum is characterised by small to medium basidiocarps with a rugulose, brown, umbonate pileus and a somewhat paler brown stipe, as well as intracellular, granular pigment, and possibly by an association to Quercus spp. Phylogenetically, it is a sister species to Entoloma rivulare Kokkonen with a $p$-distance of $1.7 \%$ in the ITS. Entoloma rivulare was described from a single collection in a moist Alnus incana/Populus tremula forest in Finland. Its basidiocarps are like those of E. brunneorugulosum in having a rather small, brown pileus, with a translucently striate margin and a farinaceous smell and taste. It differs, however, by the non-umbonate, darker pileus and smaller basidiospores with lower $Q$-values. Furthermore, these two species have different mycorrhizal hosts. Entoloma griseorugulosum Noordel. \& Fernández Sas. is similar by its rugulose, dark grey-brown pilei, which are not translucently striate, and the size and shape of the basidiospores (Noordeloos 2004). Our molecular phylogenetic analysis (Fig. 5) suggests that E. griseorugulosum is a later synonym of $E$. transvenosum Noordel. Entoloma transvenosum was described with a translucently striate pileus and larger basidiospores $(9.0-13.0 \times 7.0-10 \mu \mathrm{m})$. Both descriptions note greyish, often transvenose lamellae, a stipe paler than pileus, intracellular pigment, and occurrence in rather open forest, often together with Quercus spp. in western Europe (Noordeloos 1982, 2004). Considering both concepts, E. brunneorugulosum differs by the warmer, lighter brown colour of the pileus, the often concolorous stipe, and the different habitat. Basidiocarps of E. rugosostriatum Largent \& T.W. Henkel are like those of E. brunneorugulosum by rugulose, brown pilei with a striate margin; however, the basidiospores of $E$. rugosostriatum are isodiametrical, weakly angled and smaller (6.1-7.4×6.1-7.3 $\mu \mathrm{m})$ (Largent et al. 2008b). None of the species described by Hesler (1967), Horak (1978, 1982), Largent (1994), and Montañez et al. (2016) combine a dark rugulose, non-hygrophanous pileus, and relatively paler stipe, and an association with Quercus spp.

Entoloma mediorobustum Reschke, J. RodríguezCedeño \& Noordel., sp. nov. Figs. 6 and 7

Mycobank number MB840629.

Typification: PANAMA. CHIRIQUÍ: near Volcán, Paso Ancho, PNVB, trail towards summit of volcano, N $8^{\circ} 48^{\prime} 57.1^{\prime \prime \prime} \mathrm{W} 82^{\circ} 24^{\prime} 35.2^{\prime \prime \prime}, 2,040 \mathrm{~m}$ asl., montane forest with abundant Quercus spp. and Comarostaphylis arbutoides, 1 August 2015, J. Rodríguez, S. Cáceres, K. Barrera, R. Valdéz, JR64, holotype (UCH11749), isotype (M).

Etymology: medius $($ Latin $)=$ medium, robustus $($ Latin $)=$ robust; refers to the shape of the basidiocarps.

Description: Basidiocarps tricholomatoid. Pileus $4.2-4.8 \mathrm{~cm}$ diameter, convex, with initially incurved, later straight and undulating margin, yellowish brown (5E4, 5E5, 5D5, 5D6), pileal surface smooth, sometimes partly covered by a whitish pruina, not translucently striate, hygrophanous. Lamellae emarginate, medium-spaced to rather distant, greyish white when young, becoming dirty pink, with somewhat uneven to eroded, concolorous edges. Stipe $10.0 \times 0.8-1.0 \mathrm{~cm}$, cylindrical with radicating base, stuffed, whitish, fibrillose. Basal mycelium white, somewhat cottony. Odour and taste not tested.

Basidiospores 7.5-8.7-10.0 $\times 7.0-7.9-8.5 \mu \mathrm{m}$, $Q=1.00-1.11-1.20(n=50$ spores of 2 specimens $)$, spatial shape not determined, at least with 12 facets, base often built by 3 facets, isodiametrical to subisodiametriacal, with 5-7 rather blunt angles in outline, weakly pigmented yellowish pink, somewhat thick-walled. Basidia 30-43×9.0-11.0 $\mu \mathrm{m}$, clavate to subclavate, hyaline, 4-spored, sterigmata up to $4.0 \mu \mathrm{m}$ long. Lamellar edge fertile, hymenial cystidia 
Fig. 8 Basidiocarps and basidiospores as seen by SEM of Entoloma nubooccultatum: a, e (KaiR687, holotype) bar $=10 \mu \mathrm{m} ; \mathbf{b}$ (PA165) picture by S. Cáceres c (KaiR588); d (PA727)
Fig. 9 Microscopic structures of Entoloma nubooccultatum (KaiR687, holotype): a pileipellis, intracellular pigment not indicated, $b a r=20 \mu \mathrm{m}$; b basidiospores, bar $=10 \mu \mathrm{m}$
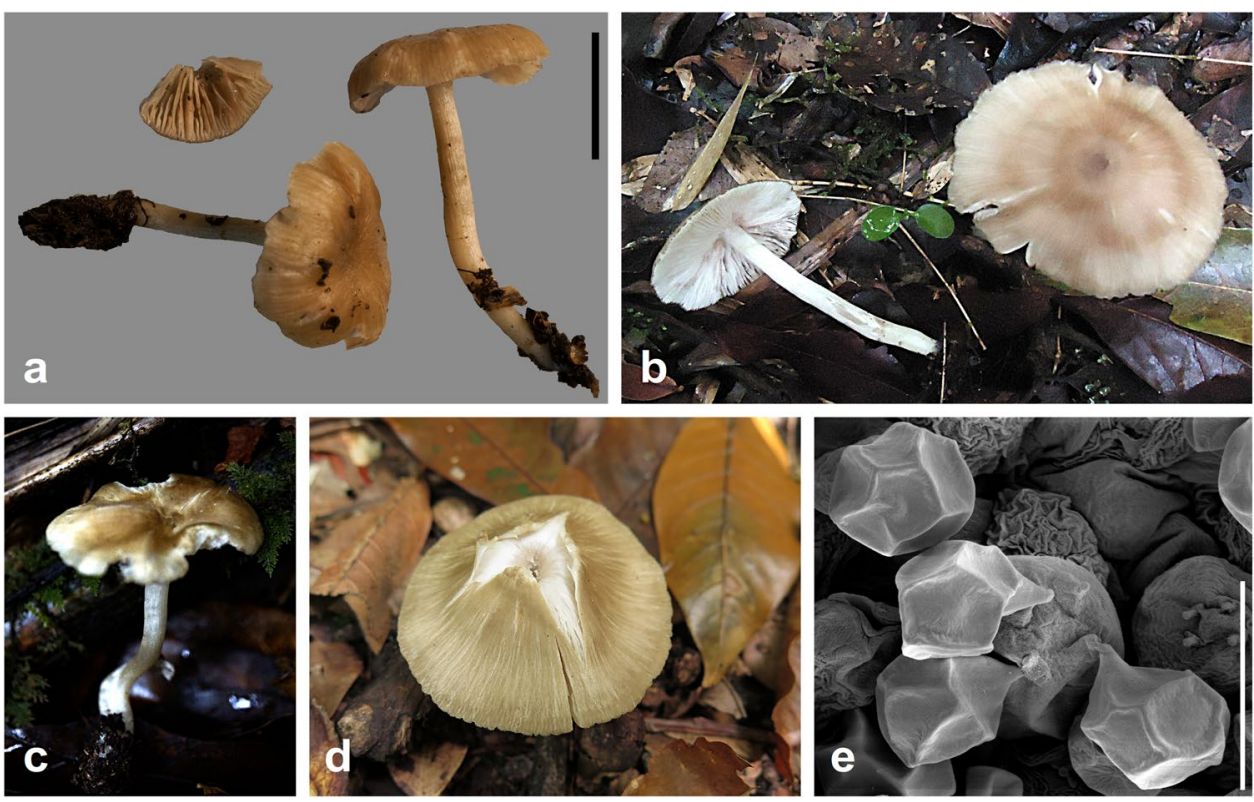

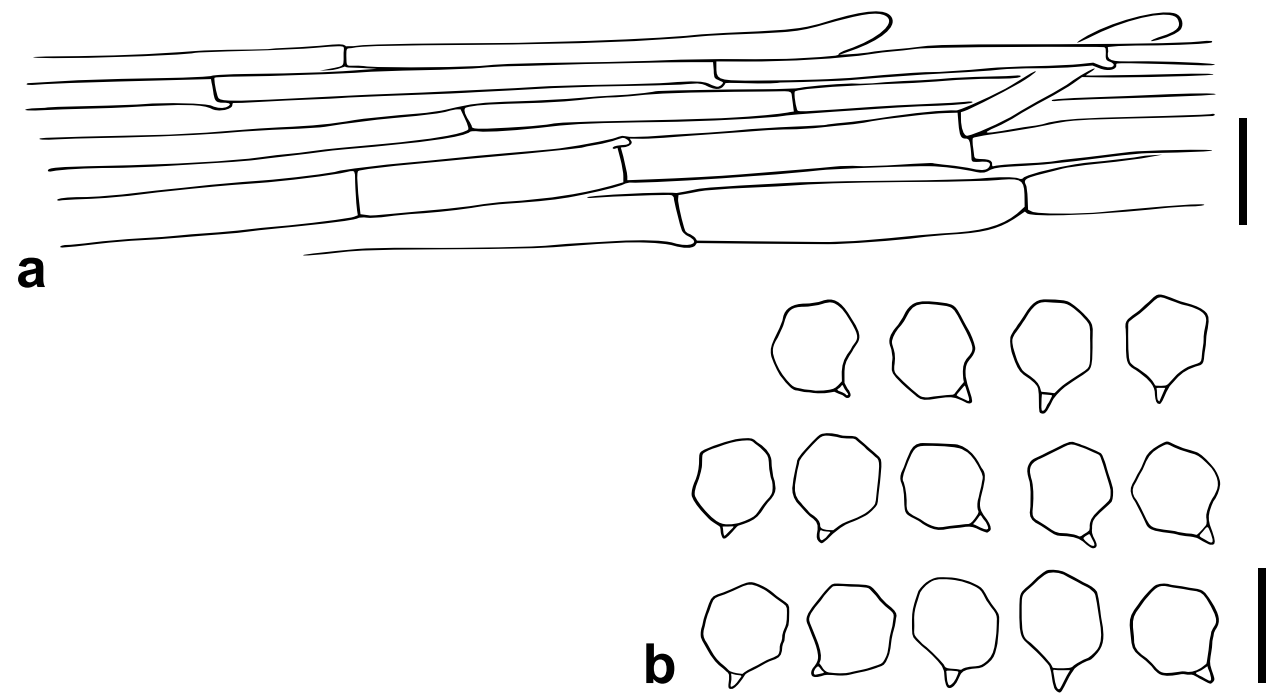

absent. Hymenophoral trama regular, formed by subcylindrical to fusiform cells, (40) 50-200 ×6.0-30 $\mu \mathrm{m}$. Pileipellis a cutis composed of narrow, cylindrical cells, 70-250 $\times 3.5-9.0 \mu \mathrm{m}$, pigment incrusting, brownish in $\mathrm{KOH}$. Stipitipellis a cutis composed of rather hyaline, cylindrical cells, 55-150 ×3.5-8.0 (9.5) $\mu \mathrm{m}$. Caulocystidia absent. Clamp connections present in all parts of the basidiocarps.

Habitat: Basidiocarps solitary on soil in a montane forest with abundant Quercus spp. and Comarostaphylis arbutoides, between 1950 and $2050 \mathrm{~m}$ asl. in Chiriquí, Panama. Probably ectomycorrhizal with Quercus spp. or Comarostaphylis arbutoides.
Additional specimen examined: PANAMA. CHIRIQUI: near Volcán, Paso Ancho, PNVB, N 848'55.4'" W 82³4'47.1'”, 1,970 m asl., montane forest with abundant Quercus spp. and Comarostaphylis arbutoides, 9 November 2015, T.A. Hofmann, J. Rodríguez, S. Cáceres, R. Villarreal, PA728 (M).

Notes: Entoloma mediorobustum is distinctive by the nonhygrophanous pileus with a distinct pruina, which is rather unusual in this subgenus. It clusters with two collections from Mexico, labelled as E. myrmecophilum and E. cf. carolinianum, respectively (Fig. 5), that differ by glabrous, relatively dark brown pilei (Montañez et al. 2016). These species have in common their possible association with Quercus spp. and the presence 
of incrusting pigments in the pileipellis. Entoloma pruinosum is somewhat similar, but its basidiocarps are slightly darker, more robust, and have a more differentiated stipe surface. The two species share the relatively small, isodiametrical to subisodiametrical spores. Phylogenetically, however, they are quite distant (Fig. 5).

Entoloma nubooccultatum Reschke \& Noordel., sp. nov., Figs. 8 and 9

\section{Mycobank number: MB840632.}

Typification: PANAMA. CHIRIQUÍ: near Volcán, Paso Ancho, PNVB, approximately $2000 \mathrm{~m}$ asl., montane forest with abundant Quercus spp. and Comarostaphylis arbutoides, 28 June 2017, K. Reschke and T.A. Hofmann KaiR687, holotype (UCH9243), isotype (M).

Etymology: nubes $($ Latin $)=$ cloud, occultatum (Latin) $=$ hidden; refers to the hidden life of this species in cloud forests.

Description: Basidiocarps collybioid. Pileus $1.5-6.5 \mathrm{~cm}$ diameter, convex umbilicate to depressed, with deflexed and uneven margin which is slightly incurved in young basidiocarps and straight in older basidiocarps, greyish yellow (4B4, 4B5, 4C5, 4C6), brownish orange (5C4, 5C5, 5C6), yellowish brown (5D5, 5D6, 5D7, 5E4, 5E5) to olive brown (4D5, 4D6), pileal surface glabrous, with a waxy appearance when wet, translucently striate at the margin about $1 / 3$ to $2 / 3$ the centre, hygrophanous, fading to yellowish grey (3B2). Lamellae broadly adnate to somewhat decurrent, segmentiform, close, whitish in young specimens, pinkish at maturity, with somewhat undulating and concolorous edges. Stipe $4.5-10 \times 0.3-0.8 \mathrm{~cm}$, cylindrical, often bent, stuffed to hollow, white, somewhat grooved, finely innately fibrillose, base often covered by adhering soil and litter. Basal mycelium white, with many small rhizomorphs. Odour indistinct or slightly sweetish, fruity, taste not tested.

Basidiospores 7.0-7.8-8.5 ×6.0-6.9-7.5 $\mu \mathrm{m}$, $Q=1.05-1.13-1.25$ ( $n=146$ spores of 6 specimens), spatial shape not determined, at least with 11-13 facets, mainly with a dièdre basal, sometimes incomplete, sometimes with a simple base, isodiametrical to broadly heterodiametrical, predominantly subisodiametrical, with 6-7 weak to pronounced, somewhat rounded angles in outline, weakly pigmented yellowish pink, somewhat thick-walled. Basidia (30) 35-43 (48) ×8.5-12.5 $\mu \mathrm{m}$, subclavate, often almost urniform (formed like an urn), hyaline, 4-spored, with up to $6.0 \mu \mathrm{m}$ long sterigmata, few 2-spored. Lamellar edge fertile, hymenial cystidia absent. Hymenophoral trama regular, formed by cylindrical, somewhat fusiform to inflated cells, 45-150×6-20 (28) $\mu \mathrm{m}$. Pileipellis a cutis of cylindrical cells, $35-185 \times(4.0) 6.0-12.5 \mu \mathrm{m}$, with intracellular pigment. Stipitipellis a cutis composed of short, cylindrical cells, 30-70×3.0-6.0 $\mu \mathrm{m}$, not pigmented. Caulocystidia absent. Oleiferous hyphae present in the trama. Clamp connections abundant in all parts of the basidiocarp.

Habitat: Basidiocarps solitary or in small groups in a montane Quercus-dominated forest with abundant
Comarostaphylis arbutoides between 1900 and $2200 \mathrm{~m}$ asl. in Chiriquí, Panama. Probably ectomycorrhizal with Quercus spp. or Comarostaphylis arbutoides.

Additional specimens examined: PANAMA. CHIRIQUÍ: near Volcán, Paso Ancho, PNVB, approximately 2000 m asl., montane forest with abundant Quercus spp. and Comarostaphylis arbutoides, 17 June 2017, K. Reschke, KaiR588 (M); ibid., $\mathrm{N} 8^{\circ} 48^{\prime} 55.3^{\prime \prime \prime} \mathrm{W} 82^{\circ} 34^{\prime} 43.5^{\prime \prime}, 2000 \mathrm{~m}$ asl., montane forest with abundant Quercus spp. and Comarostaphylis arbutoides, 28 September 2014, S. Cáceres, K. Barrera, T.A. Hofmann, R. Valdés, PA165 (M); ibid., N 848'53.4" W82³4'48.0", $1,960 \mathrm{~m}$ asl., montane forest with abundant Quercus spp. and Comarostaphylis arbutoides, 9 November 2015, S. Cáceres, R. Valdés, J. Rodríguez, T.A. Hofmann, PA696 (M); ibid., N 848'55.4'" W 82³4'47.1', 1970 m asl., montane forest with abundant Quercus spp. and Comarostaphylis arbutoides, 9 November 2015, T.A. Hofmann, J. Rodríguez, S. Cáceres, R. Valdés, PA727 (M); ibid., N 848'52.9” W 82³4'47.7", $1920 \mathrm{~m}$ asl., montane forest with abundant Quercus spp. and Comarostaphylis arbutoides, 11 September 2016, T.A. Hofmann and M. Cuevas, PA864 (M).

Notes: Entoloma nubooccultatum is characterised by basidiocarps with collybioid habit, a brown, translucently striate, hygrophanous pileus, a white stipe, intracellular pigment in the pileipellis and rather small basidiospores. Phylogenetically, it forms part of a clade including E. rhodopolium (Fr.) P. Kumm. and several similar, closely related species, which have not yet been completely resolved (Kokkonen 2015; Brandrud et al. 2018). Its $p$-distance to these species ranges from 2.8 to $3.2 \%$ in the ITS. Habitually, it is not unlike E. melenosmum Noordel. However, E. nuboocculatatum has basidiospores that are on average smaller than those of most species in the $E$. rhodopolium clade, and its distribution is probably restricted to tropical montane Quercus forests, while E. rhodopolium and related species are mainly distributed in northern temperate and boreal deciduous forests, predominantly associated with species of Betulaceae, sometimes Fagus sylvatica L., but rarely with Quercus spp. (Noordeloos 2004).

Entoloma pruinosum Reschke, Manz \& Noordel., sp. nov., Figs. 10 and 11

Mycobank number: MB840622.

Typification: PANAMA. CHIRIQUÍ: near Bajo Boquete, Jaramillo Arriba, El Musgo, forest trail towards rock lookout, N $08^{\circ} 47^{\prime} 32.3^{\prime \prime} \mathrm{W} 82^{\circ} 24^{\prime} 50.3^{\prime \prime}, 1650 \mathrm{~m}$ asl., montane forest dominated by Quercus spp., 14 June 2017, K. Reschke, KaiR533, holotype (UCH009184), isotype (M).

Etymology: pruinosus $($ Latin $)=$ pruinose; refers to the pruinose pileal surface.

Description: Basidiocarps tricholomatoid. Pileus 3.0-7.0 cm diameter, convex when young, becoming broadly convex to almost plane in old basidiocarps, with or without 
Fig. 10 Basidiocarps and basidiospores as seen by SEM of Entoloma pruinosum: a (CME14); b (PA167); c, d (KaiR533, holotype) bar $=10$ $\mu \mathrm{m}$
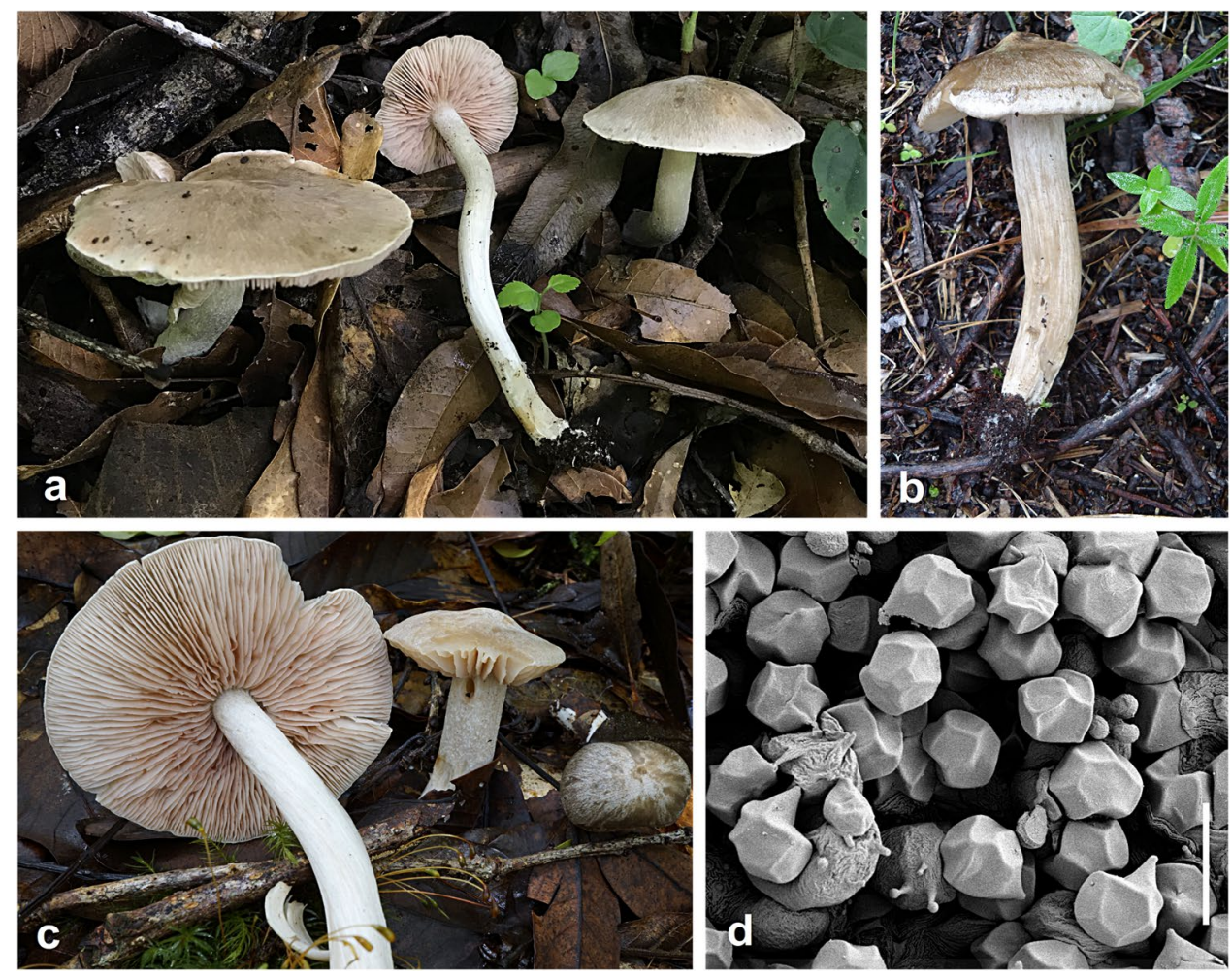

Fig. 11 Microscopic structures of Entoloma pruinosum (KaiR533, holotype): a pileipellis with incrusting pigment indicated at the right hand side, bar $=20 \mu \mathrm{m}$; b stipitipellis with caulocystidia, bar $=20 \mu \mathrm{m} ; \mathbf{c}$ basidiospores, $\mathrm{bar}=10 \mu \mathrm{m}$
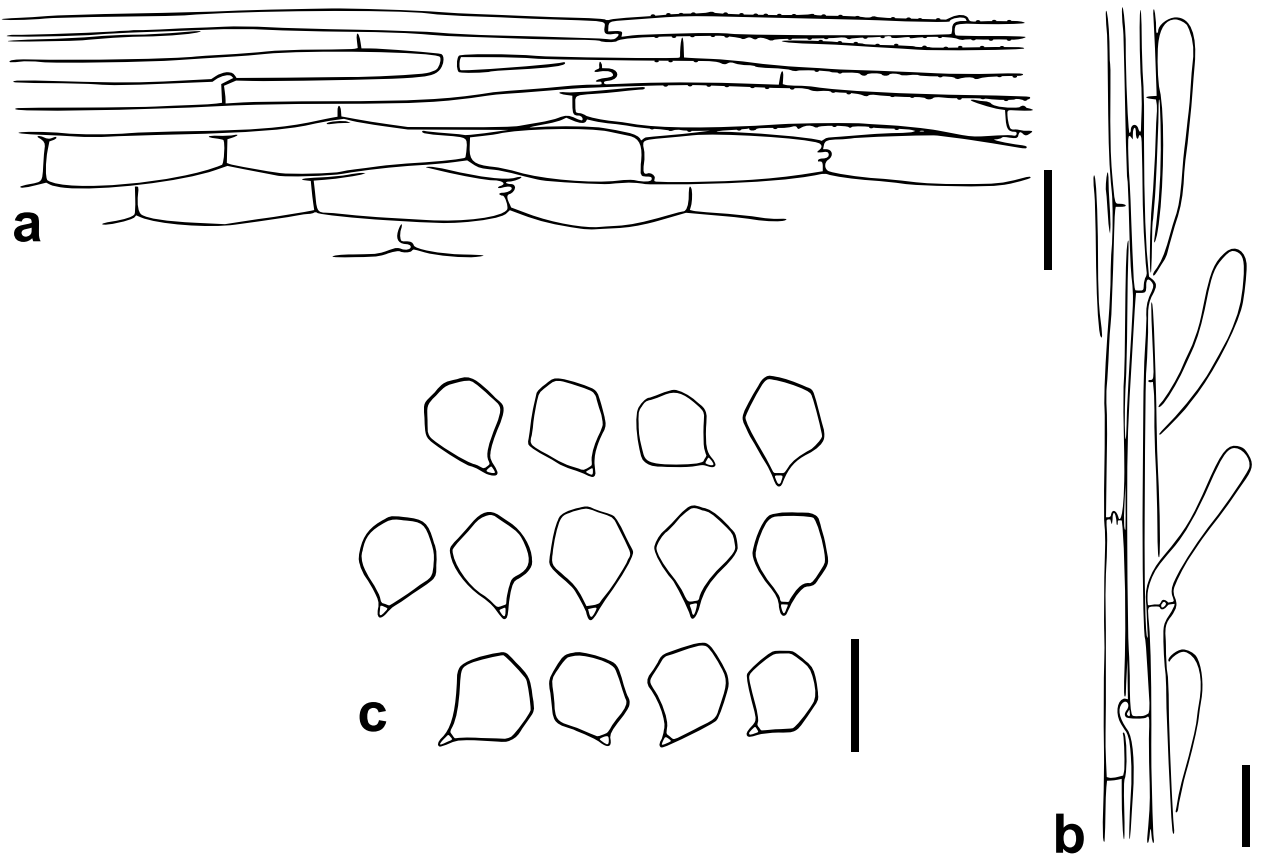

an obtuse umbo, margin initially deflexed and still slightly deflexed in old basidiocarps, greyish yellow, pale olive brown, greyish brown, brownish grey to grey (4B4, 4D5, 4D6, 5B1, $5 \mathrm{C} 2,5 \mathrm{D} 2,5 \mathrm{D} 3$ ), uniformly coloured, pileal surface glabrous, with a waxy appearance, covered by a whitish, slightly fibrillose pruina, not translucently striate, not hygrophanous.
Lamellae sinuate, segmentiform to ventricose, crowded, initially almost white to pale greyish, later pink, with slightly blunt serrate, concolorous edges and moderately to strongly transvenose sides. Stipe $8.0-12.0 \times 0.8-1.0 \mathrm{~cm}$, cylindrical to somewhat tapering towards base, solid, greyish yellow (4B4, 4B5, 4C3, 4C4, 4C5, 4C6, 4C7) under a whitish fibrillose to 


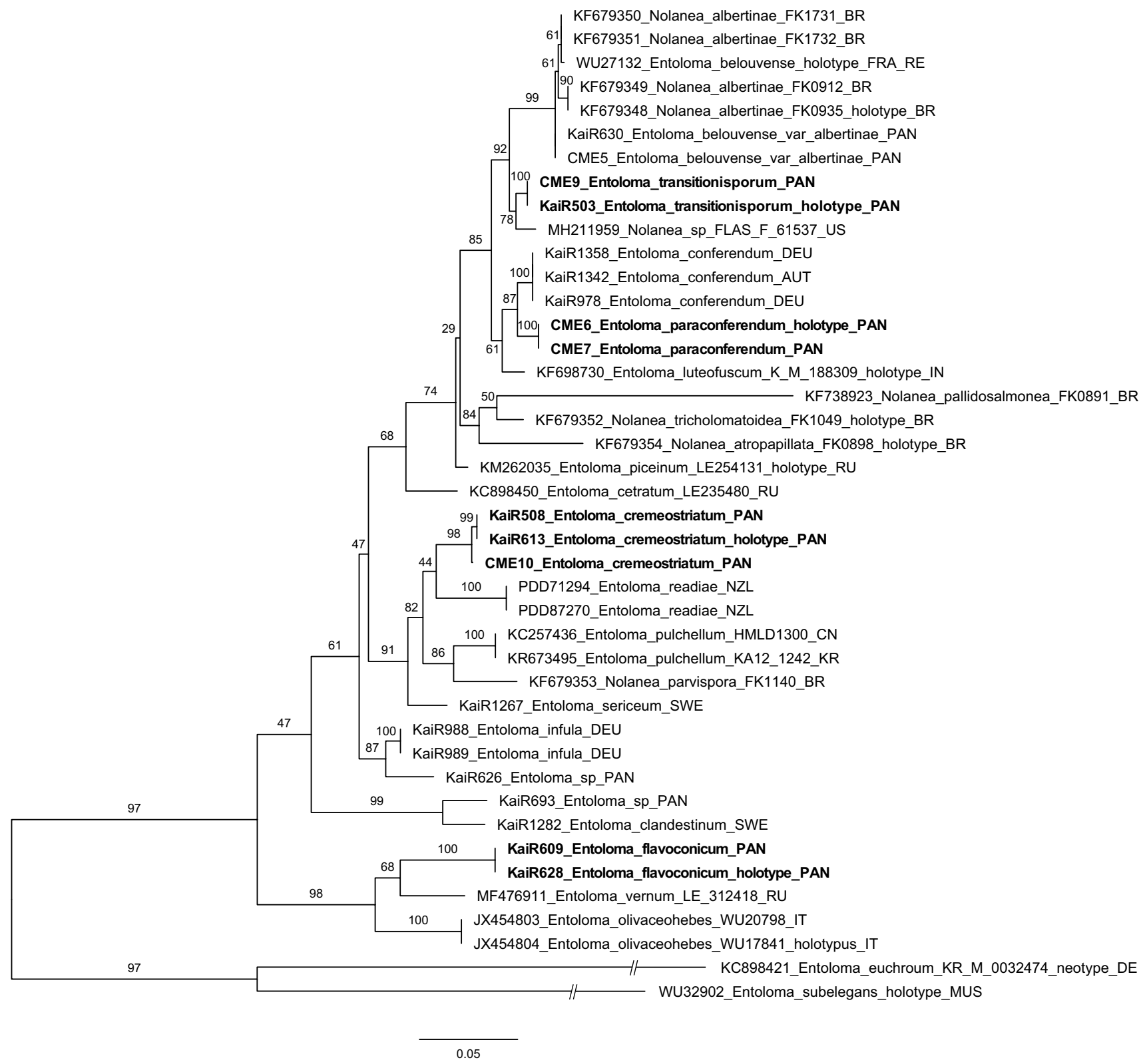

Fig. 12 Maximum Likelihood phylogram of species of subg. Nolanea based on ITS, rooted to E. subelegans and E. euchroum, bootstrap values above or below branches, bar = estimated changes/nucleotide

fibrillose-flocculose layer, staining brownish yellow (5C7, 5C8) after damage. Basal mycelium cottony, white. Odour not distinctive to weakly farinaceous when undamaged, farinaceous when cut, taste farinaceous.

Basidiospores 7.0-7.9-9.0 ×6.0-7.0-8.0 $\mu \mathrm{m}$, $Q=1.05-1.13-1.25$ ( $n=94$ spores of 4 specimens), decahedroid, composed of an adaxial facet (D), a pair of apico-adaxial facets (AD), an apical facet (A), an abaxial facet (B), two pairs of lateral facets (L1-L2), and a basal facet (Ba) forming a simple base, isodiametrical to subisodiametrical, with 5-6 pronounced angles in outline, weakly pigmented yellowish pink, somewhat thick-walled. Basidia 44-60×7.5-11.0 $\mu \mathrm{m}$, clavate, hyaline, 4 -spored, sterigmata up to $4.0 \mu \mathrm{m}$ long. Lamellar edge fertile, hymenial cystidia absent. Hymenophoral trama regular, composed of somewhat fusiform to inflated cells in the centre, $50-120 \times 6.0-14.0 \mu \mathrm{m}$, longer, up to $240 \mu \mathrm{m}$ and narrower, narrowest $4.0 \mu \mathrm{m}$, towards the subhymenium. Pileipellis a cutis formed by cylindrical cells, $65-130 \times 3.0-6.0 \mu \mathrm{m}$, with finely incrusting pigment, without distinct subpellis. Pileitrama composed of rather short and wide, subcylindrical to inflated cells, $40-65 \times 9.0-11.5 \mu \mathrm{m}$. Stipitipellis a cutis composed of cylindrical cells, $40-200 \times 3.5-7.0 \mu \mathrm{m}$, with incrusting pigment 


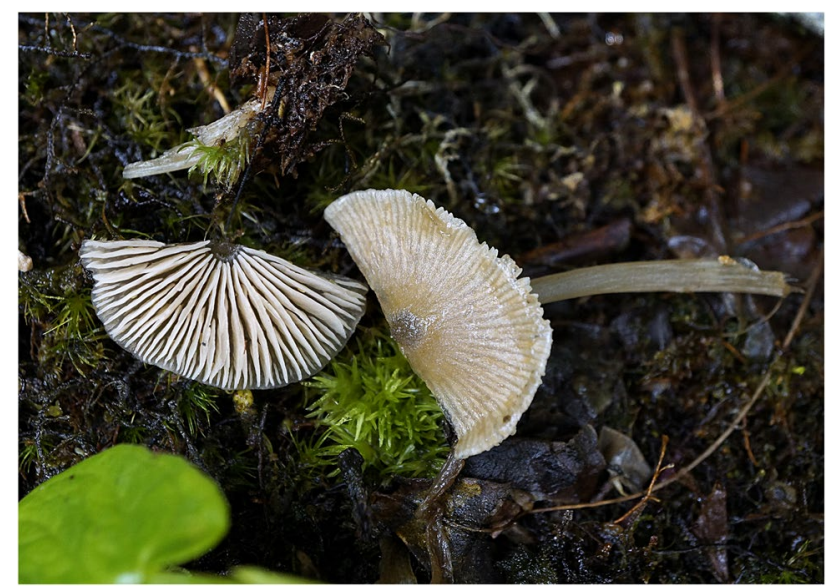

Fig. 13 Basidiocarp of Entoloma belouvense var. albertinae (KaiR630)

at some hyphae. Caulocystidia clavate to subcylindrical, $35-65 \times 6.5-10.0 \mu \mathrm{m}$. Oleiferous hyphae present in the trama. Clamp connections abundant in all parts of the basidiocarp.

Habitat: Basidiocarps solitary or gregarious, in Quercusdominated montane forests between 1650 and $1900 \mathrm{~m}$ asl. in Chiriquí, Panama. Probably ectomycorrhizal with Quercus spp.

Additional specimens examined: PANAMA. CHIRIQUÍ: near Volcán, Paso Ancho, PNVB, N 0848'55" W82 $34^{\prime} 46.8^{\prime \prime}, 1,900 \mathrm{~m}$ asl., montane forest with abundant Quercus spp. and Comarostaphylis arbutoides, 28 September 2014, S. Cáceres, K. Barrera, T.A. Hofmann, R. Villarreal, PA167 (M); near Bajo Boquete, Jaramillo Arriba, El Musgo, N 08 47'26.9” W 82²4'34.4', 1,670 m asl., montane forest dominated by Quercus spp., 24 June 2018, T.A. Hofmann, CME12 (M); Bajo Boquete, Finca Lérida, forest trail, N 08 $49^{\prime} 10.3^{\prime \prime}$ W 82 $29^{\prime} 09.2^{\prime \prime}, 1820$ m asl., montane forest with Quercus seemannii and other Quercus spp., 28 June 2018, C. Manz and F. Hampe, CME14 (M).

Notes: Basidiocarps of E. pruinosum are characterised by a tricholomatoid habit, a brown surface of the pileus with a distinct pruina and relatively small basidiospores. This combination of characters is rather unique. No other known species in subg. Entoloma has such a strongly developed pruina on the pileus. The small, isodiametrical spores are more or less like those found in the /prunuloides clade, and the European E. prunuloides may have a slight, but not so strong pruina on the pileus. Entoloma prunuloides, however, like some other similar species, is phylogenetically very distant from subg. Entoloma (Morgado et al. 2013). Entoloma pruinosum belongs to a clade of species known from Central and North America. In the ITS phylogeny (Fig. 5), it is close to E. brunneocinereum Hesler, with a $p$-distance of $2.7 \%$ in the ITS1. This species has, however, somewhat smaller
Fig. 14 Basidiospores of Entoloma belouvense var. albertinae (KaiR630), bar $=10 \mu \mathrm{m}$
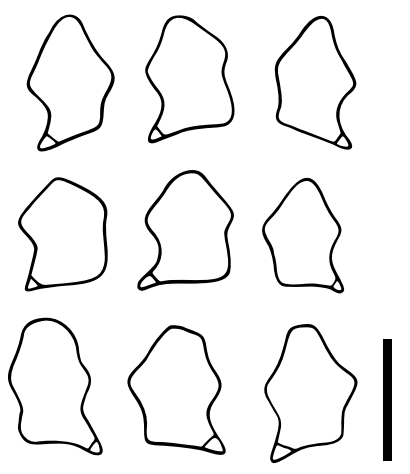

basidiospores $(7.0-8.0 \times 6.0-7.0 \mu \mathrm{m})$ and intracellular pigment (Noordeloos 1988). Based on type studies, Kokkonen (2015) demonstrated that E. lividomurinum Hesler is conspecific with E. brunneocinereum. Entoloma griseopruinatum Cheype \& Noordel., a European species with a pruinose pileus, has larger basidiospores $(9.0-11.0 \times 7.0-8.0 \mu \mathrm{m})$, more greyish colours in stipe and pileus, intracellular pigment in the pileipellis, and is phylogenetically distant (Fig. 5).

\section{Subgenus Nolanea (Fr.) Noordel (Fig. 12)}

Traditionally, species of the subg. Nolanea are characterised by basidiocarps with a mycenoid habit, a rather smooth pileus surface, and relatively long cells in the hymenophoral trama (Noordeloos 1980). A preliminary study on this subgenus in Europe was published by Vila et al. (2013). Karstedt et al. (2020) described five new species from Brazil, using Nolanea at generic rank. Their molecular phylogeny based on three loci supports Nolanea as a monophyletic clade. The results of a large, worldwide study on this subgenus are currently being prepared for publication (Reschke et al., in prep.).

Entoloma belouvense Noordel. \& Hauskn., Fungal Divers. 27: 112 (2007) var. belouvense.

Holotype WU27132: Several basidiocarps in good condition. Basidiospores heterodiametrical, 10.5-11 $.3-12.0 \times 6.5-7.1-7.5 \mu \mathrm{m}, Q=1.45-1.60-1.85(n=26)$. Basidia 4-spored, rather broadly clavate. Hymenophoral trama with abundant oily content. Stipe surface composed of long and narrow cells. Clamp connections absent.

Specimen examined: LA RÉUNION, Saint-Benoît, Forêt de Belouve, on decaying, mossy wood of broadleaf tree in tropical highland rainforest, 28 March 2005, A. Hausknecht, holotype (WU 27,132).

Notes: Entoloma belouvense is a member of the clade around E. conferendum (Britzelm.) Noordel. In contrast to the original description (Noordeloos and Hausknecht 2007), no clamp connections were observed at the base of basidia. 
Fig. 15 Basidiocarps and basidiospores as seen by SEM of Entoloma cremeostriatum: a (KaiR508); b (CME10) bar $=2 \mathrm{~cm} ; \mathbf{c}, \mathbf{d}$ (KaiR613, holotype) $b a r=10 \mu \mathrm{m}$
Fig. 16 Microscopic structures of Entoloma cremeostriatum (KaiR613, holotype): a pileipellis with incrusting pigment indicated on the right hand side, bar $=20 \mu \mathrm{m} ; \mathbf{b}$ basidiospores, bar $=10 \mu \mathrm{m}$
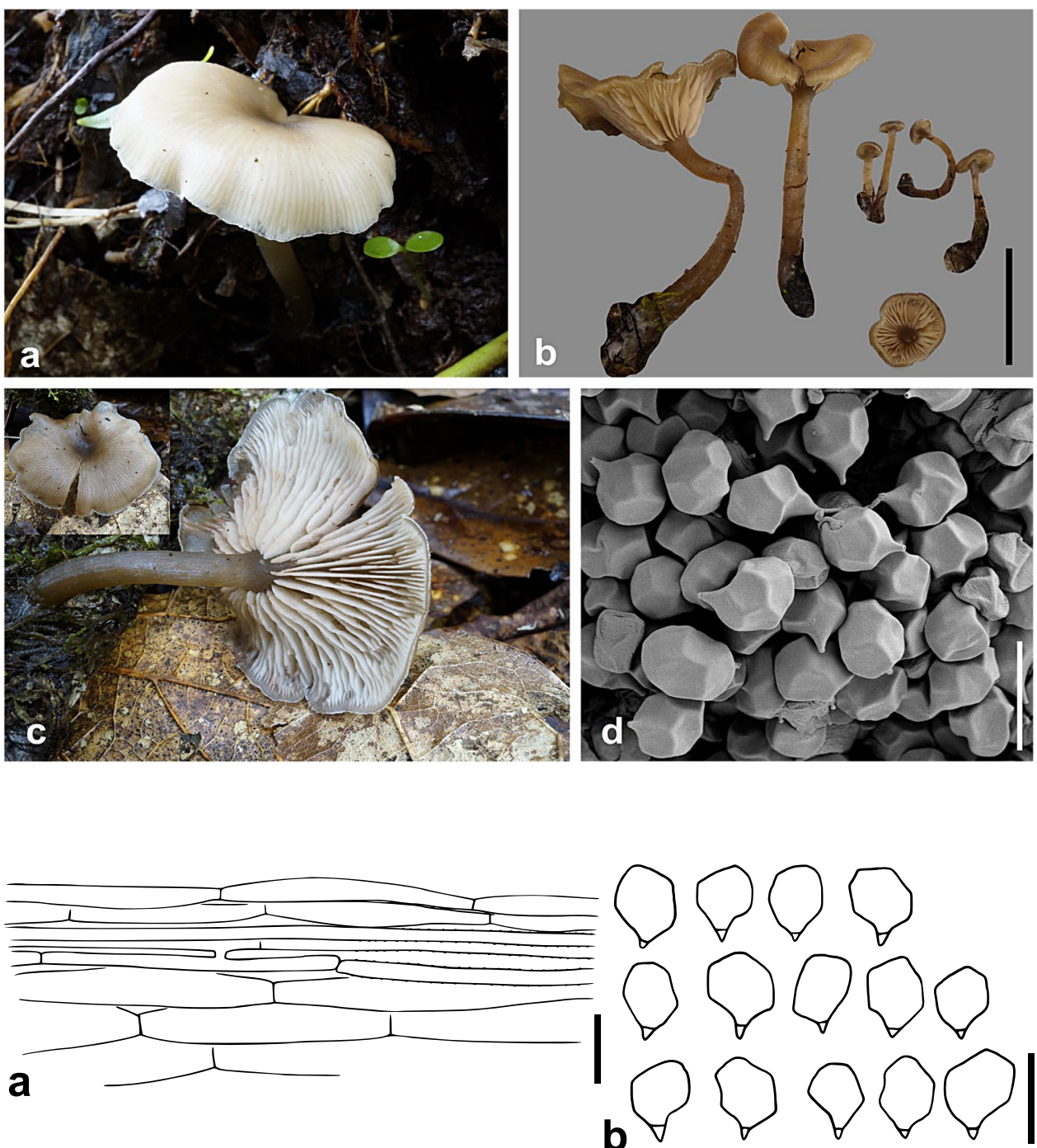

Entoloma belouvense Noordel. \& Hauskn. var. albertinae (Karstedt \& Capelari) Reschke \& Noordel. comb. \& stat. nov., Figs.13 and 14

Basionym: Nolanea albertinae Karstedt \& Capelari in Karstedt et al., Mycotaxon 135: 596 (2020).

Mycobank: MB840620.

Basidiocarps mycenoid. Pileus $1.5-2.0 \mathrm{~cm}$ diameter, broadly conical to expanded with pronounced papilla and straight to deflexed, somewhat uneven margin, greyish yellow-golden, brown to dark brown (4C6, 6E5, 6E6, 6F5, 6F6) with dark brown (6F6, 7F5) centre, pileal surface glabrous, somewhat innately fibrillose, translucently striate almost to the centre, hygrophanous and then with sericeous appearance. Lamellae adnexed to free, ventricose, mediumspaced to rather distant, greyish white when young, becoming brownish pink, with smooth and concolorous edges. Stipe
$2.0-3.5 \times 0.20-0.25 \mathrm{~cm}$, cylindrical, getting slightly broader towards base, hollow, greyish yellow, greyish yellow-golden to yellowish brown (4C5, 4C6, 5D5), polished to somewhat innately fibrillose towards base, with silvery white fibrils when contorted. Basal mycelium white, with many short and fine rhizomorphs. Odour indistinct, taste not tested.

Basidiospores $9.0-9.9-11.0 \times 6.0-7.1-7.5 \mu \mathrm{m}$, $Q=1.25-1.40-1.60(n=53$ spores of 2 specimens $)$, heterodiametrical, with 5-6 pronounced angles in outline, weakly pigmented yellowish pink, somewhat thickwalled. Basidia $26-34 \times 9.5-11.0 \mu \mathrm{m}$, subclavate, hyaline, 4 -spored, sterigmata up to $5.0 \mu \mathrm{m}$ long. Lamellar edge heterogeneous, cheilocystidia scattered, solitary or in small groups between basidia, rather infrequent, approximately $25-50 \times 5.0-8.5 \mu \mathrm{m}$, septate tibiiform to cylindrical capitate. Pileipellis a cutis of relatively long and narrow, 4.0 to 8.0 
$\mu \mathrm{m}$ wide elements, pigment intracellular, brownish in $\mathrm{KOH}$. Clamp connections absent from all parts of the basidiocarp.

Habitat: Basidiocarps found solitary or scattered in a small group in montane forests between 1600 and $2100 \mathrm{~m}$ asl. in Chiriquí, Panama.

Specimens examined: PANAMA. CHIRIQUÍ: near Bajo Boquete, PNVB, Sendero Culebra, N 08 $50^{\prime} 42.6^{\prime \prime} \mathrm{W}$ $82^{\circ} 28^{\prime} 52.5^{\prime \prime}, 1,670 \mathrm{~m}$ asl., montane forest dominated by Quercus spp., 22 June 2017, K. Reschke, J. Rodríguez, B. Wergen, KaiR630 (UCH11745, M); near Cerro Punta, Los Quetzales Lodge, N 08 52'30.4" W 82³3'14.0", 2030 m asl., montane tropical forest, 18 June 2018, C. Manz and F. Hampe, CME5 (M).

Notes: Nolanea albertinae was described from Brazil by Karstedt et al. (2020). Before, it had been treated as E. belouvense by Karstedt et al. (2019). In the phylogeny (Fig. 14), the ITS sequence of the holotype of E. belouvense var. belouvense is nested among the sequences of specimens of $E$. belouvense var. albertinae. However, the differences in spore size, resulting in higher $Q$-values in E. belouvense var. belouvense, are confirmed here. Apart from this, no differing characters were observed. Nolanea albertinae is treated here as a variety of $E$. belouvense because only one specimen of the type variety is available and ITS sequences may not be suitable to resolve such close relationships. More specimens from the type region, La Réunion, are needed to evaluate if this treatment is justified. Similar to the type variety, no clamp connections were observed in the specimens from Panama.

Entoloma cremeostriatum Reschke, Manz \& Noordel., sp. nov., Figs. 15 and 16

Mycobank number: MB840936.

Typification: PANAMA. CHIRIQUÍ: near Cerro Punta, Entre Ríos, Montaña Azul, PILA, approx. 2300 m asl., montane forest dominated by Quercus spp., 21 June 2017, J. Rodríguez, KaiR613, holotype (M).

Etymology: crème $($ French $)=$ cream (here: colour), striatus $($ Latin $)=$ striate; refers to the morphology of the pileus.

Description: Basidiocarps collybioid to omphalinoid. Pileus 2.5-3.9 cm diameter, convex umbilicate, margin deflexed to straight, slightly exceeding the lamellae, uniformly yellowish brown (5E7) in immature basidiocarps, soon paler, light yellow (4A4), greyish yellow (4B4), greyish orange $(5 \mathrm{~B} 3,5 \mathrm{~B} 4)$ to brownish orange $(5 \mathrm{C} 6)$, often darker, greyish yellow (4B6) to yellowish brown (5F7) in the centre, whitish at the very margin, pileal surface glabrous, with a waxy appearance when wet, innately fibrillose at the centre, with some fine, protruding fibrils all over, translucently striate almost to the centre, hygrophanous reaction not observed. Lamellae emarginate, segmentiform, medium-spaced to rather distant, greyish to cream when young, becoming pinkish, with slightly undulating and concolorous edges. Stipe $3.0-3.5 \times 0.30-0.35 \mathrm{~cm}$, cylindrical, hollow, similarly coloured as the pileus, greyish yellow (3B4, 4B5, 4C5), brownish orange $(5 \mathrm{C} 5,5 \mathrm{C} 6)$ to yellowish brown (5D6), innately fibrillose, partly overlaid by whitish fibrils, but not silvery fibrillose, slightly whitish fibrilloseflocculose at the tip. Basal mycelium white, with some short and fine rhizomorphs. Odour slightly nitrous or somewhat sweetish, taste not tested.

Basidiospores $6.5-7.6-8.5 \times 5.5-6.2-6.5 \mu \mathrm{m}$, $Q=1.10-1.23-1.40$ ( $n=83$ spores of 3 specimens), hendecahedroid, composed of an adaxial facet (D), a pair of apicoadaxial facets (AD), an apical facet (A), an abaxial facet (B), and three pairs of lateral facets (L1-L3), of which the basal pair (L3) forms a dièdre basal, subisodiametrical to broadly heterodiametrical, with 5-6 pronounced angles in outline, weakly pigmented yellowish pink, thick-walled. Basidia 21-29 $\times 8.5-10.0 \mu \mathrm{m}$, clavate, hyaline, 4-spored, sterigmata up to $4.0 \mu \mathrm{m}$ long, with clamp connections. Lamellar edge fertile, hymenial cystidia absent. Hymenophoral trama regular, formed by wide, somewhat fusiform cells in the mediostratum, and narrower, cylindrical cells towards the subhymenium, $100-360 \times 3.5-25 \mu \mathrm{m}$, with slightly incrusting pigment at some hyphae. Pileipellis a cutis of narrow, cylindrical cells, $60-200 \times 3.0-6.5(10.0) \mu \mathrm{m}$, pigment finely incrusting, without a subpellis, gradually passing into pileitrama, composed of wider cells. Stipitipellis a cutis formed by long, cylindrical cells, 55-220×3.0-8.0 $\mu \mathrm{m}$, with finely incrusting pigment. Caulocystidia absent. Oleiferous hyphae present in the trama. Clamp connections abundant in the hymenium, rarely present elsewhere.

Habitat: Basidiocarps solitarily to gregarious on soil, between mosses and litter, in Alnus acuminata-dominated montane forest and Quercus-dominated montane forest between 2300 and $2400 \mathrm{~m}$ asl. in Chiriquí, Panama.

Additional specimens examined: PANAMA. CHIRIQUÍ: Cerro Punta, Las Nubes, PILA Sendero Cas-

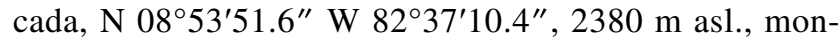
tane forest dominated by Alnus acuminata, 11 June 2017, K. Reschke and J. Rodríguez, KaiR508 (M); ibid., N

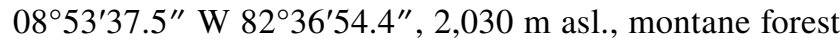
dominated by Alnus acuminata, 22 June 2018, C. Manz and T.A. Hofmann, CME10 (M).

Notes: Entoloma cremeostriatum is characterised by a convex-umbilicate, pale, striate pileus, small, heterodiametrical basidiospores, and clamp connections at the base of basidia. With a $p$-distance of $5.5 \%$ between the ITS sequences, it is relatively close to E. readiae G. Stev., described from New Zealand (Stevenson 1962). This species has basidiocarps which are like those of E. cremeostriatum in shape. Moreover, the two species share finely incrusting pigments in the hyphae of the pileipellis and clamp connections at the base of the basidia. The basidiospores of $E$. 
Fig. 17 Basidiocarps and basidiospores as seen by SEM of Entoloma flavoconicum: a (KaiR609); b (PA891); c, d (KaiR628, holotype), bar $=10 \mu \mathrm{m}$
Fig. 18 Microscopic structures of Entoloma flavoconicum (KaiR628, holotype): a pileipellis with incrusting pigment indicated on the right hand side, bar $=20 \mu \mathrm{m}$; $\mathbf{b}$ basidiospores, bar $=10 \mu \mathrm{m}$
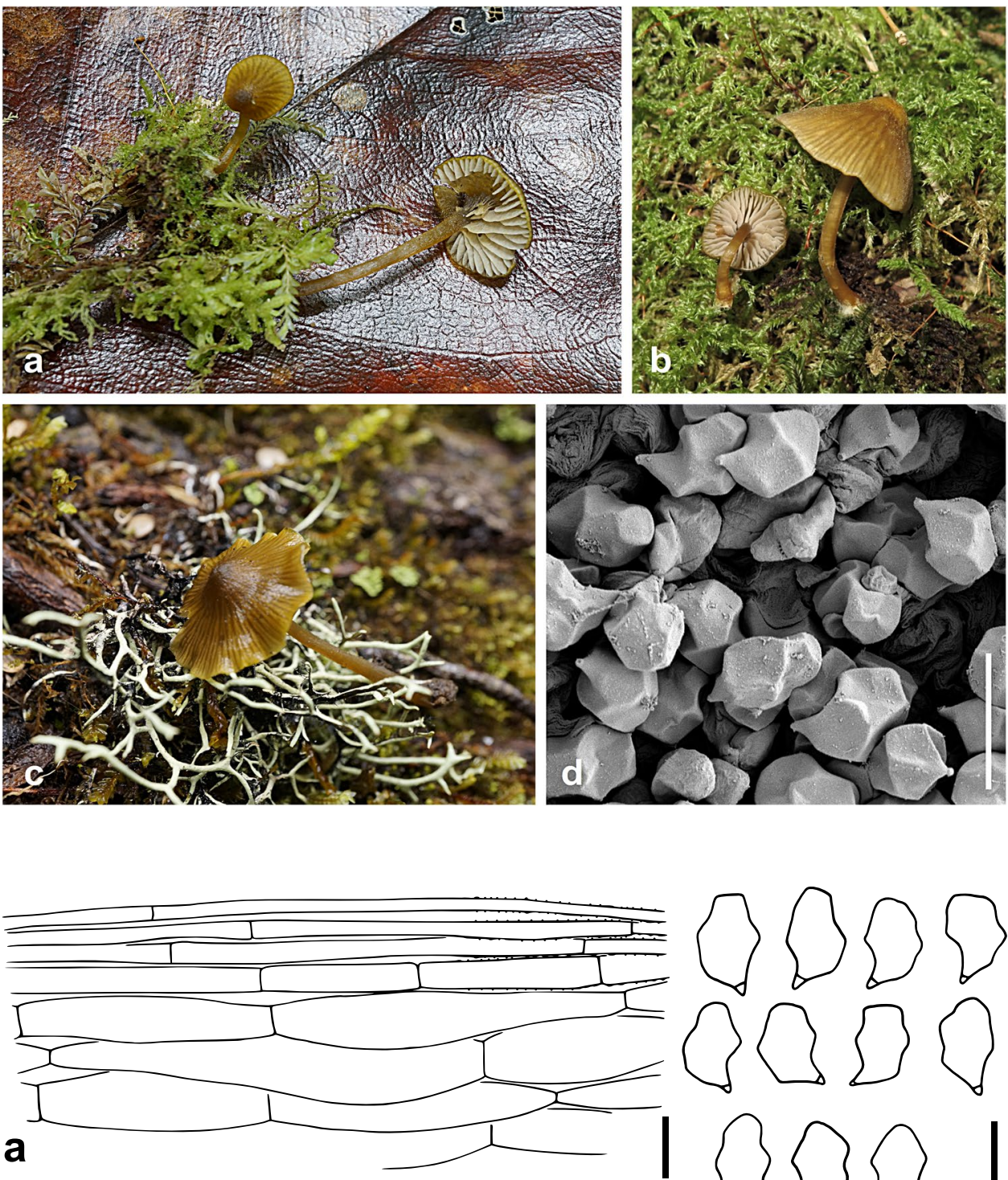

a
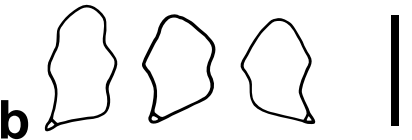

readiae are larger than those of $E$. cremeostriatum according to the original description $(9-10 \times 7-8 \mu \mathrm{m})$. Our measurements of two authentic specimens (Table 1) of E. readiae, however, resulted in somewhat smaller basidiospore sizes, 7.5-8.4-9.0 ×6.5-7.4-8.0 $\mu \mathrm{m}, Q=1.00-1.14-1.25(n=46$ of 2 specimens). However, these are still somewhat larger and have smaller $Q$-values than those of E. cremeostriatum. In addition, basidiocarps of $E$. readiae are brown and have a strongly farinaceous odour, while those of $E$. cremeostriatum are generally paler and have a slightly nitrous odour. Two sequences annotated as E. pulchellum (Hongo) Hongo are relatively close to those of E. cremeostriatum with $p$-distances of $5.2 \%$ between the ITS sequences. Entoloma pulchellum is described as having a convex-umbilicate, yellow to flesh-coloured pileus with brown tones, often a minutely squamulose pileus surface, especially in the centre, a striate pileus margin, heterodiametrical basidiospores of $10.0-12.5 \times 7.0-9.0 \mu \mathrm{m}$, clavate to capitate cheilocystidia of 25-37×13.0-14.5 $\mu \mathrm{m}$, and no clamp connections at the base of basidia (Hongo 1957). These characters, especially the squamulose pileus surface together with the absence of clamp connections and presence of distinct cheilocystidia, indicate a species of subg. Cyanula, probably close to $E$. formosum (Fr.) Noordel. Thus, the specimens corresponding to the ITS sequences (KR673495, KC257436) annotated as E. pulchellum in GenBank apparently are misidentified.

Entoloma flavoconicum Reschke \& Noordel., sp. nov., Figs. 17 and 18

Mycobank number: MB840631. 
Fig. 19 Basidiocarps and basidiospores as seen by SEM of Entoloma paraconferendum (CME6, holotpye), bar $=10 \mu \mathrm{m}$
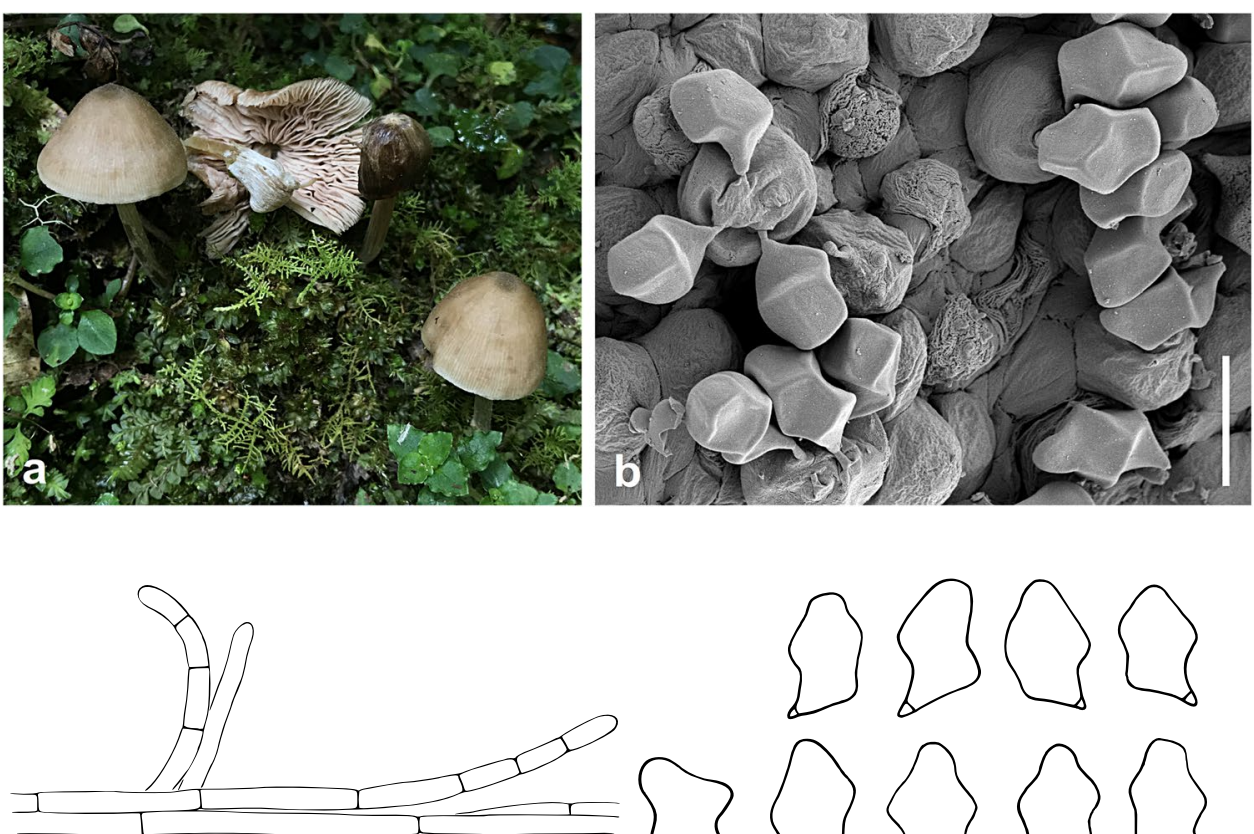

Fig. 20 Microscopic structures of Entoloma paraconferendum (CME6, holotype): a pileipellis with subpellis composed of inflated cells, intracellular pigment not indicated, $b a r=20 \mu \mathrm{m}$; b basidiospores, bar $=10 \mu \mathrm{m}$
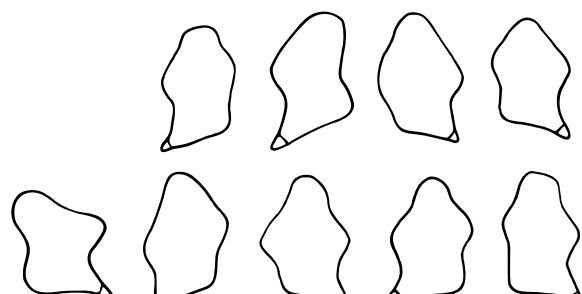
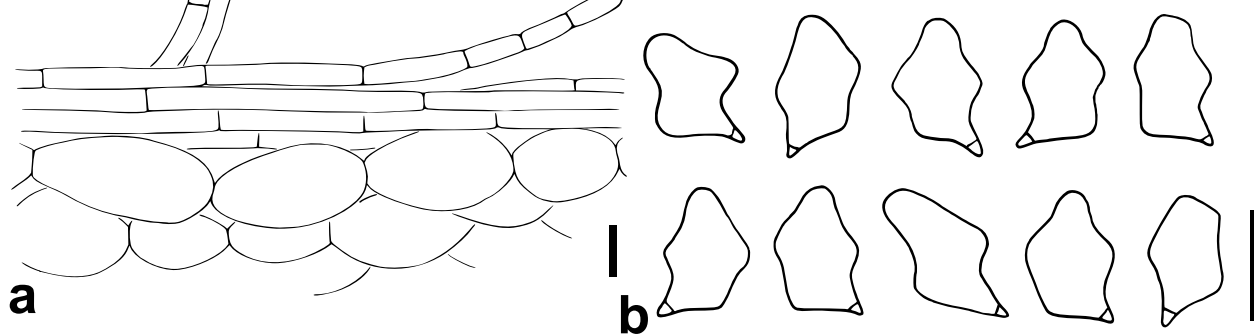

Typification: PANAMA. CHIRIQUÍ: near Cerro Punta, Entre Ríos, Montaña Azul, PILA, N 08 $53^{\prime} 41^{\prime \prime}$ W $82^{\circ} 35^{\prime} 01.5^{\prime \prime}, 2,340 \mathrm{~m}$ asl., montane forest dominated by Quercus spp., 21 June 2017, K. Reschke, KaiR628, holotype (UCH9226), isotype (M).

Etymology: flavus $($ Latin $)=$ yellow, konikos (Greek) $=$ conical; refers to the colour and shape of the pileus.

Description: Basidiocarps mycenoid. Pileus $0.7-2.2 \mathrm{~cm}$ diameter, conical when young, remaining conical or becoming convex with a pronounced, acute umbo, either dark brown (6F7) to yellowish brown (5F6) or light yellow (4A5) to orange yellow (4A6) in the centre, towards the margin at first light brown (6D6, 6D7) to yellowish brown (5D7, 5D8, $5 \mathrm{E} 8)$, then greyish yellow (4B6, 4C6, 4C7) to orange yellow (4B7) and eventually yellow (3A7) at the very margin, pileal surface glabrous, but overlaid by an ephemeral, fine, white pruina in young basidiocarps, translucently striate from the margin almost to the centre, hygrophanous reaction not observed. Pileal margin initially slightly incurved, later straight, slightly overlapping the lamellae. Lamellae emarginate to adnexed, ventricose, distant, relatively thick and broad, initially greyish, sometimes with yellow tinges, later greyish pink, with somewhat transvenose sides and smooth, concolorous edges. Stipe $1.0-3.5 \times 0.14-0.25 \mathrm{~cm}$, cylindrical to slightly clavate, hollow, brownish yellow
(5C7, 5C8) sometimes darker, yellowish brown (5D7, 5D8) towards base, glabrous to innately fibrillose, finely whitish pruinose all over, especially towards the apex of the stipe. Basal mycelium white, often cottony. Odour indistinct, taste not tested.

Basidiospores $8.5-9.4-10.5 \times 6.0-6.4-7.0 \mu \mathrm{m}$, $Q=1.30-1.46-1.65$ ( $n=70$ spores of 3 specimens), hendecahedroid, composed of an adaxial facet (D), a pair of apicoadaxial facets (AD), an apical facet (A), an abaxial facet (B), and three pairs of lateral facets (L1-L3), of which the basal pair (L3) forms a dièdre basal, heterodiametrical, with 5-6, predominantly 6 , pronounced to nodulose angles in outline, weakly pigmented yellowish pink, somewhat thick-walled. Basidia $27-34 \times 11.0-13.0 \mu \mathrm{m}$, clavate, hyaline, predominantly 4 -spored, sterigmata up to $6.0 \mu \mathrm{m}$ long. Lamellar edge fertile, hymenial cystidia absent. Hymenophoral trama regular, formed by narrow, cylindrical and centrically broad fusiform cells, $125-520 \times 3.5-27 \mu \mathrm{m}$, some hyphae with incrusting pigment, yellowish in $\mathrm{KOH}$. Pileipellis a cutis formed by narrow, cylindrical cells, 40-260 $\times 3.5-9.5 \mu \mathrm{m}$, with incrusting and in addition scattered intracellular pigment, cells wider, somewhat inflated, towards pileitrama. Stipitipellis a cutis composed of cylindrical cells, $85-400 \times 3.0-7.5 \mu \mathrm{m}$, with some incrusting pigment. Caulocystidia absent. Oleiferous hyphae present in the trama. Clamp connections absent from all parts of the basidiocarp. 
Fig. 21 Basidiocarp and basidiospores as seen by SEM of Entoloma transitionisporum (KaiR503, holotype): a stipe b pileus from above; $\mathbf{c}$ basidiospores, including reduced forms, bar $=10 \mu \mathrm{m}$
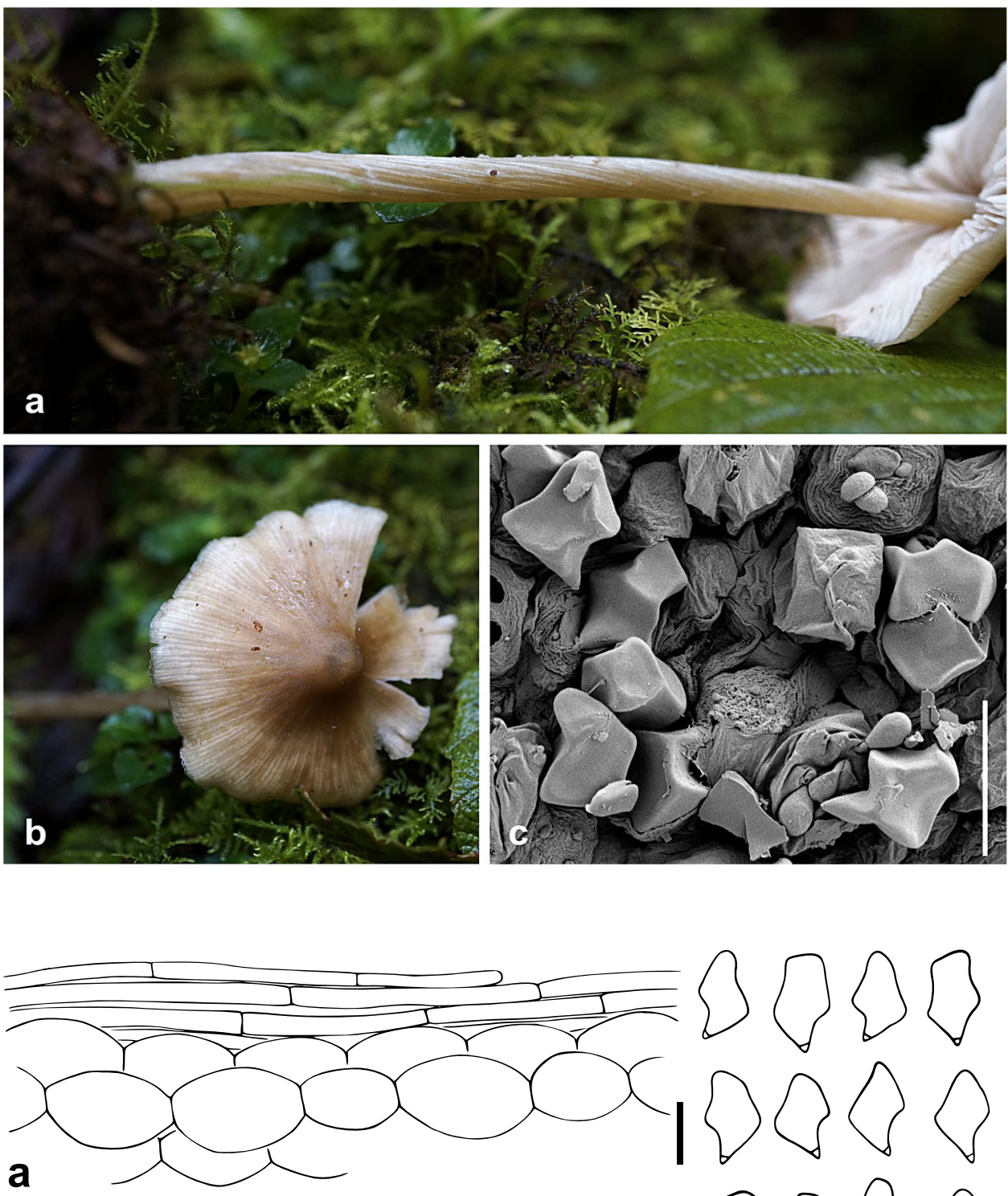
ment not indicated, bar $=20 \mu \mathrm{m}$; lis with inflated cells, intracellular pigb basidiospores, bar $=10 \mu \mathrm{m}$

Fig. 22 Microscopic structures of Entoloma transitionisporum (CME6, holotype): a pileipel-
Habitat: Basidiocarps scattered in a group, in Quercusdominated montane forests from 2000 to $2340 \mathrm{~m}$ asl. in Chiriquí, Panama.

Additional specimens examined: PANAMA. CHIRIQUí: near Cerro Punta, Entre Ríos, Montaña Azul, PILA, N 08 53'35.1" W 82³4'53.2", $2260 \mathrm{~m}$ asl., montane forest dominated by Quercus spp., 21 June 2017, K. Reschke, T.A. Hofmann, J. Rodríguez, KaiR609 (M); near Volcán, Paso Ancho, PNVB, N 0848'55.1", W 82³4'42.6", $2000 \mathrm{~m}$ asl., montane forest with abundant Quercus spp. and
Comarostaphylis arbutoides, 26 October 2016, J. Rodríguez, T.A. Hofmann, K. Barrera, PA891 (M).

Notes: Entoloma flavoconicum is characterised by mycenoid, strongly yellowish basidiocarps, conical to acutely umbonate pilei, heterodiametrical basidiospores, incrusting pigment on the cells of the pileipellis, and absence of clamp connections. It forms a clade together with E. olivaceohebes Noordel. \& Hauskn. and E. vernum S. Lundell (Fig. 14). However, these two species have basidiocarps with rather dark brown colours. In addition 
Fig. 23 Maximum likelihood phylogram of species of subg. Alboleptonia based on ITS, rooted to E. serrulatum, bootstrap values above branches, bar = estimated changes/nucleotide

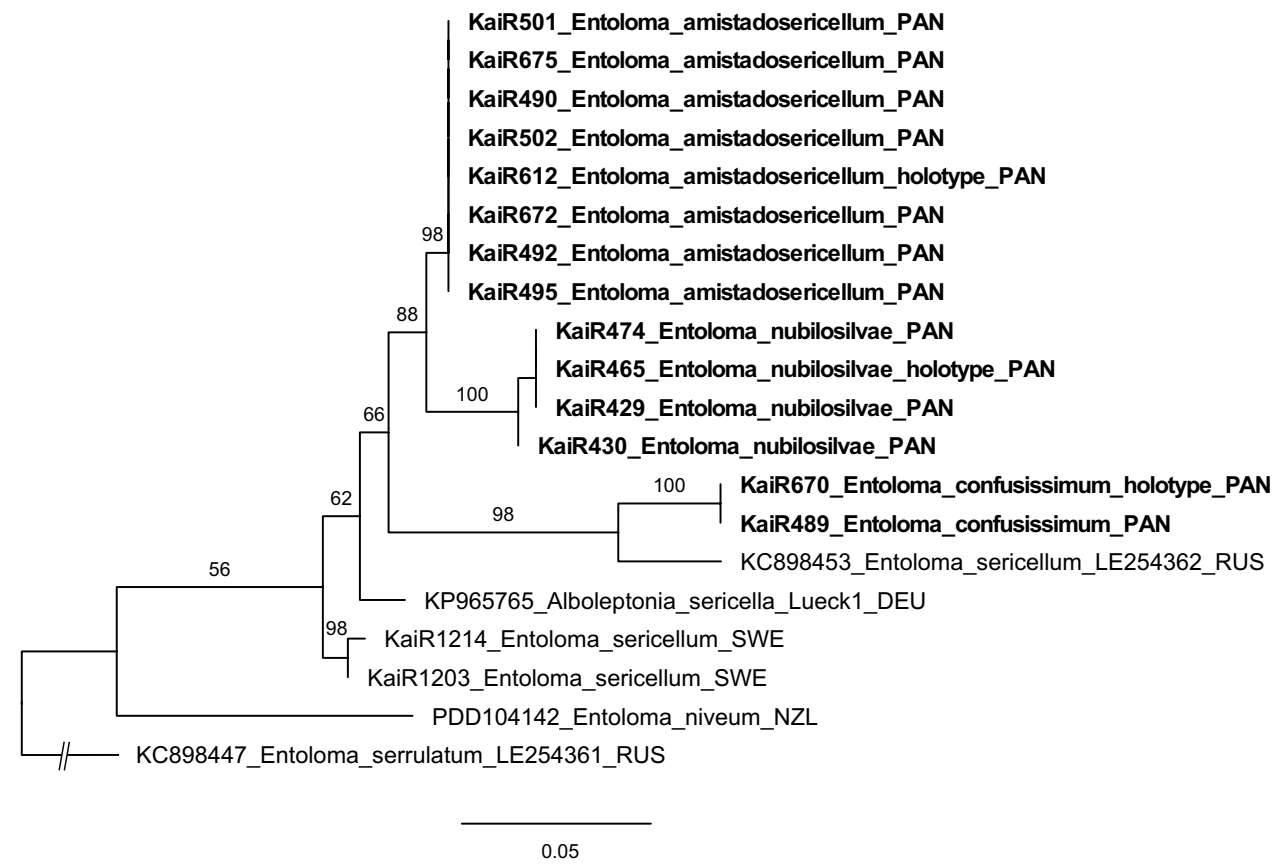

to this, they can be distinguished from E. flavoconicum by micromorphological characters, like the presence of clamp connections in the hymenium (Noordeloos 1992, 2004; Horak 2008). Entoloma subelegans Noordel. \& Hauskn., described from Mauritius (Noordeloos and Hausknecht 2016), is somewhat similar in colour and striation of the pileus. It differs, however, by depressed pilei, shape and size of the basidiospores, presence of cheilocystidia, and clamp connections in the hymenium. Phylogenetically, E. subelegans does not belong to $E$. subg. Nolanea (Fig. 14). Entoloma aromaticum E. Horak from Australia and New Zealand is another yellowish and clampless species, but the colour of the basidiocarps is somewhat more reddish yellow, and they have a strongly aromatic smell and taste (Horak 2008; Noordeloos and Gates 2012). No similar species is described in the monographs of Hesler (1967), Largent (1994), and Noordeloos (2004).

Entoloma paraconferendum Reschke, Manz, F. Hampe $\&$ Noordel., sp. nov., Figs. 19 and 20

Mycobank number: MB840628.

Typification: PANAMA. CHIRIQUÍ: near Cerro Punta, Entre Ríos, Montaña Azul, PILA, N 0853'39.7" W 82 $34^{\prime} 55.0^{\prime \prime}, 2340 \mathrm{~m}$ asl., montane forest dominated by Quercus spp., 19 June 2018, C. Manz and F. Hampe CME6, holotype (UCH11747), isotype (M).

Etymology: para $($ Latin $)=$ beside; refers to Entoloma conferendum, which is closely related and has morphologically similar basidiocarps.
Description: Basidiocarps mycenoid. Pileus $2.5-4.5 \mathrm{~cm}$ diameter, broadly conical to campanulate, slightly papillate, with straight, slightly uneven margin, greyish yellow (4B4, 4B5), with darker greyish yellow (4C5), delimited centre, whitish at the very margin, pileal surface glabrous, but finely scaly-pruinose if seen through a lens, translucently striate at about $1 / 3$ the radius, hygrophanous. Lamellae adnexed to almost free, ventricose, close, initially whitish, later pink, with rather even and concolorous edges. Stipe $4.5-7.0 \times 0.25-0.40 \mathrm{~cm}$, cylindrical, hollow, greyish yellow (4B4, 4B5), fibrillose, overlaid by whitish, silky fibrils. Basal mycelium white, somewhat cottony. Odour somewhat musty, taste not tested.

Basidiospores $8.5-10.5-12.0 \times 6.5-7.3-8.0 \mu \mathrm{m}$, $Q=1.25-1.44-1.70(n=54$ spores of 2 specimens $)$, heptahedroid, composed of an adaxial facet (D), a pair of apico-adaxial facets (AD), an apical facet (A), a pair of lateral facets (L), and a basal facet (Ba) forming a simple base, heterodiametrical, rarely irregularly cruciform, with 4-6, predominantly 5, pronounced, blunt angles in outline, weakly pigmented yellowish pink, somewhat thick-walled. Basidia 30-42 × 10.5-12.5 $\mu \mathrm{m}$, clavate to subclavate, hyaline, 4-spored, sterigmata up to $4.0 \mu \mathrm{m}$ long. Lamellar edge fertile, hymenial cystidia absent. Hymenophoral trama regular, formed by long, cylindrical to somewhat inflated cells, rather wide centrally, narrower towards hymenium, $80-550 \times 3.5-25 \mu \mathrm{m}$. Pileipellis a cutis composed of cylindrical cells, 45-145 $\times 5.0-12.0 \mu \mathrm{m}$, often disrupted by trichodermal sections formed by a few erect hyphal ends, composed 
of cells of the same size or of relatively short cells, $15.0-40 \times 6.5-12.0 \mu \mathrm{m}$, pigment intracellular, with a subpellis composed of inflated cells, $40-90 \times 20-50 \mu \mathrm{m}$. Stipitipellis a cutis composed of long, cylindrical cells, $60-400 \times 3.0-5.5 \mu \mathrm{m}$. Caulocystidia absent. Oleiferous hyphae frequently present in the trama. Clamp connections absent from all parts of the basidiocarp.

Habitat: Basidiocarps in small groups in Quercus-dominated montane forest at $2340 \mathrm{~m}$ asl. in Chiriquí, Panama.

Additional specimen examined: PANAMA. CHIRIQUÍ: near Cerro Punta, Entre Ríos, Montaña Azul, PILA, N 08 53'39.7" W 82 34'55.0", 2,340 m asl., montane forest dominated by Quercus spp., 19 June 2018, C. Manz and F. Hampe, CME7 (M).

Notes: Entoloma paraconferendum is characterised by mycenoid basidiocarps with a translucently striate pileus, a silky, fibrillose stipe, and heterodiametrical basidiospores. Its basidiocarps are macromorphologically like those of $E$. conferendum. These two species are also closely related based on ITS sequences ( $p$-distance $=1.8 \%$ ). However, they can easily be distinguished by the almost exclusively cruciform basidiospores of E. conferendum and predominantly heterodiametrical, only rarely subcruciform basidiospores of E. paraconferendum.

Entoloma transitionisporum Reschke, Manz \& Noordel., sp. nov., Figs. 21 and 22

Mycobank number: MB840626.

Typification: PANAMA. CHIRIQUÍ: Cerro Punta, Las Nubes, PILA, Sendero Cascada, N 08 $53^{\prime} 48.0^{\prime \prime}$ W $82^{\circ} 37^{\prime} 05.7^{\prime \prime}, 2320 \mathrm{~m}$ asl., montane forest dominated by Alnus acuminata, 11 June 2017, K. Reschke and J. Rodríguez KaiR503, holotype (UCH11743), isotype (M).

Etymology: transitio (Latin) $=$ transition; refers to the transitional shape of the basidiospores, between heterodiametrical and cruciform.

Description: Basidiocarps mycenoid. Pileus $3.5-4.0 \mathrm{~cm}$ diameter, broadly conical to convex umbilicate, margin slightly incurved and uneven, brown to light brown (5E7, $5 \mathrm{D} 6,5 \mathrm{D} 7)$ at centre, paler, brownish orange to greyish orange (5C4, 5C5 to 5B3), towards margin, pileal surface glabrous, translucently striate up to $2 / 3$ of the centre, hygrophanous. Lamellae adnexed, almost free, medium-spaced to rather close, white to slightly greyish in immature basidiocarps, pink upon maturity, with slightly undulating and concolorous edges and transvenose sides. Stipe $7.0 \times 0.4-0.5 \mathrm{~cm}$, cylindrical to slightly broadening towards base, hollow, brownish orange (5C5, 5C6), overlaid by silvery whitish fibrils, innately fibrillose, sometimes contorted. Basal mycelium not recorded. Odour indistinct, taste not tested.

Basidiospores $7.5-9.2-10.5 \times 6.0-6.6-7.5 \mu \mathrm{m}$, $Q=1.15-1.40-1.65$ ( $n=65$ spores of 2 specimens), predominantly heptahedroid, composed of an adaxial facet (D), a pair of apico-adaxial facets (AD), an apical facet (A), a pair of lateral facets $(\mathrm{L})$, and a basal facet $(\mathrm{Ba})$ forming a simple base, reduced forms hexahedroid or more rarely pentahedroid (prismatic), with single AD-facet and/or reduced to absent A-facet, heterodiametrical to irregularly cruciform, with 4-5 pronounced angles in outline, weakly pigmented yellowish pink, somewhat thick-walled. Basidia
Fig. 24 Basidiocarps and basidiospores as seen by SEM of Entoloma amistadosericellum: a (KaiR612, holotype); b (KaiR502); c (KaiR672); d (KaiR612, holotype) $\mathrm{bar}=10 \mu \mathrm{m}$
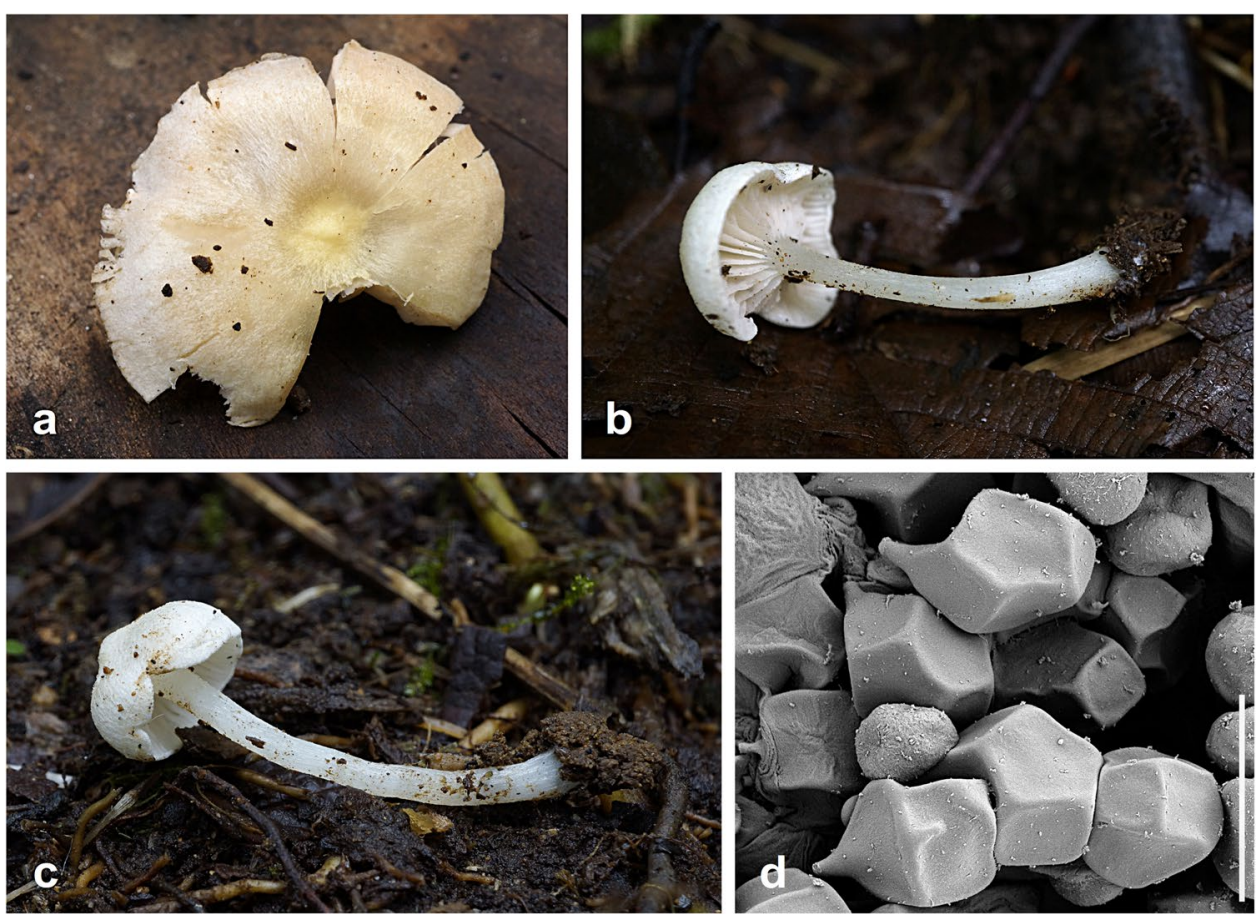
Fig. 25 Microscopic structures of Entoloma amistadosericellum (KaiR612, holotype): a pileipellis, bar $=20 \mu \mathrm{m}$; b basidiospores, $\mathrm{bar}=10 \mu \mathrm{m} ; \mathbf{c}$ cheilocystidia, bar $=20 \mu \mathrm{m}$

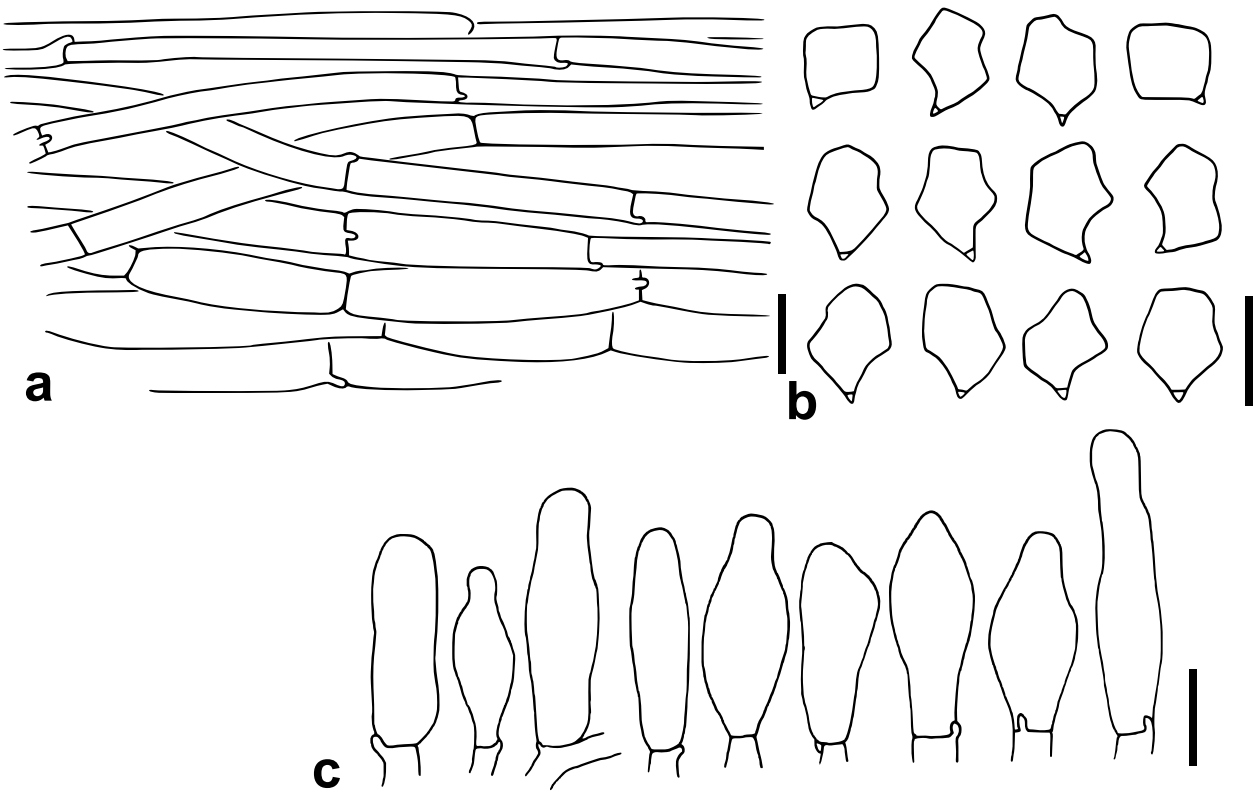

34-41×11.0-13.0 $\mu \mathrm{m}$, subclavate, hyaline, 4-spored, sterigmata up to $5.0 \mu \mathrm{m}$ long. Lamellar edge fertile, hymenial cystidia absent. Hymenophoral trama regular, formed by long, cylindrical to somewhat inflated cells, centrally $140-430 \times 6.5-20 \mu \mathrm{m}$, narrower, $170-450 \times 2.5-7.0 \mu \mathrm{m}$, towards hymenium. Pileipellis a cutis of relatively narrow cells, 70-110 ×3.0-9.0 $\mu \mathrm{m}$, with yellowish to brownish, intracellular pigment and a distinct subpellis of inflated cells, 40-65 $\times 28-40 \mu \mathrm{m}$. Stipitipellis a cutis composed of long, cylindrical cells, $290-950 \times 4.0-14.0 \mu \mathrm{m}$, with some intracellular, pale yellowish brown pigment, difficult to locate. Caulocystidia absent. Oleiferous hyphae present, abundant in hymenophoral trama. Clamp connections absent from all parts of the basidiocarp.

Habitat: Basidiocarps found solitary among mosses in Alnus acuminata-dominated montane forests between 2000 and $2400 \mathrm{~m}$ asl. in Chiriquí, Panama.

Additional specimen examined: PANAMA. CHIRIQUI: Cerro Punta, Las Nubes, PILA, Sendero Cascada, N $08^{\circ} 53^{\prime} 37.5^{\prime \prime \prime} \mathrm{W} 82^{\circ} 36^{\prime} 54.4^{\prime \prime}, 2,030 \mathrm{~m}$ asl., montane forest dominated by Alnus acuminata, 22 June 2018, C. Manz and T.A. Hofmann, CME9 (M).

Notes: Entoloma transitionisporum belongs to the clade of $E$. conferendum and its allies. It is characterised by a conical to convex umbilicate, brown, translucently striate pileus, a silvery fibrillose stipe, absence of clamps, and the shape of the basidiospores, which can be interpreted as a transitional state between heterodiametrical and cruciform. Entoloma belouvense is closely related based on ITS sequence data (Fig. 14). Its basidiocarps are on average smaller and paler than those of E. transitionisporum and their pilei have a contrasting darker centre, which was not observed in pilei of the latter species. In addition, the basidiospores of $E$. belouvense are somewhat longer and without transitional states to a cruciform shape. Basidiocarps of E. conferen$d u m$ can have a similar habit, but $E$. conferendum is easily distinguished from E. transitionisporum by exclusively cruciform basidiospores. Entoloma luteifuscum K.N.A. Raj $\&$ Manim., described from India, differs by yellowish tones of the basidiocarps and slightly larger basidiospores, which are exclusively heterodiametrical (Raj et al. 2014). Entoloma dissimile (Singer) Horak, described from Nothofagus-forest in Argentinia, may be similar to E. transitionisporum. However, the pilei of $E$. dissimile are darker, basidiospores are slightly broader, and pigment is incrusting in the pileipellis (Horak 1978). No similar species were found in Largent (1994), Horak (1982), and Hesler (1967).

\section{Subgenus Alboleptonia (Largent \& R.G. Benedict) Noordel}

The subgenus Alboleptonia in the traditional sense (Largent and Benedict 1970; Noordeloos 1987, 2004) is an assemblage of white or whitish species, often with a differentiated pileipellis. It appears to be polyphyletic, considering recent phylogenies (He et al. 2015c; Largent et al. 2016). Here, we focus on the core group of Alboleptonia, i.e., species around the type species E. sericellum (Fr.) P. Kumm. This species is widespread in Europe and appears to be a complex of several species, both in and outside of Europe. Entoloma cuboidoalbum Noordel. \& Hauskn. was described from Austria (Noordeloos and Hausknecht 2009), but there are more species waiting to be described in this group, as evident by the results of the phylogenetic analysis (Fig. 23). In the present study, three new species from Panama are 
Fig. 26 Basidiocarps and basidiospores as seen by SEM of Entoloma confusissimum: a (KaiR489); b, c, d (KaiR670, holotype) bars $=10 \mu \mathrm{m}$
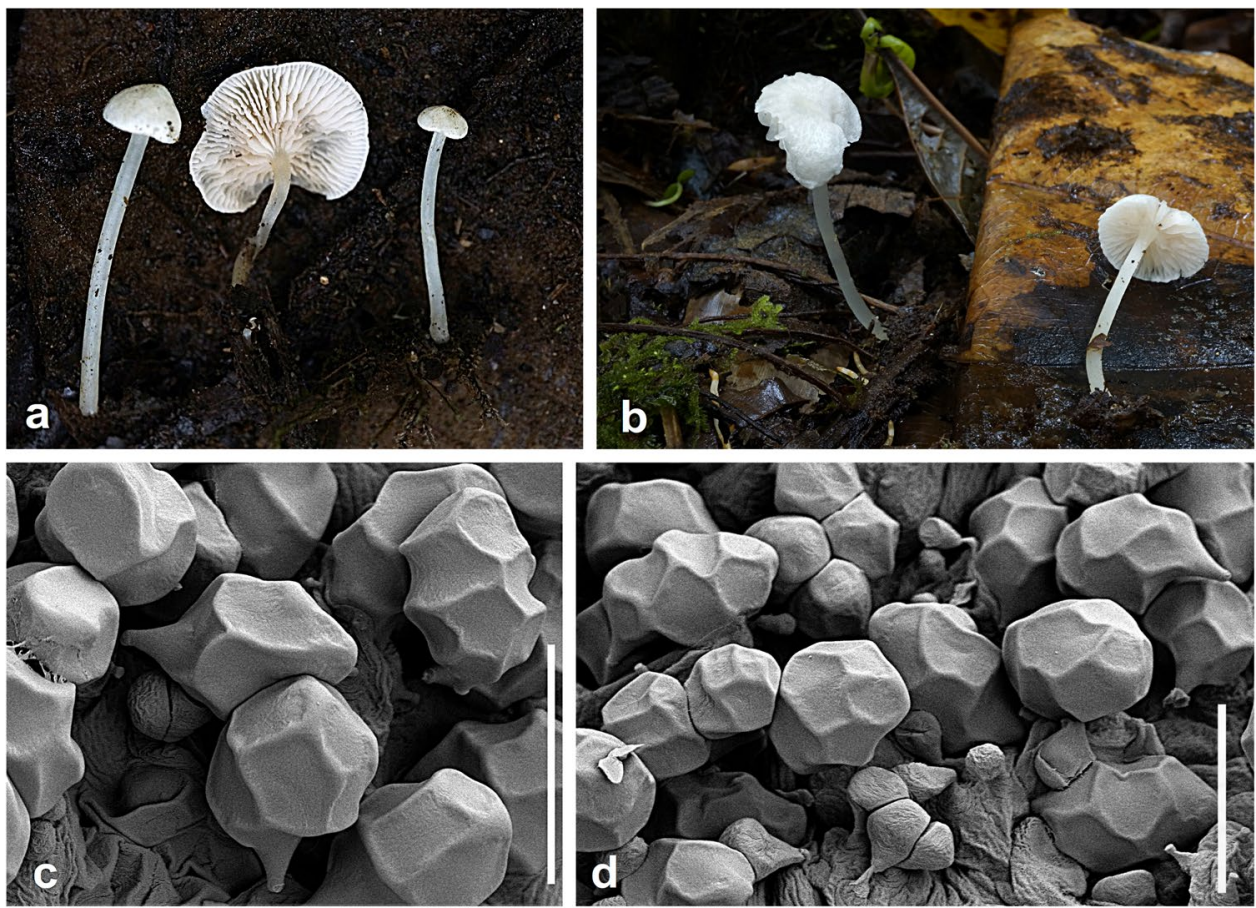

described in the clade of $E$. sericellum that can be well differentiated by their basidiospore characters.

Entoloma amistadosericellum Reschke \& Noordel., sp. nov., Figs. 24 and 25

Mycobank number: MB840937.

Typification: PANAMA. CHIRIQUÍ: near Cerro Punta, Entre Ríos, Montaña Azul, PILA, around 2300 m asl., montane forest dominated by Quercus spp., 21 June 2017, J. Rodríguez, KaiR612, holotype (M).

Etymology: named after its similarity to Entoloma sericellum and its occurrence in the Parque Internacional La Amistad, honouring the principle of friendship in nature conservation.

Description: Basidiocarps collybioid. Pileus $1.0-5.5 \mathrm{~cm}$ diameter, convex and often with an obtuse umbo when
Fig. 27 Microscopic structures of Entoloma confusissimum (KaiR670, holotype): a stipitipellis with caulocystidia, bar $=20 \mu \mathrm{m} ; \mathbf{b}$ pileipellis bar $=20 \mu \mathrm{m}$; $\mathbf{c}$ basidiospores, bar $=10 \mu \mathrm{m} ; \mathbf{d}$ cheilocystidia, bar $=20 \mu \mathrm{m}$

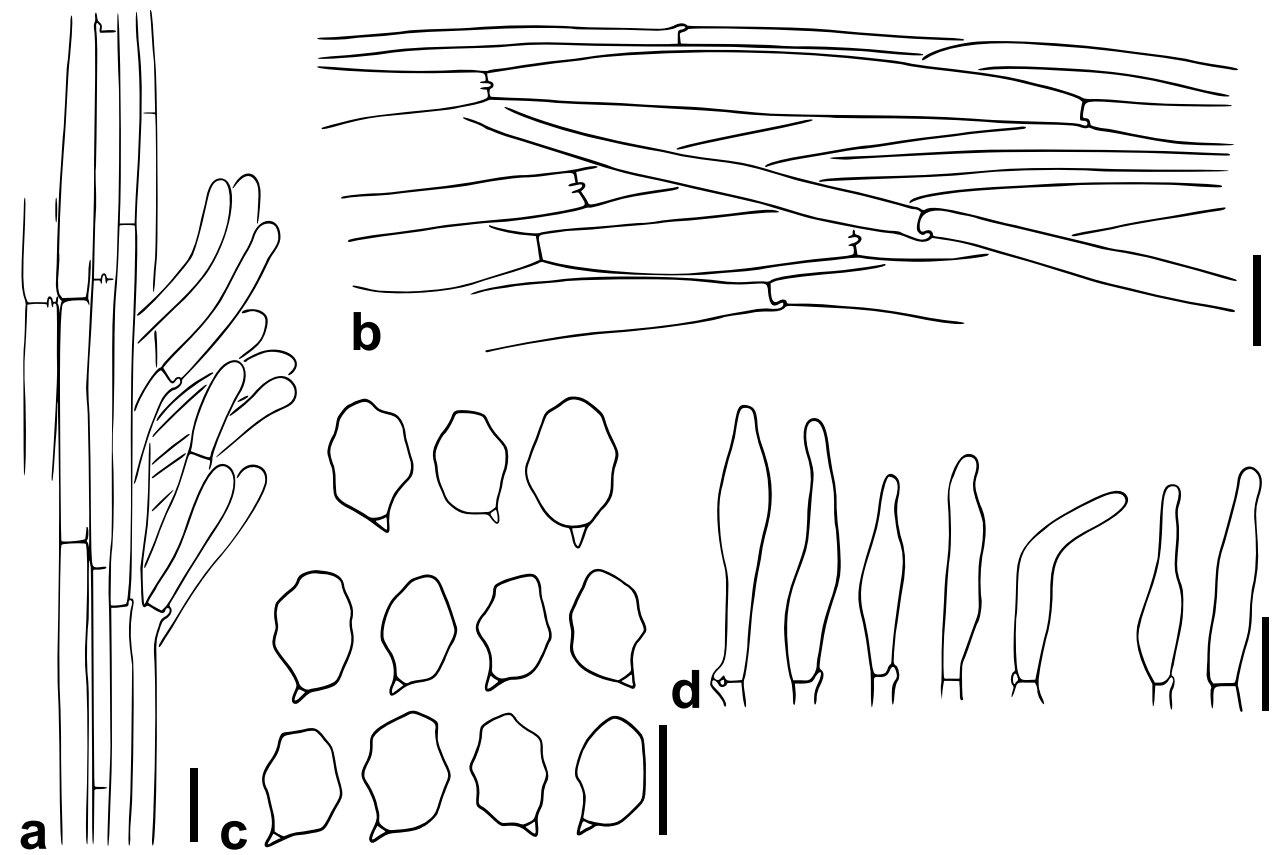


young, becoming depressed, often remaining a small papilla, margin initially incurved, later straight, white in young and fresh basidiocarps, older basidiocarps with yellowish to pale brownish patches, pileal surface radially fibrillose, not translucently striate. Lamellae sinuate, adnate to decurrent, medium-spaced to rather distant, initially white, later pink, with smooth to slightly uneven, concolorous edges. Stipe $1.0-4.7 \times 0.20-0.60 \mathrm{~cm}$, cylindrical to slightly clavate towards base, rather fragile and hollow, translucently whitish, inconspicuously fibrillose and slightly pruinose all over. Basal mycelium white. Odour not distinctive, taste not tested.

Basidiospores $8.5-9.4-10.5 \times 6.5-7.6-8.5 \mu \mathrm{m}$, $Q=1.10-1.25-1.40$ ( $n=111$ spores of 5 specimens), enneahedroid, composed of an adaxial facet (D), a pair of apico-adaxial facets (AD), an apical facet (A), an abaxial facet (B), and two pairs of lateral facets (L1-L2), of which the basal pair (L2) forms a dièdre basal, reduced forms octa- or heptahedroid, often with single AD-facet and/ or reduced to absent A-facet, mainly broadly heterodiametrical, some subisodiametrical, rhomboid, cruciform or almost quadratic, with 4-6, predominantly 5, pronounced angles in outline, weakly pigmented yellowish pink, somewhat thick-walled. Basidia 36-55×10.0-12.5 $\mu \mathrm{m}$, clavate, hyaline, 4-spored, sterigmata up to $5.5 \mu \mathrm{m}$ long. Lamellar edge almost sterile, cheilocystidia cylindrical, clavate to broadly lageniform, sometimes capitate, $37-73 \times 10-19 \mu \mathrm{m}$. Hymenophoral trama composed of rather broadly cylindrical cells, $30-175 \times 5-22 \mu \mathrm{m}$. Pileipellis a cutis formed by cylindrical cells, $70-175 \times 3.5-11.5 \mu \mathrm{m}$, pigment absent; subpellis absent, gradually passing into pileitrama, composed of somewhat wider cells. Stipitipellis a cutis composed of cylindrical cells, 50-200×4.0-8.5 $\mu \mathrm{m}$. Caulocystidia absent. Oleiferous hyphae present in the trama but rather infrequent. Clamp connections abundant in all parts of the basidiocarp.

Habitat: Basidiocarps solitary to scattered, in Alnus acuminata-dominated montane forest and Quercus-dominated montane forest at around $2300 \mathrm{~m}$ asl. in Chiriquí, Panama.

Additional specimens examined: PANAMA. CHIRIQUÍ: Cerro Punta, Las Nubes, PILA, Sendero Cascada, N 08 $53^{\prime} 46.0^{\prime \prime} \mathrm{W} 82^{\circ} 37^{\prime} 01$." $^{\prime \prime} 2270 \mathrm{~m}$ asl., montane forest dominated by Alnus acuminata, 11 June 2017, K. Reschke and J. Rodríguez, KaiR490 (UCH11736, M); ibid., N 08 ${ }^{\circ} 53^{\prime} 46.8^{\prime \prime} \mathrm{W} 82^{\circ} 37^{\prime} 01.4^{\prime \prime}, 2280 \mathrm{~m}$ asl., montane forest dominated by Alnus acuminata, 11 June 2017, K. Reschke and J. Rodríguez, KaiR492 (UCH11737, M); ibid., N 08 $53^{\prime} 46.8^{\prime \prime} \mathrm{W} 82^{\circ} 37^{\prime} 01.4^{\prime \prime}, 2280 \mathrm{~m}$ asl., montane forest dominated by Alnus acuminata, 11 June 2017, K. Reschke and J. Rodríguez, KaiR495 (UCH11738, M); ibid., $\mathrm{N} 08^{\circ} 53^{\prime} 48.0^{\prime \prime} \mathrm{W} 82^{\circ} 37^{\prime} 05.7^{\prime \prime}, 2320 \mathrm{~m}$ asl., montane forest dominated by Alnus acuminata, 11 June 2017, K. Reschke and J. Rodríguez, KaiR501 (M); ibid., N 08 53'48.0" W $82^{\circ} 37^{\prime} 05.7^{\prime \prime}, 2320 \mathrm{~m}$ asl., montane forest dominated by Alnus acuminata, 11 June 2017, K. Reschke and J. Rodríguez, KaiR502 (M); ibid., N 08 53'46.2" W 82³7'01.4”, $2280 \mathrm{~m}$ asl., montane forest dominated by Alnus acuminata, 27 June 2017, K. Reschke, KaiR672 (M).

Notes: Entoloma amistadosericellum is characterised by whitish basidiocarps with convex to depressed pilei, a radially fibrillose pileal surface, abundant clamp connections, relatively broad cheilocystidia, and the presence of rhomboid to cruciform basidiospores. It is closely related to E. nubilosilvae, described below. Most species of subg. Alboleptonia s.l. are macromorphologically similar, however, they differ in micromorphological characters. Entoloma cylindrocapitatum (T.J. Baroni \& Ovrebo) Noordel. $\&$ Co-David, also described from Panama, has rather small basidiospores as well as long, narrow, and capitate cheilocystidia (Ovrebo and Baroni 2007). Entoloma cuboidoalbum has larger basidiospores $(9.0-11.5 \times 7.5-10.5 \mu \mathrm{m})$ and lower $Q$-values (1.0-1.3) (Noordeloos and Hausknecht 2009) than E. amistadosericellum $(8.5-10.5 \times 6.5-8.5 \mu \mathrm{m}$, $Q=1.10-1.40)$. Entoloma crocotillum Xiao L. He has large, exclusively heterodiametrical basidiospores ( $\mathrm{He}$ et al. 2015c). Entoloma davidii Noordel. \& Co-David (syn. Alboleptonia largentii T.J. Baroni \& Lodge), E. laccarioides T.H. Li et al. and E. subroseum (T.J. Baroni \& Lodge) Noordel. \& Co-David have cuboid basidiospores (Baroni and Lodge 1998; He et al. 2015a). Entoloma sericellum s. auct. has a temperate and boreal distribution, and heterodiametrical, 5-8 angled basidiospores. Entoloma shwethum Manim et al. has rather large basidiocarps (pileus 3-5 cm diameter), sterile lamellar edges, and large basidiospores (9-12 $\times 6-9 \mu \mathrm{m})$ (Manimohan et al. 1995). Entoloma subochraceum Blanco-Dios (syn. Alboleptonia ochracea Largent \& R.G. Benedict) has basidiospores with an average length of $10.5 \mu \mathrm{m}$ and only scattered clamp connections (Largent and Benedict 1970). Basidiocarps of Entoloma theekshnagandhum Manim. et al. can be differentiated from those of E. amistadosericellum by their odour of fermented rice soup and cuboid to isodiametrical basidiospores (Manimohan and Leelavathy 1988; Manimohan et al. 1995).

Entoloma confusissimum Reschke \& Noordel., sp. nov., Figs. 26 and 27

Mycobank number: MB840938.

Typification: PANAMA. CHIRIQUÍ: Cerro Punta, Las Nubes, PILA, Sendero Cascada, N 08 ${ }^{\circ} 3^{\prime} 46.2^{\prime \prime}$ W $82^{\circ} 37^{\prime} 01.4^{\prime \prime}, 2280 \mathrm{~m}$ asl., montane forest dominated by Alnus acuminata, 27 June 2017, K. Reschke, KaiR670, holotype (M).

Etymology: confusus $($ Latin $)=$ confused; refers to the fact, that basidiocarps of this species can easily be 
Fig. 28 Basidiocarps and basidiospores as seen by SEM of Entoloma nubilosilvae: a (KaiR429); b (KaiR465, holotype) $b a r=1 \mathrm{~cm} ; \mathbf{c}, \mathbf{d}$ (KaiR465, holotype) bars $=10 \mu \mathrm{m}$
Fig. 29 Microscopic structures of Entoloma nubilosilvae (KaiR465, holotype): a pileipellis, $b a r=20 \mu \mathrm{m} ; \mathbf{b}$ cheilocystidia, bar $=20 \mu \mathrm{m}$; $\mathbf{c}$ basidiospores, bar $=10 \mu \mathrm{m}$
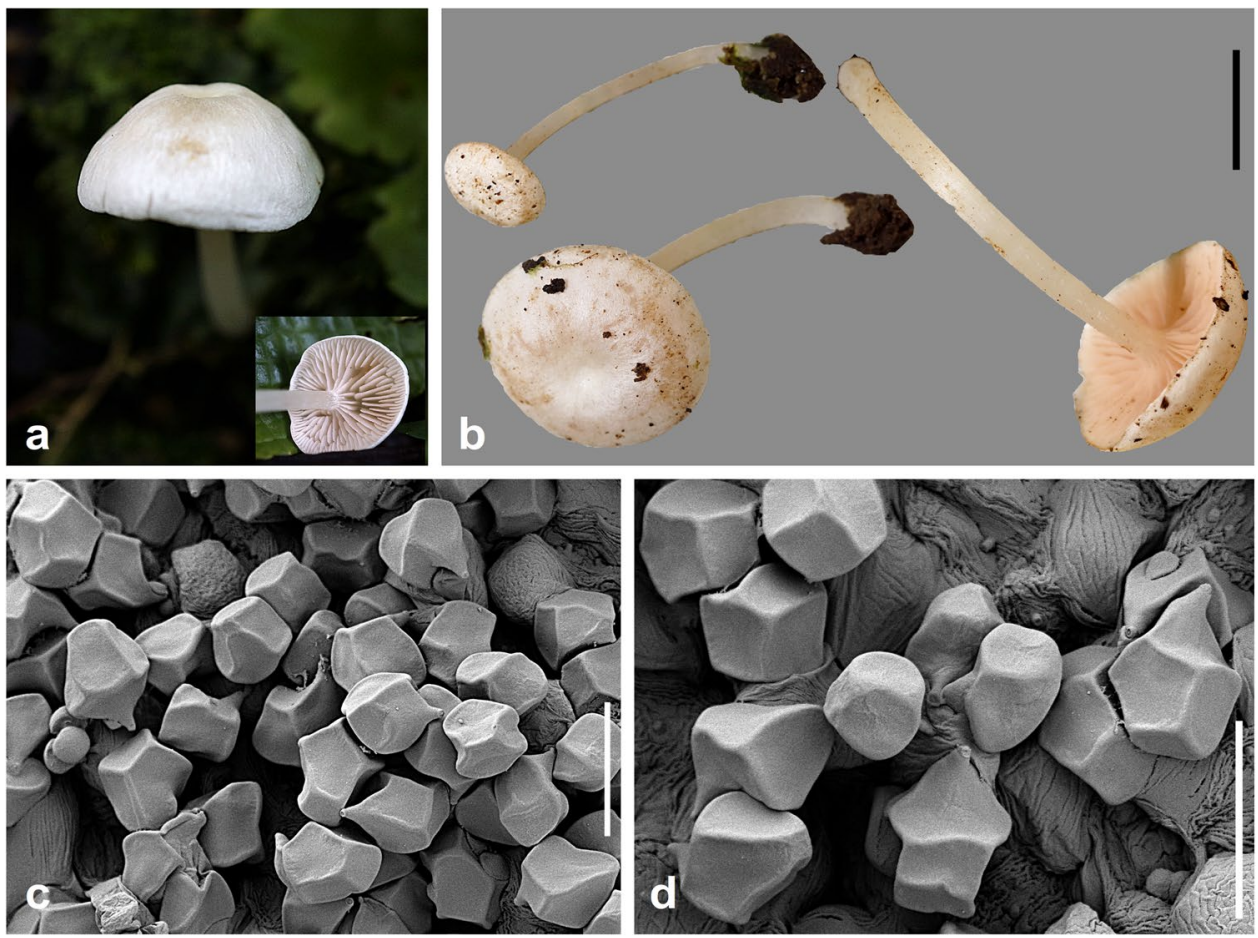

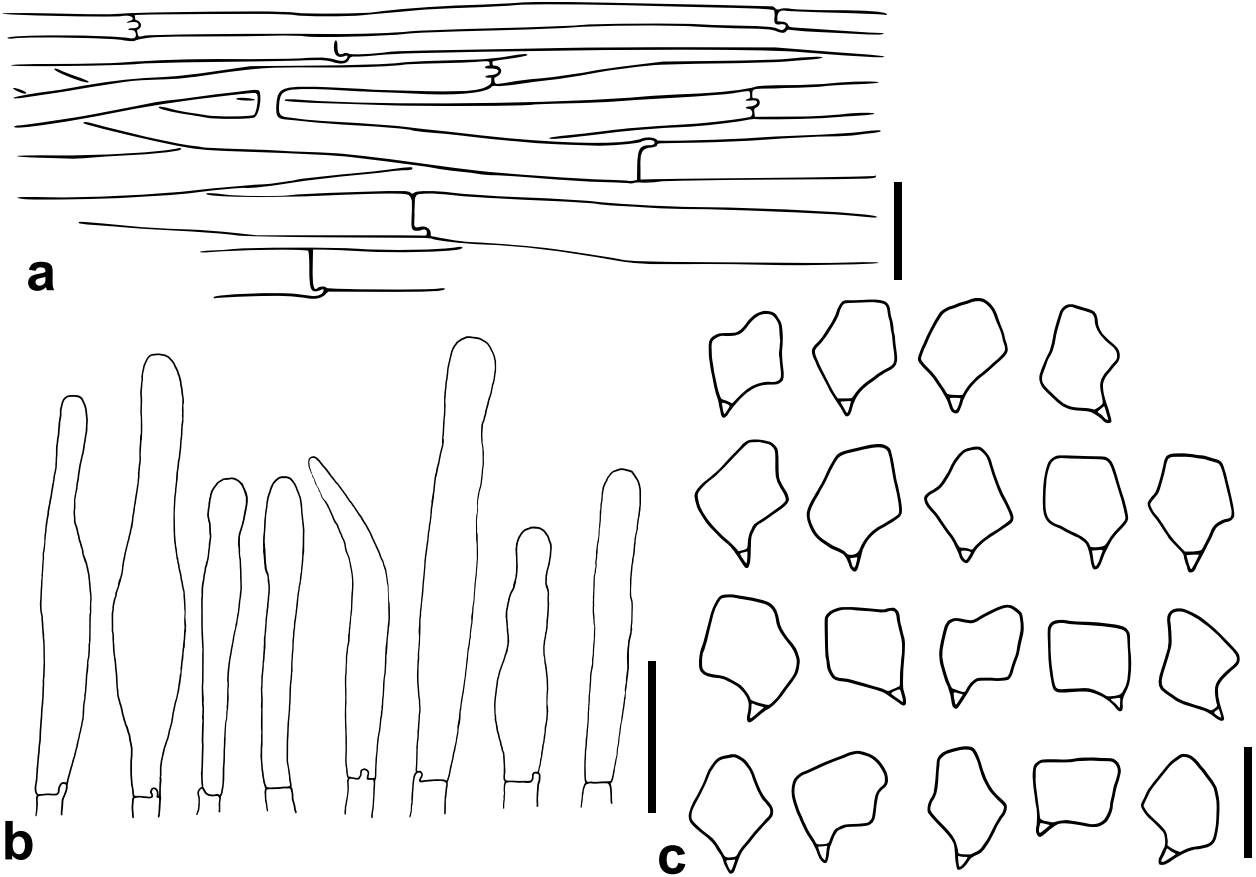

confused with those of several other species of $E$. subg. Alboleptonia.

Description: Basidiocarps mycenoid to collybioid. Pileus $0.5-5.0 \mathrm{~cm}$ diameter, broadly conical to convex, becoming depressed in old basidiocarps, margin initially somewhat incurved, later straight, white in young and fresh basidiocarps, older basidiocarps with slightly yellowish patches, pileal surface finely fibrillose squamulose, not translucently striate, not hygrophanous. Lamellae emarginate with decurrent tooth to decurrent, segmentiform, medium-spaced to distant, sometimes distinctly transvenose, initially white, later pink, with even to slightly undulating, concolorous edges. Stipe $2.0-5.0 \times 0.15-0.25 \mathrm{~cm}$, cylindrical, translucently whitish, polished to slightly fibrillose and pruinose, especially towards the apex, staining slightly yellowish after damage. Odour indistinct, taste not tested. 


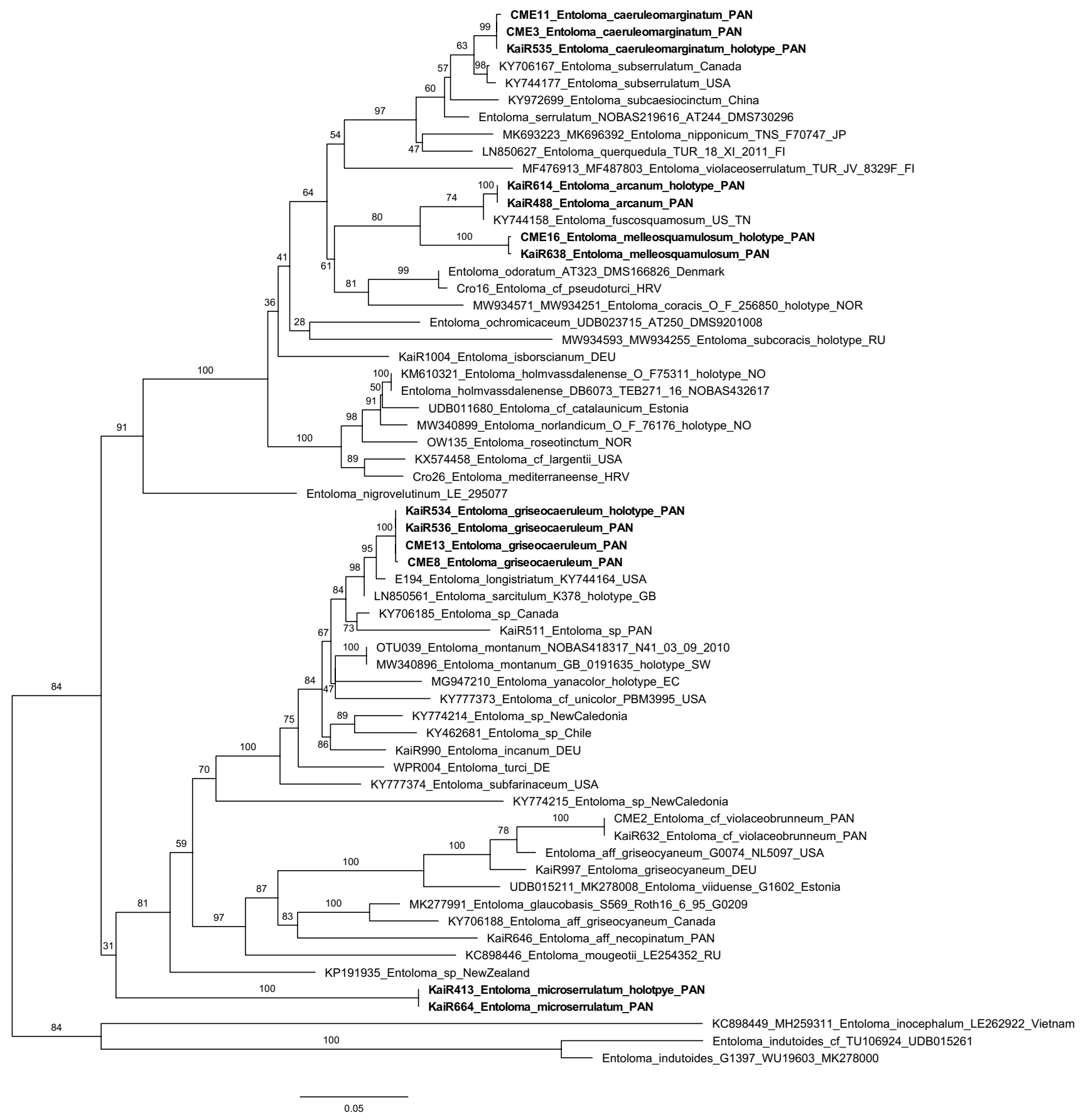

Fig. 30 Maximum likelihood phylogram of species of subg. Cyanula based on concatenated ITS and LSU sequences, rooted to E. inocephalum, $E$. indutoides, and $E$. cf. indutoides, bootstrap values above or below branches, bar=estimated changes/nucleotide

Basidiospores $9.0-10.3-12.0 \times 6.5-7.2-8.0 \mu \mathrm{m}$, $Q=1.35-1.44-1.60$ ( $n=44$ spores of 2 specimens $)$, tetradecahedroid, composed of an adaxial facet (D), a pair of apico-adaxial facets (AD), an apical facet (A), two abaxial facets (B1, B2), and four pairs of lateral facets (L1-L4), of which the basal pair (L4) forms a sometimes incomplete dièdre basal, heterodiametrical, with 6-9 nodulose angles in outline, weakly pigmented yellowish pink, somewhat thick-walled. Basidia $30-40 \times 10.0-13.0 \mu \mathrm{m}$, clavate to subclavate, hyaline, predominantly 4 -spored, with up to $4.0 \mu \mathrm{m}$ long sterigmata, few 2 -spored. Lamellar edge heterogeneous, at some parts almost sterile, cheilocystidia $35-60 \times 7.0-11.0 \mu \mathrm{m}$, subcylindrical to lageniform, often in clusters. Hymenophoral trama regular, mainly composed of rather short, broadly cylindrical to somewhat inflated cells, $70-200 \times 7-25 \mu \mathrm{m}$, longer and narrower cells towards 
the subhymenium, approximately 150-300 $\times 4.0-5.0 \mu \mathrm{m}$. Pileipellis a cutis formed by cylindrical to somewhat fusiform or locally inflated cells, $70-250 \times 3.0-16.0 \mu \mathrm{m}$, without pigment, subpellis not developed, pileipellis gradually passing into pileitrama, composed of similar to somewhat wider cells. Stipitipellis a cutis composed of cylindrical cells, $60-180 \times 4.5-8.0 \mu \mathrm{m}$. Caulocystidia present in dense bundles, cylindrical, often subcapitate, 30-65 (85) $\times(5.0)$ 6.5-10.0 (12.5) $\mu \mathrm{m}$. Oleiferous hyphae present in the trama. Clamp connections abundant in all parts of the basidiocarp.

Habitat: Basidiocarps scattered in small groups in Alnus acuminata-dominated montane forest between 2200 and $2300 \mathrm{~m}$ asl. in Chiriquí, Panama.

Additional specimen examined: PANAMA. CHIRIQUÍ: Cerro Punta, Las Nubes, PILA, Sendero Cascada, $\mathrm{N} 08^{\circ} 53^{\prime} 46.0^{\prime \prime} \mathrm{W} 82^{\circ} 37^{\prime} 01.5^{\prime \prime}, 2270 \mathrm{~m}$ asl., montane forest dominated by Alnus acuminata, 11 June 2017, K. Reschke and J. Rodríguez, KaiR489 (UCH11735, M).

Notes: Entoloma confussisimum is characterised by its E. sericellum-like habit and rather large and complex basidiospores with 6-9 angles in outline. Its ITS sequences have a $p$-distance of $5 \%$ to that of a specimen identified as E. sericellum from Caucasus, Russia (Fig. 23). Entoloma sericellum differs by smaller basidiospores with lower $Q$-values $(1.1-1.5)$ and $5-8$, predominantly 6 angles (Noordeloos 1992). Entoloma subsericellum Murrill, described from a coniferous forest of North America, has basidiospores of similar size, however, with only 5-6 angles (Murrill 1917; Largent and Benedict 1970). The absence of cheilocystidia, rare clamp connections, and a farinaceous odour indicates that E. subsericellum does not belong to the core clade of subg. Alboleptonia. Entoloma aripoanum Dennis, described from Trinidad, is similar in macromorphology and spore size, but differs by its very narrow lamellae, large, cylindrical cheilocystidia $(70-160 \times 10-16 \mu \mathrm{m})$, and occurrence on rotten wood (Dennis 1953).
Entoloma nubilosilvae Reschke \& Noordel., sp. nov., Figs. 28 and 29

Mycobank number: MB840623.

Typification: PANAMA. CHIRIQUÍ: near Boquete, PNVB, Sendero Culebra, N 08 51'12.5" W 82²9'01", 1,830 m asl., montane forest with abundant Quercus spp., 9 June 2017, K. Reschke, KaiR465, holotype (UCH11733), isotype (M).

Etymology: nubilus $($ Latin $)=$ cloudy, silva $($ Latin $)=$ forest; refers to the occurrence in cloud forest.

Description: Basidiocarps collybioid. Pileus $0.8-2.7 \mathrm{~cm}$ diameter, convex, becoming depressed in old basidiocarps, margin initially incurved, later straight, white in young and fresh basidiocarps, older basidiocarps with yellowish to pale brownish patches, pileal surface radially fibrillose, not translucently striate. Lamellae slightly to distinctly decurrent, rather distant, initially white, later pink, with slightly uneven and finely pruinose, concolorous edges. Stipe $1.8-3.5 \times 0.15-0.50 \mathrm{~cm}$, cylindrical, rather fragile and hollow, translucently whitish, inconspicuously fibrillose and slightly pruinose all over, staining yellowish after damage. Odour sometimes perfume-like, taste not tested.

Basidiospores $7.0-8.8-10.0 \times 6.0-7.1-8.0 \mu \mathrm{m}$, $Q=1.05-1.24-1.40$ ( $n=137$ spores of 4 specimens), octahedroid, composed of a adaxial facet (D), predominantly a single apico-adaxial facet (sAD), an apical facet (A), an abaxial facet (B), and two pairs of lateral facets (L1-L2), of which the basal pair (L2) forms a dièdre basal, subisodiametrical to broadly heterodiametrical, often rhomboid to almost quadratic or cruciform, with 4-5 pronounced angles in outline, weakly pigmented yellowish pink, somewhat thick-walled. Basidia 36-45 $\times 9.0-10.5 \mu \mathrm{m}$, clavate, hyaline, mainly 4-spored with up to $5.0 \mu \mathrm{m}$ long sterigmata, some 2 -spored. Lamellar edge heterogeneous, cheilocystidia $40-60 \times 5.0-13.0 \mu \mathrm{m}$, subcylindrical, lageniform to capitate, often in clusters, with variable abundance. Hymenophoral trama regular, composed of rather short, broadly cylindrical cells, $40-100 \times 5.0-18.0 \mu \mathrm{m}$. Pileipellis a cutis formed by
Fig. 31 Basidiocarps of Entoloma arcanum: a (KaiR488); b (KaiR614)
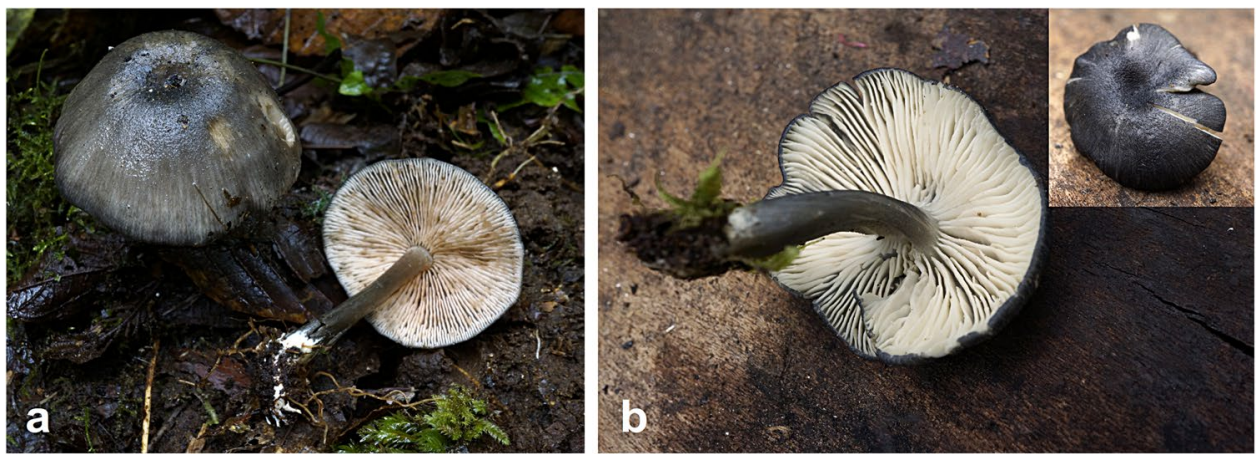
Fig. 32 Microscopic structures of Entoloma arcanum: a-c (KaiR488); a pileipellis, bar $=20 \mu \mathrm{m}$; b stipitipellis with caulocystidia, bar $=20 \mu \mathrm{m}$; c basidiospores, bar $=10 \mu \mathrm{m}$; d (KaiR614) cheilocystidia, bar $=20 \mu \mathrm{m}$

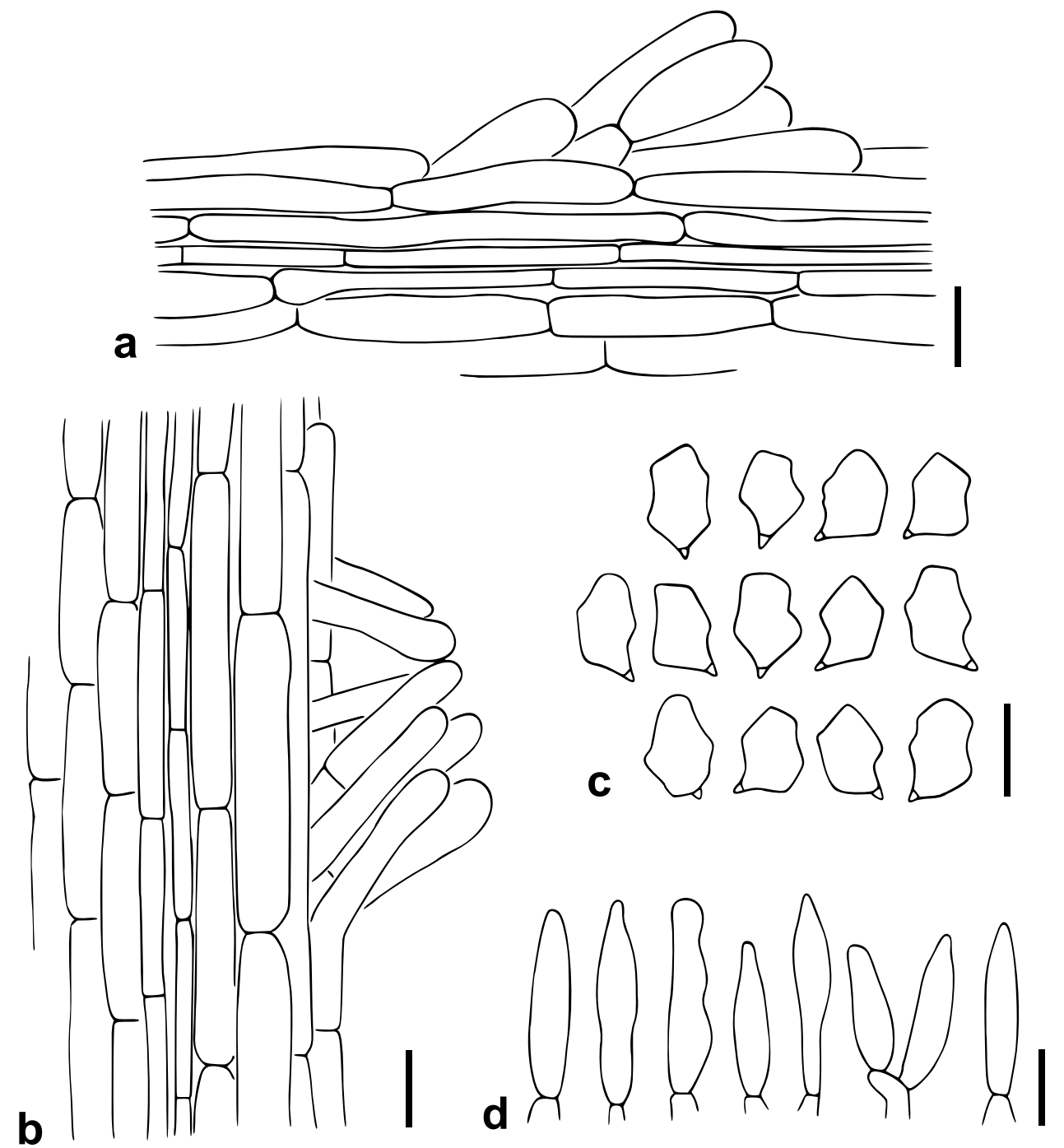

cylindrical to subcylindrical cells, $65-250 \times 4.5-12.0 \mu \mathrm{m}$, pigment absent, without subpellis, gradually passing into pileitrama, composed of somewhat wider cells. Stipitipellis a cutis composed of narrow cylindrical cells, $60-210 \times 3.0-6.0 \mu \mathrm{m}$. Caulocystidia absent. Oleiferous hyphae rare, but present at least in the pileitrama. Clamp connections abundant in all parts of the basidiocarp.

Habitat: Basidiocarps found solitary to scattered in Quercus-dominated montane forest between 1750 and 1900 m asl. in Chiriquí, Panama.

Additional specimens examined: PANAMA. CHIRIQUÍ: near Boquete, PNVB, Sendero Culebra, N $08^{\circ} 51^{\prime} 00.7^{\prime \prime} \mathrm{W} 82^{\circ} 28^{\prime} 55.2^{\prime \prime}, 1,760 \mathrm{~m}$ asl., montane forest with abundant Quercus spp., 6 June 2017, K. Reschke, KaiR429 (M); ibid., N 08 51'00.7" W 82²8'55.2", $1,760 \mathrm{~m}$ asl., montane forest with abundant Quercus spp., 6 June 2017, K. Reschke, KaiR430 (M); ibid., N $08^{\circ} 51^{\prime} 21.1^{\prime \prime} \mathrm{W} 82^{\circ} 29^{\prime} 02.5^{\prime \prime}, 1880 \mathrm{~m}$ asl., montane forest with abundant Quercus spp., 9 June 2017, K. Reschke, KaiR474 (M).

Notes: Entoloma nubilosilvae is characterised by whitish basidiocarps with a convex to depressed pileus, a radially fibrillose pileal surface, abundant clamp connections, rather narrow cheilocystidia, and the presence of rhomboid to cruciform basidiospores. It is closely related to $E$. amistadosericellum, described above, which has broader cheilocystidia and slightly larger basidiospores. As basidiocarps of E. nubilosilvae are quite similar to those of E. amistadosericellum micro- and macromorphologically, it differs from all the species mentioned in the notes of the latter in the same way. Entoloma adnatifolium (Murrill) Blanco-Dios has basidiospores and cheilocystidia of similar size as E. nubilosilvae; however, rhomboid basidiospores were not mentioned in the description of E. adnatifolium and clamp connections are rare to scattered on the hyphae of the pileipellis and the stipe surface (Largent and Benedict 1970). 
Fig. 33 Basidiocarp and cellular structures as seen by SEM of Entoloma caeruleomarginatum (KaiR535, holotype): a view from below, depicting lamellae with serrulatum structure; $\mathbf{b}$ view from above $\mathbf{c}$ basidiospore, bar $=10 \mu \mathrm{m} ; \mathbf{d}$ cheilocystidia, bar $=10 \mu \mathrm{m}$
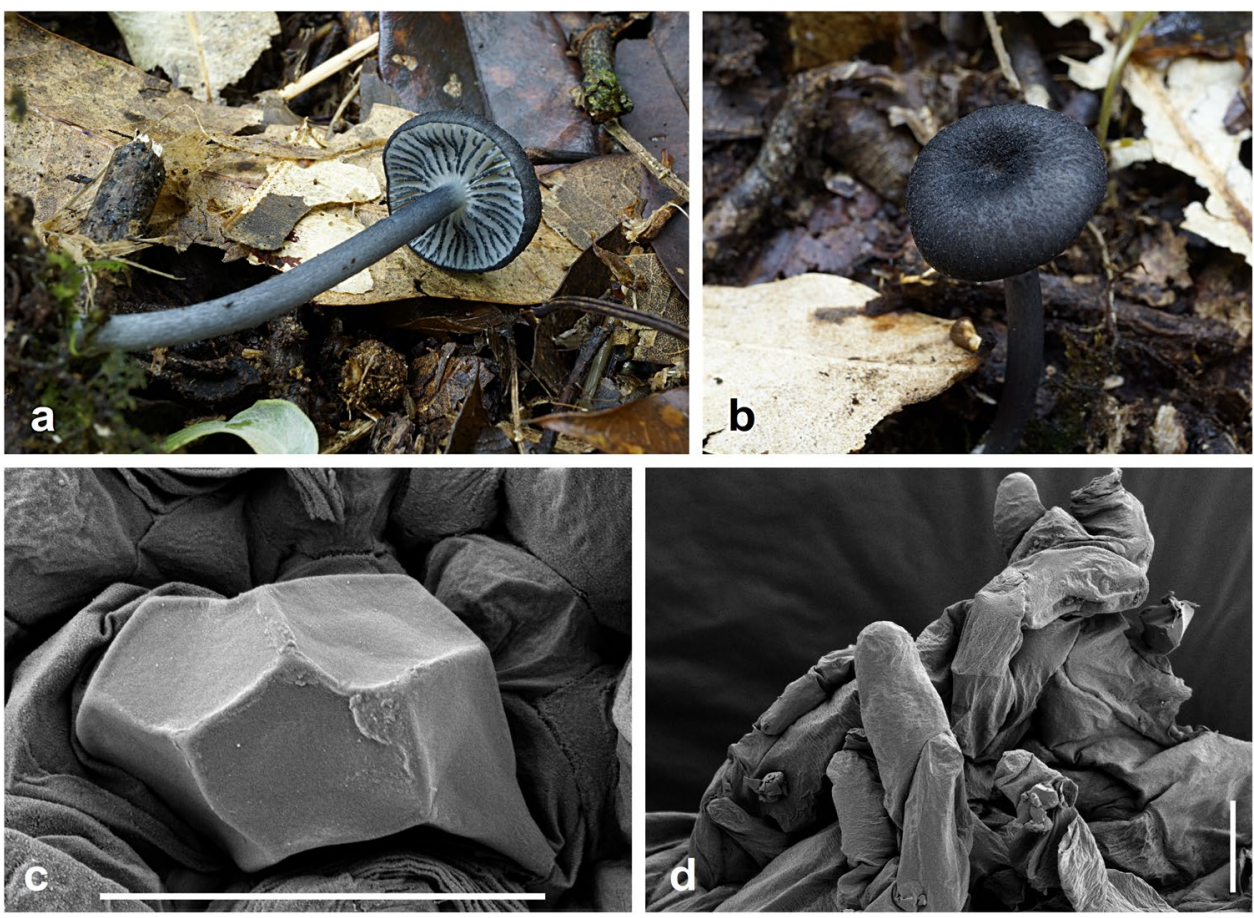

\section{Subgenus Cyanula (Romagn.) Noordel}

Species of the subgenus Cyanula form a well-supported clade in the ITS/LSU phylogeny (Fig. 30). They develop basidiocarps with often bright colours, a differentiated pileipellis with a trichodermal structure, intracellular pigment, and clampless hyphae. The lamellar edge of many species is formed by tramal hyphae that grow through the hymenium forming a sterile band along the edge, with dense clusters of more or less clavate or fusiform terminal cells. These terminal cells often contain blue or brown intracellular pigment, causing a coloured border along the edge, the "serrulatum-type" lamellar edge (Noordeloos 2004). Species of this clade occur worldwide, from the arctic tundra to the tropical rainforest. In Europe, they are characteristic of oligotrophic grasslands, habitats which are generally threatened in Europe (Janssen et al. 2016). The subgenus Cyanula is the most species-rich subgenus within Entoloma, with approximately 500-600 species already described (Hesler 1967; Horak 1980, 2008; Largent 1994; Noordeloos 2004; Noordeloos and Gates 2012; Crous et al. 2021; Noordeloos et al. 2021; Dima et al. 2021). Species delimitation is often rather difficult. Morphological look-alikes occurring on several continents are often phylogenetically distant and must therefore be considered as semi-cryptic.

Entoloma arcanum Reschke \& Noordel., sp. nov., Figs. 31 and 32

Mycobank number: MB840624.
Typification: PANAMA. CHIRIQUÍ: Cerro Punta, Las Nubes, PILA, Sendero Cascada, N 08 ${ }^{\circ} 53^{\prime} 46.0^{\prime \prime}$ W $82^{\circ} 37^{\prime} 01.5^{\prime \prime}, 2,270 \mathrm{~m}$ asl., montane forest dominated by Alnus acuminata, 11 June 2017, K. Reschke and J. Rodríguez, KaiR488, holotype (UCH11734), isotype (M).

Etymology: arcanus (Latin)=arcane; refers to the dark appearance of the basidiocarps and its isolated position in the phylogenetic tree.

Description: Basidiocarps collybioid. Pileus $3.0-4.5 \mathrm{~cm}$ diameter, hemispherical to convex with umbilicate centre, margin initially incurved, remaining somewhat incurved in old basidiocarps, blackish blue (19F5, 19F6, 19F7), blue tones becoming brownish while ageing, pileal surface squamulosevelutinous in the centre, squamulose to squamulose-fibrillose towards margin, not translucently striate, not hygrophanous. Lamellae broadly adnate to slightly decurrent, segmentiform, close, white with creamish tinge, becoming pink at maturity, with somewhat crenate and concolorous edges. Stipe $2.0-4.0 \times 0.5 \mathrm{~cm}$, cylindrical, sometimes compressed, hollow, initially concolorous to the pileus, blue tones soon becoming brownish, finely squamulose. Basal mycelium white, cottony, sometimes with obvious, thick rhizomorphs. Odour unpleasant, similar to old basdidiocarps of Tricholoma spp. or burnt potatoes, taste not tested.

Basidiospores $9.5-10.3-11.0 \times 6.5-7.0-7.5 \mu \mathrm{m}$, $Q=1.30-1.48-1.65$ ( $n=53$ spores of 2 specimens), heterodiametrical, with 5-6 pronounced angles in outline, weakly pigmented yellowish pink, somewhat thick-walled. Basidia 30-38 (40) $\times 8.5-11.0 \mu \mathrm{m}$, clavate to subclavate, hyaline, 
Fig. 34 Microscopic structures of Entoloma caeruleomarginatum (KaiR535, holotype): a pileipellis, $\mathrm{bar}=20 \mu \mathrm{m}$; $\mathbf{b}$ basidiospores, $b a r=10 \mu \mathrm{m}$; c stipitipellis, bar $=20 \mu \mathrm{m} ; \mathbf{d}$ cheilocystidia, bar $=20 \mu \mathrm{m}$

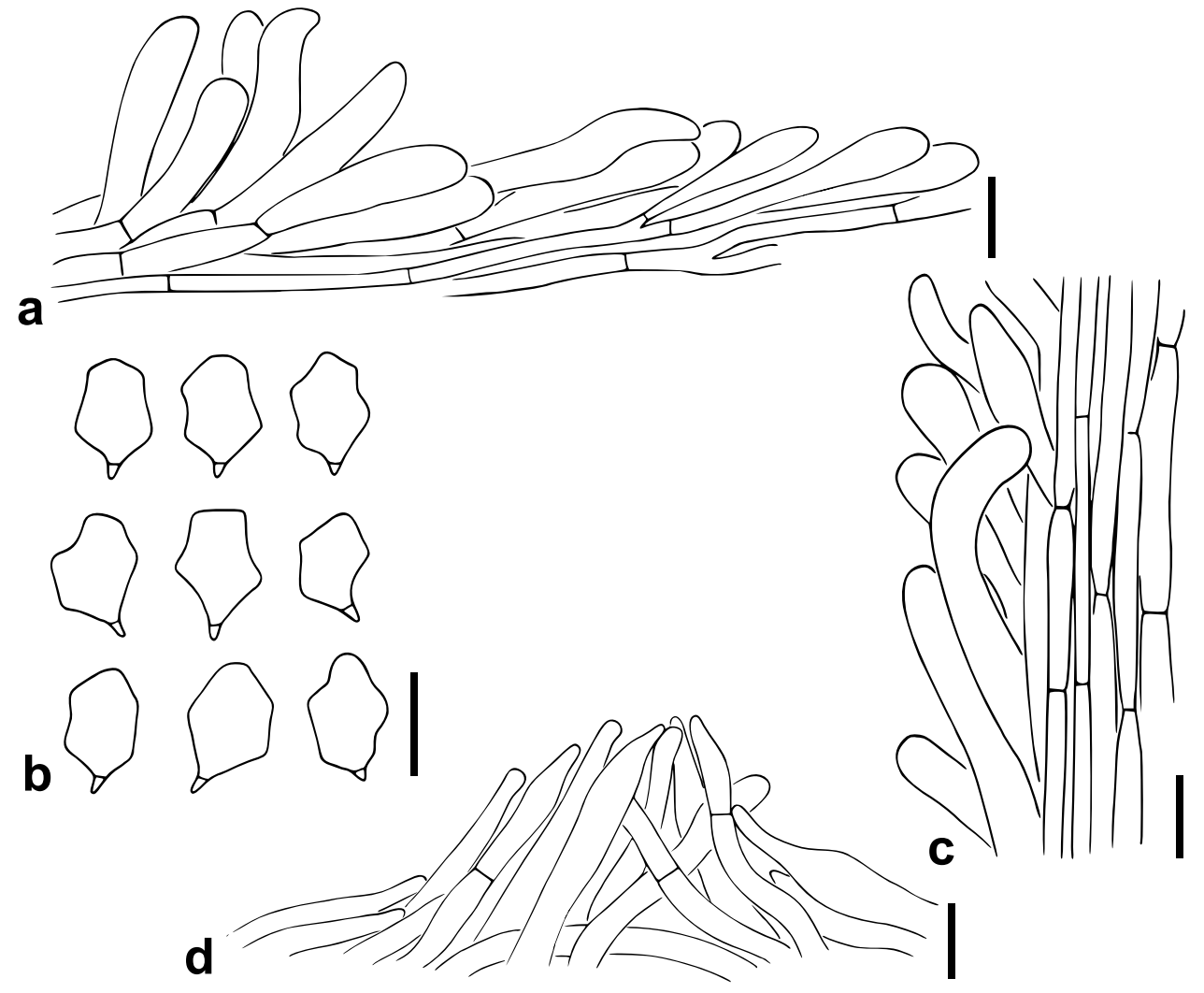

4-spored, with up to $5.5 \mu \mathrm{m}$ long sterigmata. Lamellar edge sterile, cheilocystidia predominantly broadly fusiform, sometimes lageniform, more rarely irregularly cylindrical to moniliform, 25-55×8.0-14.0 $\mu \mathrm{m}$. Hymenophoral trama regular, formed by subcylindrical cells, somewhat constricted at septae, 55-275 $\times 3-20 \mu \mathrm{m}$. Pileipellis a cutis with transitions to a trichoderm, composed of broadly cylindrical to inflated end cells, 40-140×10.5-19.0 $\mu \mathrm{m}$, upper pileipellis cells $43-110 \times 5.0-15.0 \mu \mathrm{m}$, and a subpellis of narrower cells, 4.0-7.0 $\mu \mathrm{m}$ wide, pigment intracellular as clumps, violet in water, soluble and then brownish in $\mathrm{KOH}$. Stipitipellis similar to pileipellis, composed of subcylindrical to somewhat inflated cells, $50-180 \times 7.5-15.0 \mu \mathrm{m}$, with emerging end cells in bundles and below a layer of narrower hyphae, 4.0-7.5 $\mu \mathrm{m}$ wide. Caulocystidia absent. Oleiferous hyphae present in the trama. Brilliant granules abundant. Clamp connections absent from any part of the basidiocarp.

Habitat: Basidiocarps solitary to scattered in a small group in Quercus- and Alnus-dominated montane forests between 2250 and $2300 \mathrm{~m}$ asl. in Chiriquí, Panama.

Additional specimen examined: PANAMA. CHIRIQUÍ: near Cerro Punta, Entre Ríos, Montaña Azul, PILA, approximately $2300 \mathrm{~m}$ asl., montane forest dominated by Quercus spp., 21 June 2017, E. Heinemann, KaiR614 (M).

Notes: Entoloma arcanum is characterised by dark, blackish blue basidiocarps and a sterile lamellar edge with mainly fusiform cheilocystidia. It is phylogenetically relatively close to a specimen identified as E. fuscosquamosum Hesler (Fig. 30). This species has basidiocarps with more greyish colours, larger basidiospores $(9-13 \times 6-7.5 \mu \mathrm{m})$, and cylindric-capitate cheilocystidia (Hesler 1967) or no cheilocystidia at all (Noordeloos 1988). The RPB2 sequence of $E$. arcanum is close to a sequence (KR233903) labelled $E$. trichomatum (Largent) Noordel. \& Co-David with a $p$-distance of $3 \%$. This species is morphologically similar to $E$. arcanum but differs by clavate to cylindrical cheilocystidia. Entoloma trichomatum is known from coniferous forests in western North America (Largent 1994), while E. arcanum was found in tropical montane forests with broadleaved trees.

Entoloma caeruleomarginatum Reschke, Manz, \& Noordel., sp. nov., Figs. 33 and 34

Mycobank number: MB840627.

Typification: PANAMA. CHIRIQUÍ: near Bajo Boquete, Jaramillo Arriba, El Musgo, N 0847'27.3" W 82²4'34.3", $1660 \mathrm{~m}$ asl., montane forest dominated by Quercus spp., 14 June 2017, K. Reschke and M. Cuevas, KaiR535, holotype (UCH11744), isotype (M).

Etymology: caeruleus $($ Latin $)=$ dark blue, margo (Latin) = edge; refers to the dark blue lamellar edge.

Description: Basidiocarps collybioid to somewhat omphalinoid. Pileus $1.5-2.0 \mathrm{~cm}$ diameter, convex 
Fig. 35 Basidiocarps and cellular structures as seen by SEM of Entoloma griseocaeruleum: a, b (KaiR534, holotype) bar $=10 \mu \mathrm{m} ; \mathbf{c}($ KaiR536); d (KaiR534, holotype) cheilocystidia, bar $=10 \mu \mathrm{m}$
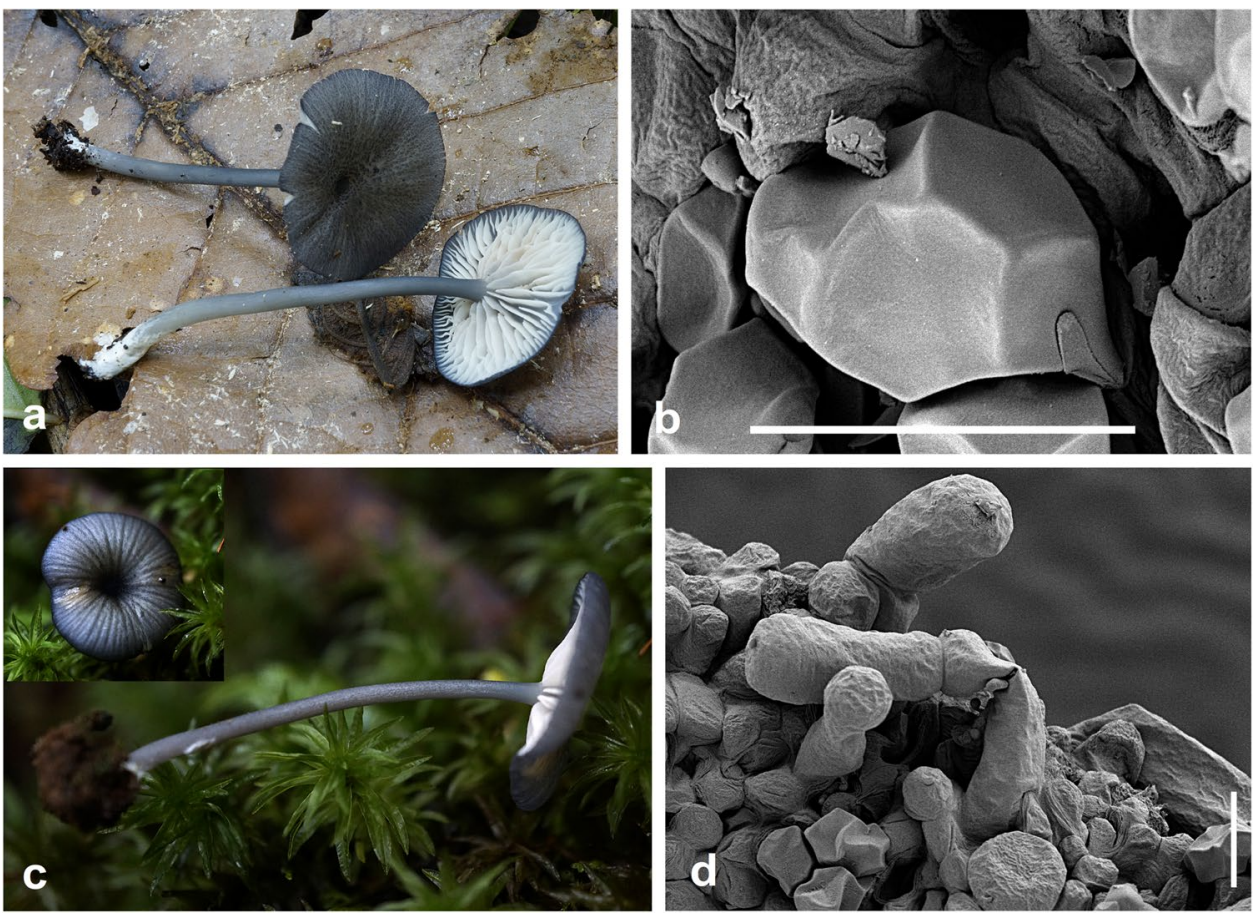

Fig. 36 Microscopic structures of Entoloma griseocaeruleum (KaiR534, holotype): a pileipellis, bar $=20 \mu \mathrm{m}$; b cheilocystidia, bar $=20 \mu \mathrm{m}$; $\mathbf{c}$ basidiospores, bar $=10 \mu \mathrm{m}$
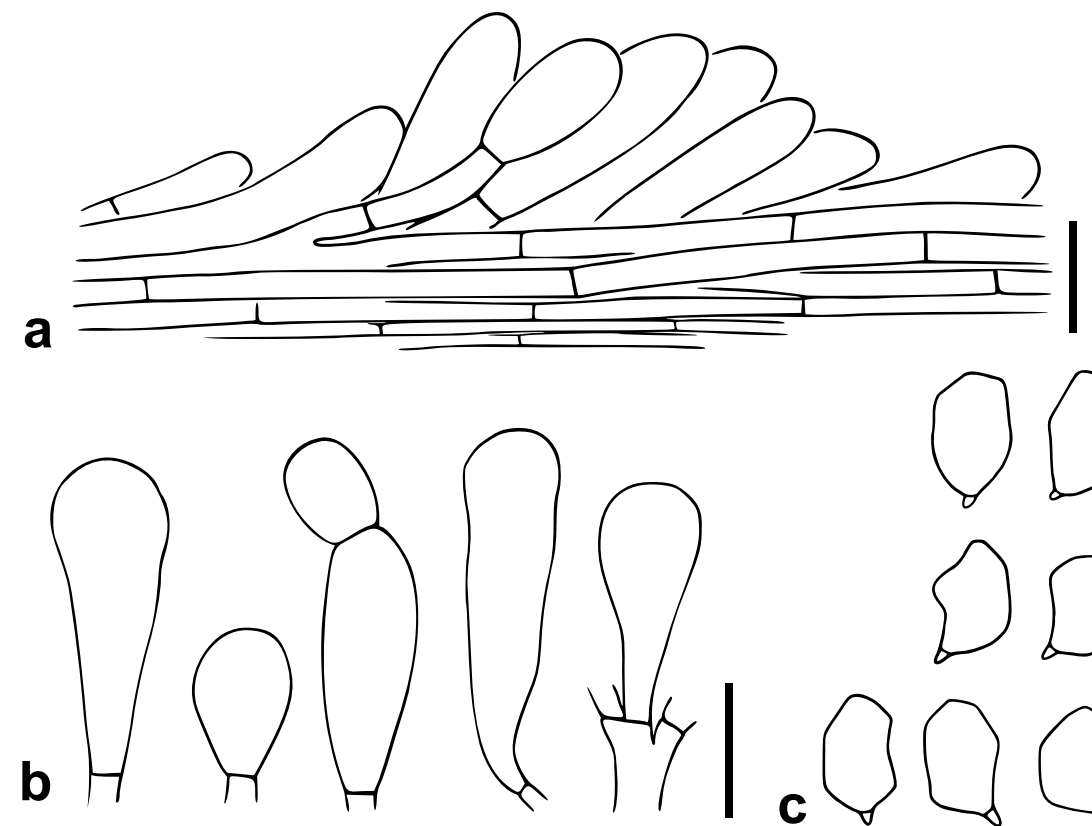
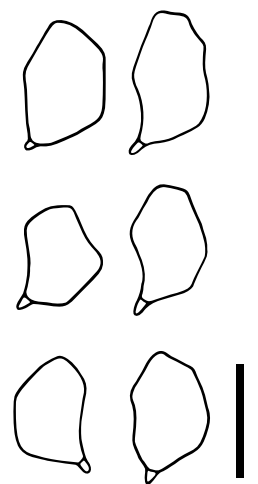

umbilicate with incurved margin in young basidiocarps, expanded umbilicate with straight margin in older basidiocarps, bluish grey to greyish blue (20C2, 20D6), centre and squamules dark blue (20E4) to blackish blue (20F8), pileal surface squamulose, not translucently striate in young and fresh basidiocarps, but somewhat translucently striate at the margin of old and soaked basidiocarps. Lamellae broadly adnate, slightly emarginate to decurrent, segmentiform to arcuate, medium-spaced to rather distant, pale blue in young basidiocarps, later pinkish, edges blackish blue (20F6) serrulate. Stipe $4.0-5.0 \times 0.30-0.35 \mathrm{~cm}$, cylindrical, hollow, bluish grey to greyish blue (20D3, 21C6, 21C7, 21D7) with dark blue (20E5) fine, fibrillose squamules. Bluish tones discolouring to brown in old basidiocarps. Basal mycelium white, cottony. Odour indistinct, taste not tested.

Basidiospores $9.0-9.8-11.0 \times 6.0-7.0-8.0 \mu \mathrm{m}$, $Q=1.20-1.41-1.60(n=69$ spores of 3 specimens $)$, 
hendecahedroid, composed of an adaxial facet (D), a pair of apico-adaxial facets (AD), an apical facet (A), an abaxial facet (B), and three pairs of lateral facets (L1-L3), of which the basal pair (L3) forms a dièdre basal, heterodiametrical, with 5-6 (7) pronounced, sometimes rather nodulose angles in outline, weakly pigmented yellowish pink, somewhat thick-walled. Basidia 34-48 $\times 8.0-11.0 \mu \mathrm{m}$, subclavate, hyaline, 4 -spored, with up to $4.0 \mu \mathrm{m}$ long sterigmata. Lamellar edge sterile, of the serrulatum-type, cheilocystidia 40-85 (135) ×(5.5) 7.5-12.0 (17.0) $\mu \mathrm{m}$, lageniform, subfusiform to cylindrical, sometimes subcapitate, with dark violet, intracellular pigment in clumps, soluble, and then becoming brown in $\mathrm{KOH}$. Hymenophoral trama regular, formed by long, cylindrical to slightly fusiform cells, $55-175 \times 6.0-16.0 \mu \mathrm{m}$. Pileipellis a cutis with transitions to a trichoderm, especially towards centre, composed of clavate, sometimes fusiform end cells, $70-210 \times 13-26 \mu \mathrm{m}$, with violet, intracellular pigment, cells narrower, $6.0-12.0 \mu \mathrm{m}$ wide, towards pileitrama, cylindrical to slightly fusiform. Stipitipellis similar to pileipellis, composed of cylindrical cells, 60-210 $\times 4.0-7.5(9.5) \mu \mathrm{m}$, with subcylindrical to somewhat fusiform terminal cells, $75-150 \times 10.5-16.0 \mu \mathrm{m}$. Oleiferous hyphae absent or not distinctive. Clamp connections absent from any part of the basidiocarp.

Habitat: Basidiocarps found solitary in a Quercusdominated montane forest between 1650 and $1700 \mathrm{~m}$ asl. in Chiriquí, Panama.

Additional specimens examined: PANAMA. CHIRIQUÍ: near Bajo Boquete, Jaramillo Arriba, El Musgo,

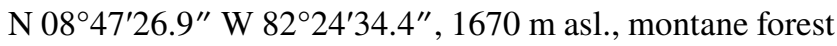
dominated by Quercus spp., 15 June 2018, C. Manz and F. Hampe, CME3 (M); ibid., 24 June 2018, C. Manz and F. Hampe, CME11 (M).

Notes: Entoloma caeruleomarginatum belongs to the clade of E. serrulatum and closely related species. It is characterised by basidiocarps with a dark blue pileus, blue serrulate lamellar edges, a fibrillose-squamulose stipe surface, and heterodiametrical basidiospores with an average length of approximately $10 \mu \mathrm{m}$. The European E. serrulatum is morphologically very similar and hard to distinguish. The latter, however, is widely distributed and common in northern hemisphere temperate to boreal grasslands. It is phylogenetically rather distant with a $p$-distance of $10.5 \%$ in the ITS sequences. For this reason, we consider them semi-cryptic species, separated by ecological and geographical characters as well as molecular sequence data. Both, E. subserrulatum (Peck) Hesler and E. subcaesiocinctum Xiao-Lan He \& W.H. Peng are phylogenetically closer to E. caeruleomarginatum based on ITS/LSUdata than E. serrulatum (Fig. 30). Entoloma subserrulatum differs by basidiocarps with a pale and translucently striate pileus (Hesler 1967). Entoloma subcaesiocinctum differs from E. caeruleomarginatum by basidiocarps with a pale pileus and by smaller basidiospores (He et al. 2017). Entoloma proximum Horak, described from Argentina, differs by basidiocarps with an appressed fibrillose to subsquamulose pileal surface, slightly larger basidiospores, and relatively short, cylindrical to subclavate cheilocystidia (Horak 1978).

Entoloma griseocaeruleum Reschke, Manz \& Noordel., sp. nov., Figs. 35 and 36

Mycobank number: MB840630.

Typification: PANAMA. CHIRIQUÍ: near Bajo Boquete, Jaramillo Arriba, El Musgo, N 08 47'26.1" W $82^{\circ} 24^{\prime} 29.9^{\prime \prime}, 1,650 \mathrm{~m}$ asl., montane forest dominated by Quercus spp., 14 June 2017, K. Reschke, KaiR534, holotype (UCH9185), isotype (M).

Etymology: griseus $($ Latin $)=$ grey, caeruleus $($ Latin $)=$ dark blue; refers to the colour of the basidiocarps.

Description: Basidiocarps collybioid to somewhat omphalinoid. Pileus $1.5-3.5 \mathrm{~cm}$ diameter, hemispherical to convex with depressed to umbilicate centre, margin initially incurved, later straight, initially greyish blue to bluish grey (20B3, 20B4, 20B5, 20B6) with dark blue to blackish blue (20E6, 20F6) squamules, blue tones becoming brownish while ageing, pileal surface squamulose, squamulosevelutinous in the centre, slightly sulcate-rimose to distinctly sulcate almost to the centre, not hygrophanous. Lamellae broadly adnate, sometimes with decurrent tooth, segmentiform, rather distant, white with greyish tinge, becoming pink at maturity, edges even and concolorous. Stipe 3.0-4.5 $\times 0.15-0.30 \mathrm{~cm}$, cylindrical, hollow, greyish blue to bluish grey (20D5, 20D4, 20D3), blue tones becoming brownish, innately fibrillose to polished, rarely finely flocculose. Basal mycelium white, cottony, with some short and fine rhizomorphs, often staining red when touched and then remaining reddish also in dried specimens. Odour indistinct, taste not tested.

Basidiospores 9.0-10.1-11.5 $\times 6.0-6.8-7.5 \mu \mathrm{m}$, $Q=1.35-1.49-1.65$ ( $n=96$ spores of 4 specimens), hendecahedroid, composed of an adaxial facet (D), a pair of apicoadaxial facets (AD), an apical facet (A), an abaxial facet (B), and three pairs of lateral facets (L1-L3), of which the basal pair (L3) forms a dièdre basal, heterodiametrical, with 5-6 blunt angles in outline, weakly pigmented yellowish pink, somewhat thick-walled. Basidia 25-31 (40) $\times 8.5-10.0 \mu \mathrm{m}$, clavate, hyaline, predominantly 4-spored, with up to $6.0 \mu \mathrm{m}$ long sterigmata, few 2-spored. Lamellar edge heterogeneous, cheilocystidia scattered between basidia, rather inconspicuous, broadly clavate to cylindrical, often subcapitate, (19) 25-63 $(75) \times 12.0-15.0 \mu \mathrm{m}$. Hymenophoral trama regular, formed by cylindrical to fusiform cells, 60-310 $\times 5-25$ (33) $\mu \mathrm{m}$. Pileipellis a cutis with transitions to a trichoderm, a trichoderm at the very centre, composed of relatively short and wide end-cells, 55-140×15-30 (33) $\mu \mathrm{m}$, upper 
Fig. 37 Basidiocarps and cellular structures as seen by SEM of Entoloma melleosquamulosum: a, b (KaiR638); c (CME16, holotype) bar= $1 \mathrm{~cm} ; \mathbf{d}$ (CME16, holotype) $\mathrm{bar}=10 \mu \mathrm{m}$
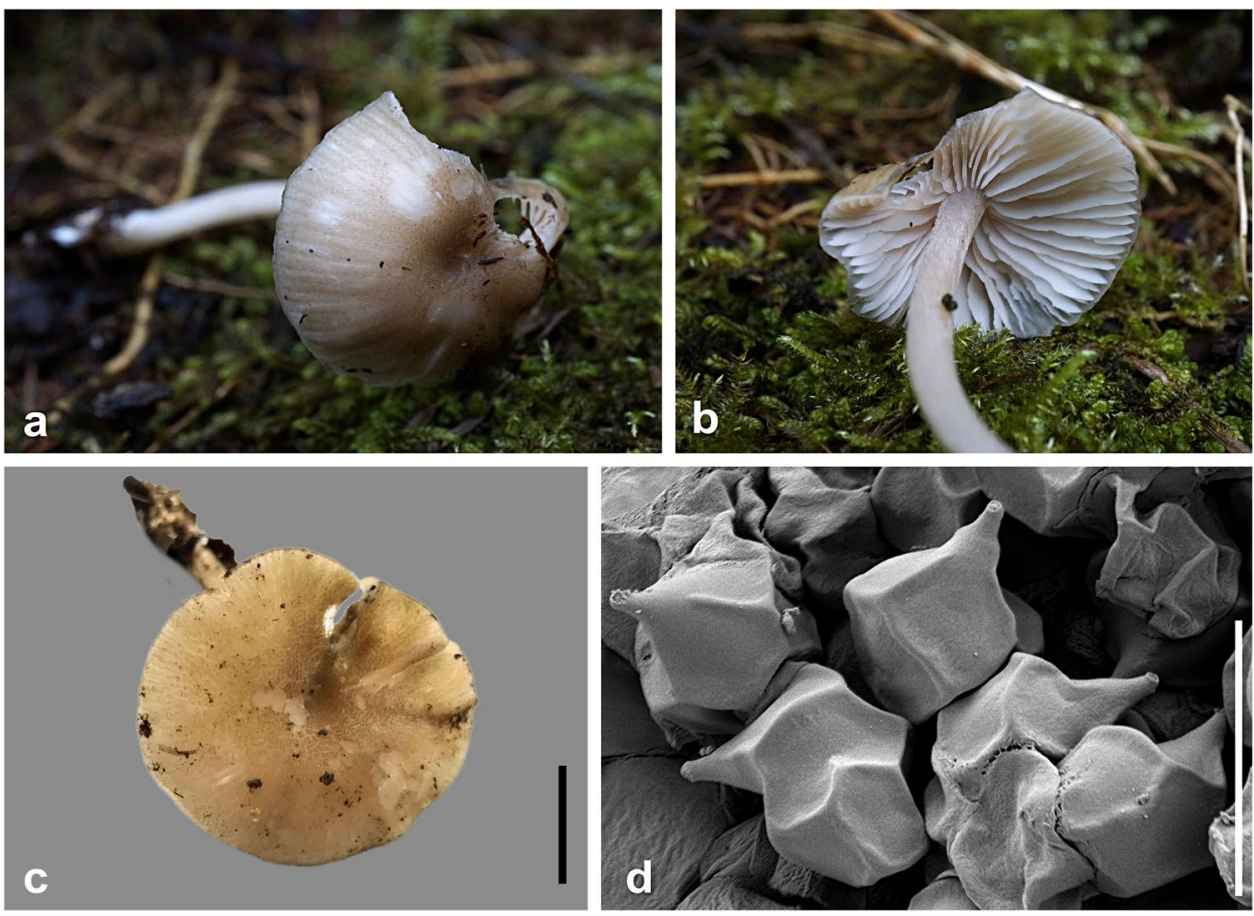

Fig. 38 Microscopic structures of Entoloma melleosquamulosum (KaiR413, holotype): a stipitipellis with outgrowths, bar $=10 \mu \mathrm{m}$; b pileipellis, bar $=20 \mu \mathrm{m}$; c basidiospores, bar $=10 \mu \mathrm{m} ; \mathbf{d}$ cheilocystidia, bar $=10 \mu \mathrm{m}$
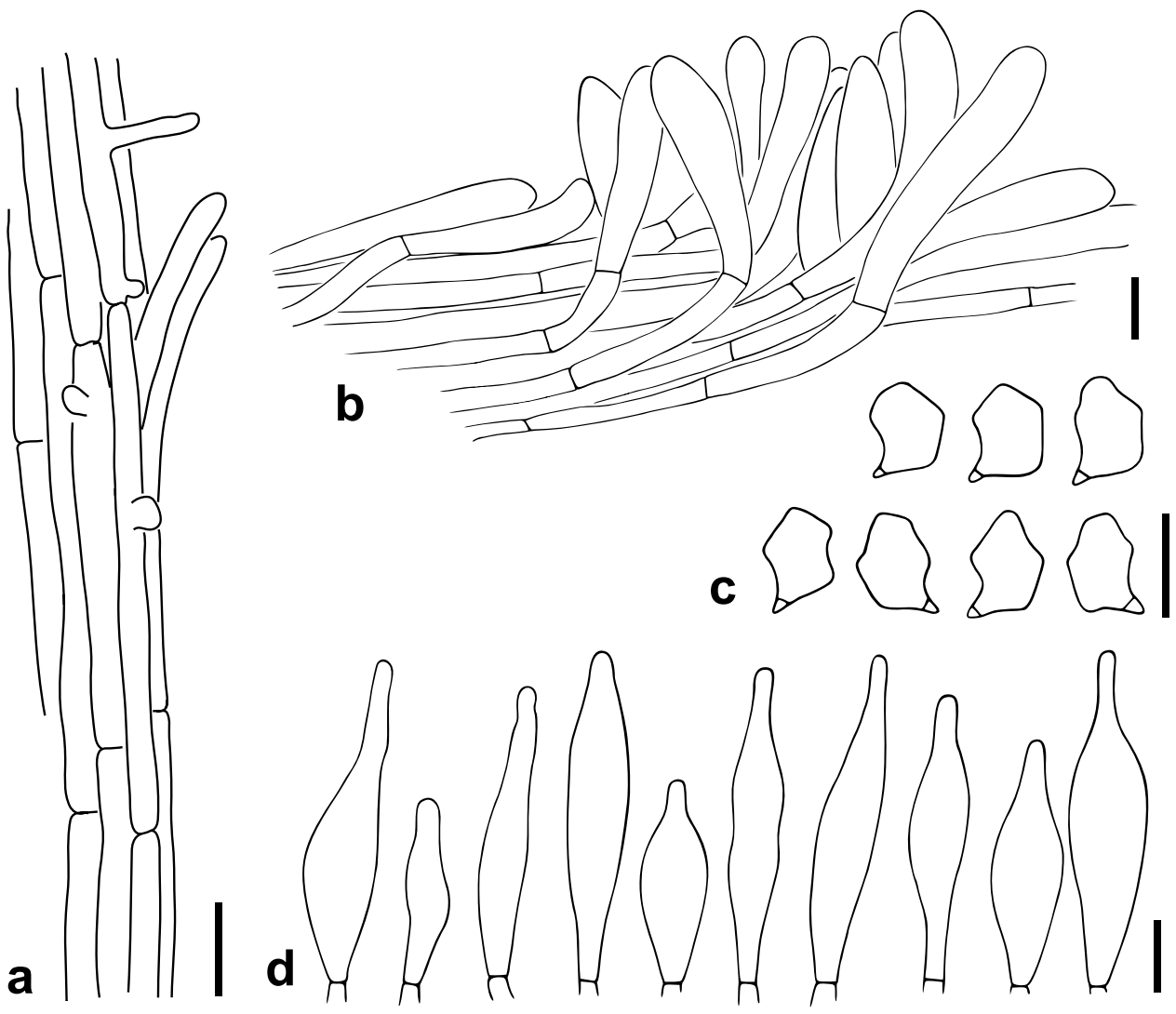
Fig. 39 Basidiocarps and basidiospore as seen by SEM of Entoloma microserrulatum: a, b (KaiR413, holotype); c (KaiR664); d (KaiR413, holotype) $\mathrm{bar}=10 \mu \mathrm{m}$
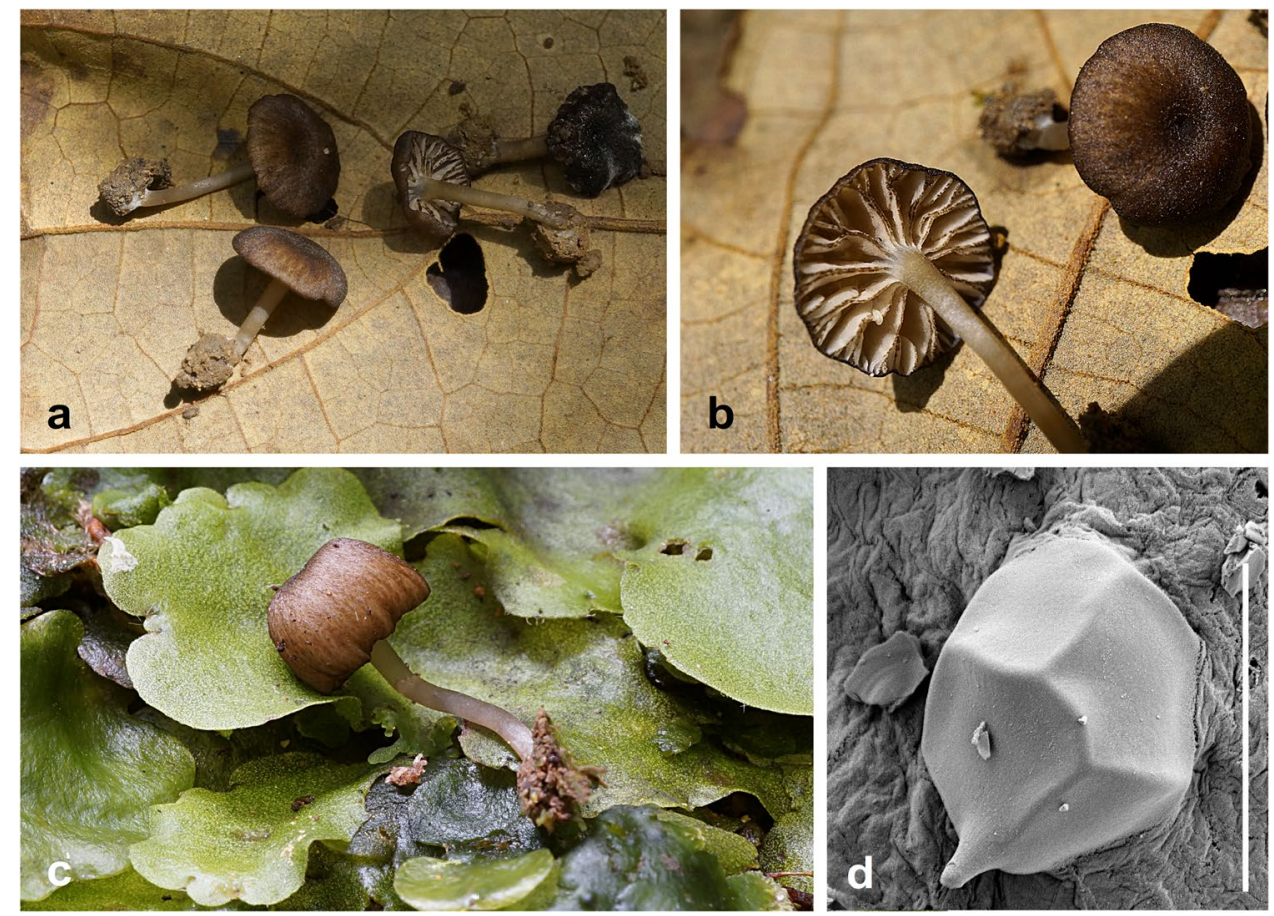

pileipellis cells $43-110 \times 5.0-10.0 \mu \mathrm{m}$, and a subpellis of narrower cells, 3.0-7.0 $\mu \mathrm{m}$ wide, pigment intracellular as clumps, violet in water, soluble and then brownish in $\mathrm{KOH}$. Stipitipellis a cutis composed of narrow, cylindrical cells, 105-210 (330) ×3.0-6.0 $\mu \mathrm{m}$. Caulocystidia absent. Oleiferous hyphae present in the trama, but rare. Clamp connections absent from any part of the basidiocarp.

Habitat: Basidiocarps solitary to scattered in a small group in Quercus-dominated montane forests between 1650 and $2350 \mathrm{~m}$ asl. in Chiriquí, Panama.

Additional specimens examined: PANAMA. CHIRIQUÍ: near Bajo Boquete, Jaramillo Arriba, El Musgo, $\mathrm{N} \mathrm{08}{ }^{\circ} 47^{\prime} 32.3^{\prime \prime} \mathrm{W} 82^{\circ} 24^{\prime} 50.3^{\prime \prime}, 1650 \mathrm{~m}$ asl., montane forest dominated by Quercus spp., 14 June 2017, K. Reschke, KaiR536 (M); near Cerro Punta, Entre Ríos, Montaña Azul, PILA, N 08 53'39.7' W 82³4'55.0'", 2340 m asl., montane forest dominated by Quercus spp., 19 June 2018, C. Manz and F. Hampe, CME8 (M); Bajo Boquete, Finca Lerida, N 08 49'10.3" W 82 29'09.2", $1820 \mathrm{~m}$ asl., montane forest with Quercus seemannii and other Quercus spp., 28 June 2018, C. Manz and F. Hampe, CME13 (M).

Notes: Entoloma griseocaeruleum is a typical representative of subg. Cyanula by its blue colours, deeply striate, minutely squamulose pileus, and white lamellae. It forms a well-supported clade together with E. longistriatum (Peck) Noordel. and E. sarcitulum (P.D. Orton) Arnolds (Fig. 30). These species have brown basidiocarps, which do not look like those of E. griseocaeruleum. Entoloma yanacolor A. Barili et al., described from Ecuador, has basidiocarps with blue tones according to the picture of the holotype specimen
(Crous et al. 2018). This was, however, described as black, resembling E. corvinum (Kühner) Noordel., and with a smooth, waxy pileus surface. No species similar to E. griseocaeruleum were found in Hesler (1967), Horak (1978, 1982), Largent (1994), and Noordeloos (1992, 2004).

Entoloma melleosquamulosum Reschke, Manz \& Noordel., sp. nov., Figs. 37 and 38

Mycobank number: MB840939.

Typification: PANAMA, CHIRIQUÍ: near Hornito, N $08^{\circ} 45^{\prime} 11.1^{\prime \prime} \mathrm{W} 82^{\circ} 14^{\prime 2} 2.6^{\prime \prime}, 1210 \mathrm{~m}$ asl., submontane tropical forest dominated by Oreomunnea mexicana in transition to montane Quercus-dominated forest, 29 June 2018, C. Manz and F. Hampe, CME16, holotype (M).

Etymology: melleus (Latin) $=$ honey, squamulosus (Latin) $=$ minutely scaly; refers to the colour of the pileus and the structure of its surface.

Description: Basidiocarps collybioid. Pileus $2.3-2.7 \mathrm{~cm}$ diam., convex umbilicate in young basidiocarps, expanding to plane umbilicate, with straight, slightly uneven to undulating margin, beige to brownish orange (4C3, 5C4, 5C5), darker, yellowish brown towards the centre (5D5, 5E5), pileal surface finely scaly all over, but most distinct in the centre, indistinctly translucently striate at the very margin to distinctly translucently striate at about half the centre. Lamellae sinuate to adnate, segmentiform to ventricose, medium-spaced to rather distant, initially greyish white, later pink, with uneven, slightly serrate to irregularly undulating, concolorous to somewhat paler edges. Stipe $4.0-5.0 \times 0.3 \mathrm{~cm}$, cylindrical, slightly broader towards base, hollow, pale yellow to yellowish white (4A3, 4A2), 
Fig. 40 Microscopic structures of Entoloma microserrulatum (KaiR413, holotype): a pileipellis, bar $=20 \mu \mathrm{m}$; b cheilocystidia, bar $=20 \mu \mathrm{m} ; \mathbf{c}$ basidiospores, $\mathrm{bar}=10 \mu \mathrm{m}$
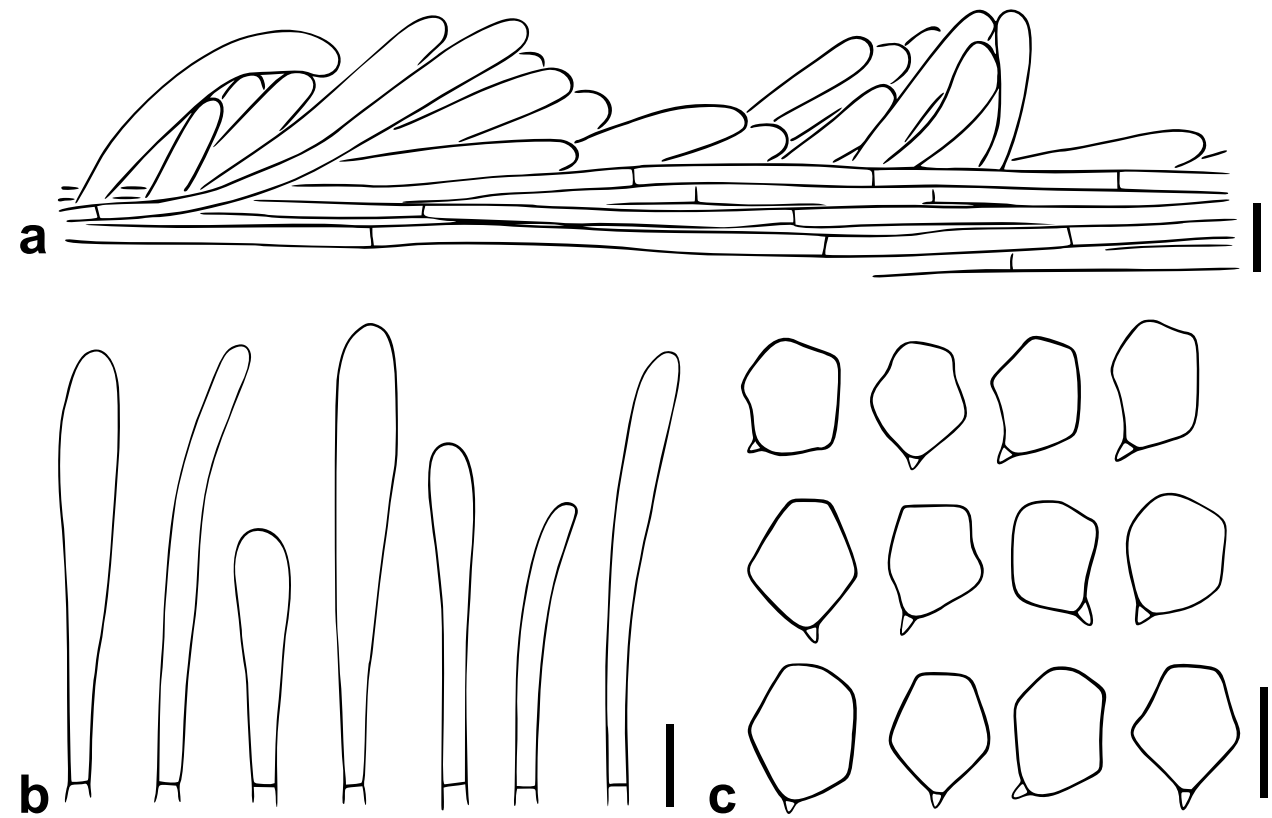

fibrillose, apical pruinose to finely scaly. Basal mycelium white, cottony, with some short and fine rhizomorphs. Odour indistinct to slightly fruity, taste not tested.

Basidiospores $8.5-9.4-10.5 \times 6.0-6.8-8.0 \mu \mathrm{m}$, $Q=1.20-1.38-1.55$ ( $n=58$ spores of 2 specimens), dodecahedroid, composed of an adaxial facet (D), a pair of apicoadaxial facets (AD), an apical facet (A), two abaxial facets (B1, B2), and three pairs of lateral facets (L1-L3), of which the basal pair (L3) forms a dièdre basal, heterodiametrical, with 5-6 pronounced angles in outline, weakly pigmented yellowish pink, somewhat thick-walled. Basidia 26-35 $\times 8.0-10.0 \mu \mathrm{m}$, clavate, hyaline, predominantly 4-spored, with small sterigmata, $1.0-2.0 \mu \mathrm{m}$, rarely up to $3.0 \mu \mathrm{m}$ long, 2-spored and 1-spored basidia rather frequent. Lamellar edge sterile. Cheilocystidia $23-64 \times 6.5-10.0$ (15.0) $\mu \mathrm{m}$, lageniform, hyaline. Hymenophoral trama regular, formed by cylindrical cells, $65-200 \times 4.0-19.0 \mu \mathrm{m}$. Pileipellis a cutis with transitions to a trichoderm composed of rather broad, cylindrical cells, 50-130×(11) 14-21 $\mu \mathrm{m}$, pigment intracellular, soluble in $\mathrm{KOH}$. Stipitipellis a cutis composed of long, cylindrical cells, 40-250×3.0-6.0 $\mu \mathrm{m}$, rather loosely arranged marginally, with some clumped erect hyphae and scattered outgrowths at the apex of the stipe, pigment faint, intracellular. Caulocystidia absent. Oleiferous hyphae present in the trama. Clamp connections absent from any part of the basidiocarp.

Habitat: Basidiocarps solitary in transitional state of submontane Oreomunnea mexicana-dominated to montane Quercus-dominated forest and Quercus-dominated montane forest between 1200 and $1750 \mathrm{~m}$ asl. in Chiriquí, Panama.
Additional specimen examined: PANAMA. CHIRIQUÍ: near Bajo Boquete, PNVB, Sendero Culebra, N 08 $50^{\prime} 56.7^{\prime \prime}$ W $82^{\circ} 28^{\prime} 54.6^{\prime \prime}, 1,730 \mathrm{~m}$ asl., montane forest dominated by Quercus spp., 22 June 2017, K. Reschke, J. Rodríguez, B. Wergen, KaiR638 (UCH11746, M).

Notes: Entoloma melleosqamulosum is characterised by basidiocarps with a honey-coloured, squamulose pileus, basidia with small sterigmata, rather small basidiospores, and lageniform cheilocystidia. It has a relatively isolated position in the molecular phylogenetic analysis (Fig. 30). Entoloma olivaceosquamosum Hesler is a somewhat similar species; however, its basidiocarps differ from those of E. melleosquamosum by larger squamules, olivaceous to greenish tones of the pileus and larger cheilocystidia (Hesler 1967; Noordeloos 1988). Basidiocarps of Entoloma mediterraneense Noordel. \& Hauskn. have a somewhat similar habit but show ephemeral blue tones, form smaller basidiospores and clavate cheilocystidia (Noordeloos and Hausknecht 2002). In addition, this species is phylogenetically distant from E. melleosquamulosum (Fig. 30). No similar species were found in Horak $(1978,1982)$ and Largent (1994).

Entoloma microserrulatum Reschke \& Noordel., sp. nov., Figs. 39 and 40

Mycobank number: MB840625.

Typification: PANAMA. CHIRIQUÍ: near Bajo Boquete, PNVB, Sendero Culebra, N 08 $50^{\prime} 56.3^{\prime \prime} \mathrm{W} 82^{\circ} 28^{\prime} 54.9^{\prime \prime}$, $1730 \mathrm{~m}$ asl., montane forest with abundant Quercus spp., 6 June 2017, K. Reschke, KaiR413, holotype (UCH11742), isotype (M). 
Fig. 41 Basidiocarps and basidiospores as seen by SEM of Entoloma cf. violaceobrunneum: a, b (KaiR632); c (CME2) bar $=1 \mathrm{~cm} ; \mathbf{d}$ (KaiR632) bar $=10 \mu \mathrm{m}$
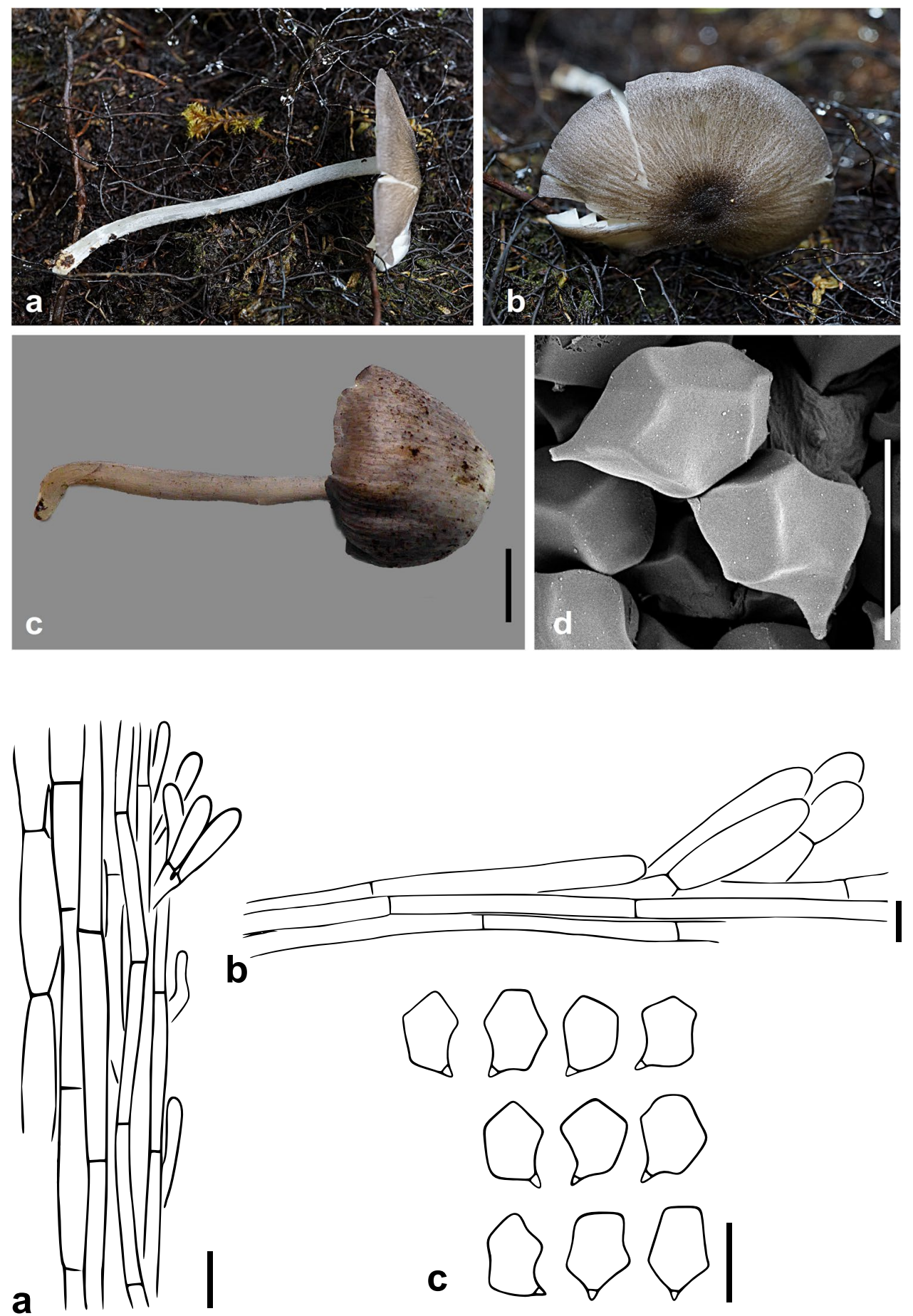

Fig. 42 Microscopic structures of Entoloma cf. violaceobrunneum (KaiR632): a stipitipellis with caulocystidia, bar $=20 \mu \mathrm{m}$; b pileipellis, bar $=25 \mu \mathrm{m}$; c basidiospores, $\mathrm{bar}=10 \mu \mathrm{m}$
Etymology: mikros (Greek)= small; refers to the small basidiocarps and the serrulatum-type lamellar edge.

Description: Basidiocarps collybioid. Pileus $0.6-1.0 \mathrm{~cm}$ diameter, hemispherical to convex umbilicate, margin incurved in young basidiocarps and remaining so, violetbrown (10F5) in young basidiocarps, violet tinges soon discolouring to brown, pileal surface squamulose, not translucently striate. Lamellae broadly adnate to slightly decurrent, segmentiform, medium-spaced to rather distant, whitish in young basidiocarps, later pinkish, with dark violet-brown, serrulate edges. Stipe $1.2-1.5 \times 0.10-0.15 \mathrm{~cm}$, cylindrical, white, greyish yellow (3B5) to olive yellow (3C6), smooth to finely pruinose, shining. Basal mycelium white, with dense, short, hirsute rhizomorphs. Odour indistinct, taste not tested.

Basidiospores $8.5-10.4-12.5 \times 7.0-8.5-10.0 \mu \mathrm{m}$, $Q=1.10-1.23-1.35$ ( $n=53$ spores of 2 specimens), octahedroid, composed of an adaxial facet (D), a single apico-adaxial facet (sAD), an apical facet (A), an abaxial facet (B), and two 
Fig. 43 Maximum Likelihood phylogram of species of subg. Cubospora based on ITS, rooted to $E$. virescens, bootstrap values above or below branches, bar $=$ estimated changes/nucleotide

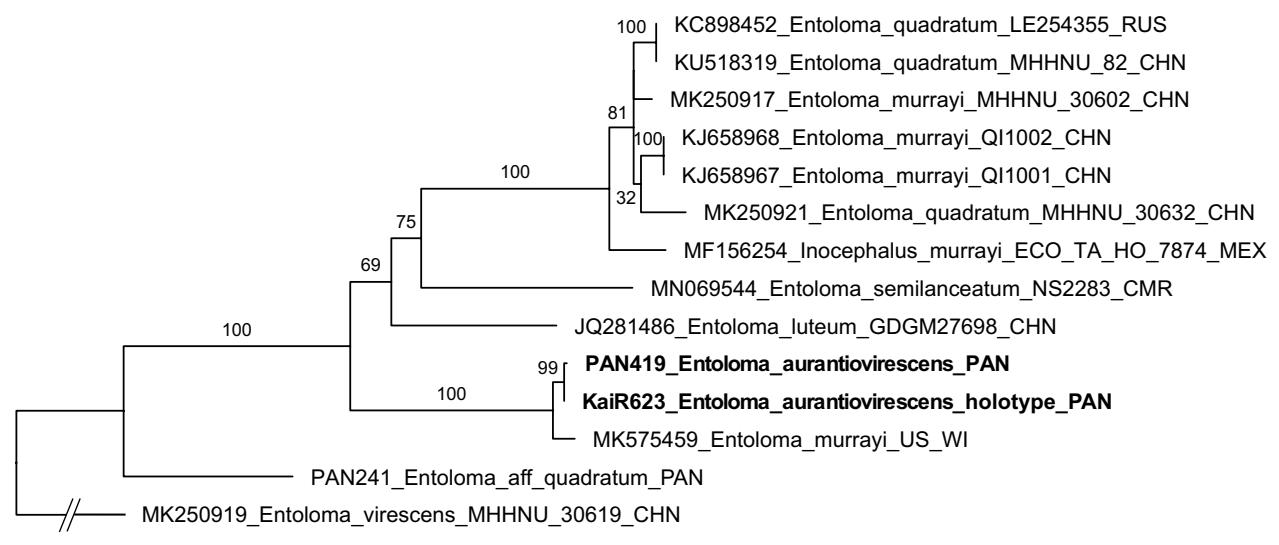

0.05
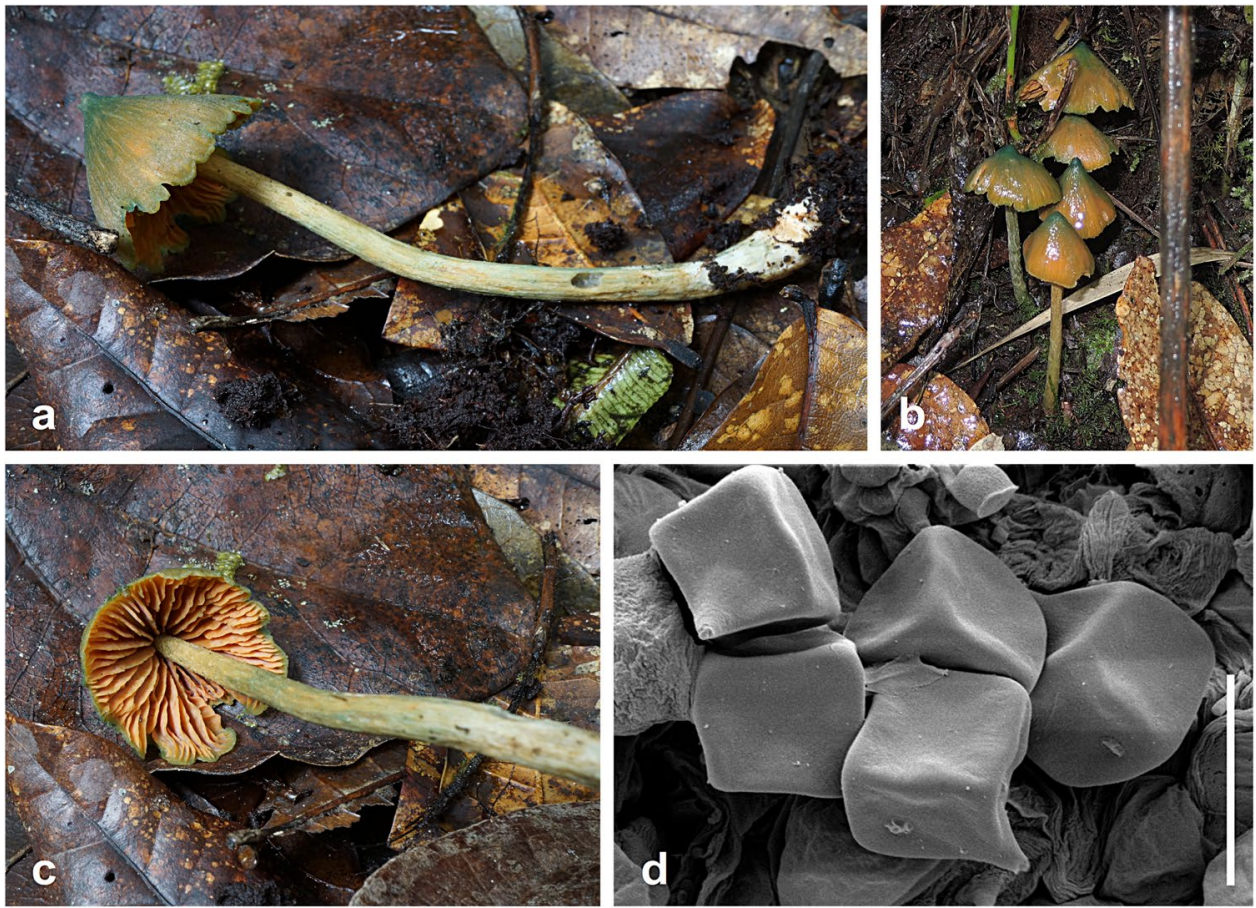

Fig. 44 Basidiocarps, and basidiospores as seen by SEM of Entoloma aurantiovirescens a (KaiR623, holotype) b (PAN419) picture by H. Lotz-Winter c, $\mathbf{d}$ (KaiR623, holotype) bar $=10 \mu \mathrm{m}$ pairs of lateral facets (L1-L2), of which the basal pair (L2) forms a dièdre basal, broadly heterodiametrical, with 5, rarely 4 , pronounced angles in outline, weakly pigmented yellowish pink, somewhat thick-walled. Basidia 33-38×10.0-16.5 $\mu \mathrm{m}$, clavate, hyaline, 2 -spored, with up to $6.5 \mu \mathrm{m}$ long sterigmata, rarely 1 -spored. Lamellar edge sterile, of the serrulatumtype, cheilocystidia clavate, 55-120×6.0-15.0 $\mu \mathrm{m}$, with purplish brown, intracellular pigment. Hymenophoral trama regular, formed by cylindrical to somewhat inflated cells, $35-180 \times 4.0-15.0 \mu \mathrm{m}$. Pileipellis a cutis with transitions to a trichoderm, end cells 35-115 $(200) \times 8.0-14.0 \mu \mathrm{m}$, pigment intracellular, brown in $\mathrm{KOH}$. Stipitipellis a cutis composed of narrow, cylindrical cells, $45-125 \times 2.5-5.5 \mu \mathrm{m}$. Caulocystidia absent. Pigment not soluble in $5 \% \mathrm{KOH}$. Oleiferous hyphae present in the trama. Clamp connections absent from any part of the basidiocarp.

Habitat: Basidiocarps solitary to scattered in a small group in Alnus acuminata-dominated montane forest between 1650 and $1750 \mathrm{~m}$ asl. in Chiriquí, Panama.

Additional specimen examined: PANAMA. CHIRIQUÍ: near Bajo Boquete, Jaramillo Arriba, El Musgo, N $08^{\circ} 47^{\prime 26.9} 9^{\prime \prime} \mathrm{W} 82^{\circ} 24^{\prime} 32.9^{\prime \prime}, 1660 \mathrm{~m}$ asl., montane forest with abundant Quercus spp., 25 June 2017, K. Reschke, KaiR664 (M).

Notes: Entoloma microserrulatum occupies a basal position in the subgenus Cyanula and is very distant from all other species of Cyanula included in the analysis (Fig. 30). It is characterised by minute basidiocarps with purplish brown 
Fig. 45 Microscopic structures of Entoloma aurantiovirescens (KaiR623, holotype) a pileipellis, bar $=25 \mu \mathrm{m}$ b cheilocystidia, bar $=20 \mu \mathrm{m}$ c basidiospores, $\mathrm{bar}=10 \mu \mathrm{m}$

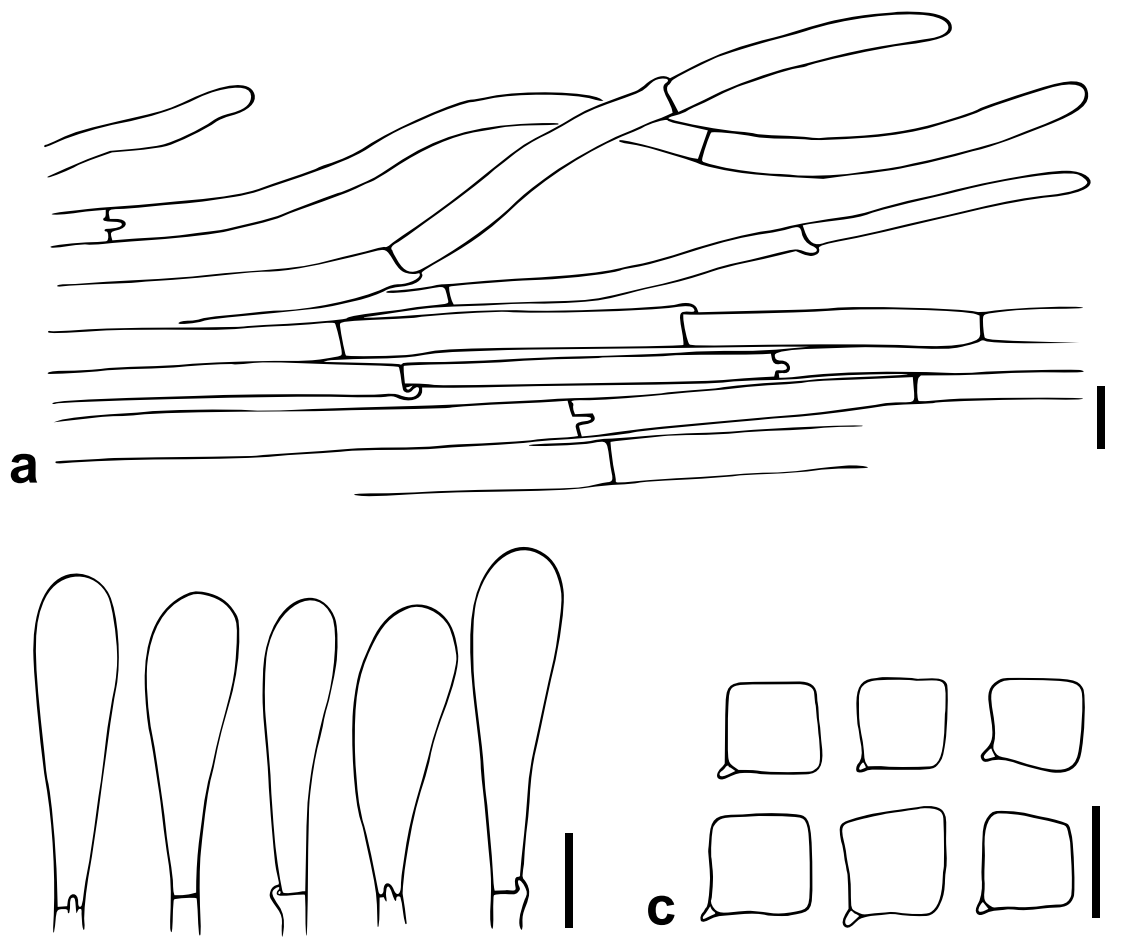

colour, a dark violet-brown serrulatum-type lamellar edge and 2-spored basidia. This set of features is unique within the subgenus Cyanula. No similar species were found in literature.

Entoloma cf. violaceobrunneum Hesler, Beih. Nova Hedwigia 23: 51 (1967), Figs. 41 and 42

三Leptoniella alachuana Murrill, Proc. Fla. Acad. Sci. 7: 117 (1945).

non Entoloma alachuanum Murrill, Mycologia 33: 443 (1941).

Description: Basidiocarps collybioid. Pileus 2.8-3.7 cm diameter, broadly conical when young becoming low convex, somewhat depressed in centre with broad papilla, with straight and even to slightly uneven margin, initially bluish grey, violet-grey to grey $(16 \mathrm{E} 2,23 \mathrm{~B} 1$, 23B2, 23C1, 23C2) and darker bluish grey to violet-grey in the centre (16F2, 23D2, 23D3), bluish and violet tones fading to brownish tones while ageing, with squamulose surface, slightly radially sulcate almost to the centre. Lamellae broadly adnate to emarginate, medium-spaced to rather distant, segmentiform, white, with slightly undulating and concolorous edges. Stipe 5.0-6.0 $\times 0.25-0.30 \mathrm{~cm}$, cylindrical, hollow, dull blue to grey (23A1, 23B1, 23C1), overlaid by whitish, fibrillose floccules. Basal mycelium white, sparse. Odour indistinct, taste not tested.

Basidiospores $9.5-10.2-11.5 \times 7.0-7.7-8.5 \mu \mathrm{m}$, $Q=1.20-1.33-1.45$ ( $n=43$ spores of 2 specimens), hendecahedroid, composed of an adaxial facet (D), a pair of apicoadaxial facets (AD), an apical facet (A), an abaxial facet (B), and three pairs of lateral facets (L1-L3), of which the basal pair (L3) forms a dièdre basal, often with reduced apical facet, heterodiametrical, with 5-6 pronounced angles in outline, weakly pigmented yellowish pink, somewhat thick-walled. Basidia 35-40 × 10.0-13.5 $\mu \mathrm{m}$, clavate to subclavate, hyaline, predominantly 4 -spored, with up to $4.5 \mu \mathrm{m}$ long sterigmata, rarely 2 -spored. Lamellar edge fertile, hymenial cystidia absent. Hymenophoral trama regular, mainly formed by long, cylindrical cells, 70-250×4.0-9.0 $\mu \mathrm{m}$, with some larger cells, $300-350 \times 12.0-18.0 \mu \mathrm{m}$. Pileipellis a cutis with transitions to a trichoderm, with rather wide end cells, 40-125×13.5-27 $\mu \mathrm{m}$, pigment diffusely intracellular as well as in clustering granules and clumps. Stipitipellis a cutis of narrow, cylindrical cells, 30-125 ×(3.0) 4.5-7.0 $\mu \mathrm{m}$. Caulocystidia cylindrical to clavate, $20-55 \times 6.0-8.0 \mu \mathrm{m}$. Oleiferous hyphae present in the trama. Clamp connections absent from any part of the basidiocarp.

Habitat: Basidiocarps found solitary in Quercus-dominated montane forest between 1650 and $1850 \mathrm{~m}$ asl. in Chiriquí, Panama.

Specimens examined: PANAMA. CHIRIQUÍ: near Bajo Boquete, PNVB, Sendero Culebra, N 08 $50^{\prime} 44.5^{\prime \prime}$ $\mathrm{W} 82^{\circ} 28^{\prime} 54.2^{\prime \prime}, 1680 \mathrm{~m}$ asl., montane forest dominated by Quercus spp., 22 June 2017, K. Reschke and J. Rodriguez, B. Wergen, KaiR632 (M); Bajo Boquete, Finca Lerida, N 08 49'10.3" W 82²9'09.2", 1820 m asl., montane forest with Quercus seemannii and other Quercus spp., 13 June 2018, T.A. Hofmann, CME2 (M).

Notes: Entoloma cf. violaceobrunneum is characterised by a bluish grey to violet-grey pileus that soon becomes 
Fig. 46 Basidiocarps of Entoloma cf. indigoferum: a (KaiR509); b (KaiR678)
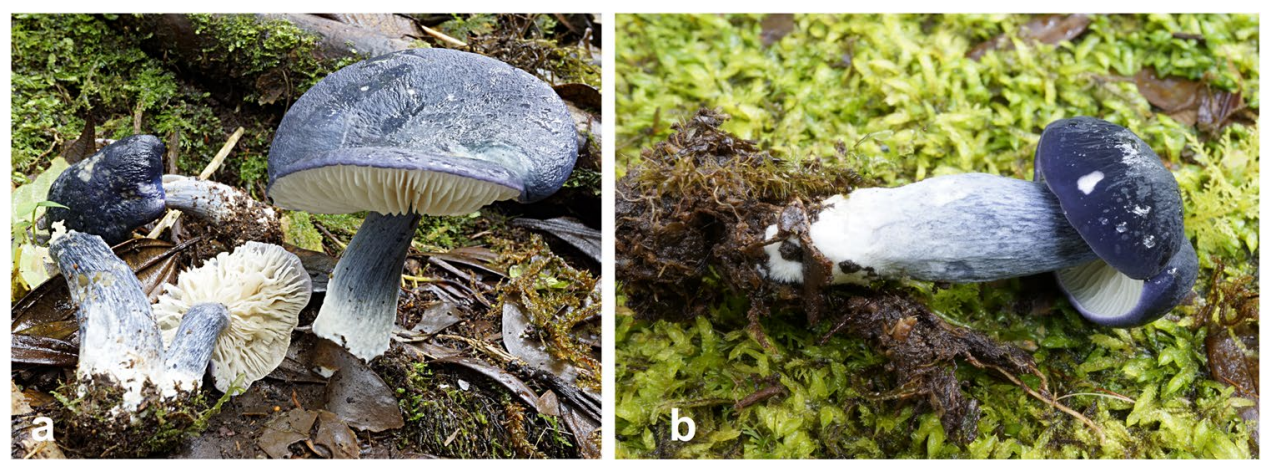

brownish, and the absence of cheilocystidia. It is phylogenetically relatively close to E. griseocyanum with a $p$-distance of $6 \%$ in the ITS2. This species is common in oligotrophic grasslands in Europe and forms basidiocarps with a greyish brown pileus and a blue stipe. Entoloma violaceobrunneum was described by Murrill (1944), as Leptoniella alachuana, from a Quercus forest in Florida. The pileus of this species was described as shining in fresh basidiocarps, which was not the case in the specimens from Panama. However, new collections and DNA sequence data are necessary to resolve the identity of E. violaceobrunneum.

\section{Subgenus Cubospora Karstedt et al. (Fig. 43)}

The subgenus Cubospora was recently erected by Karstedt et al. (2019) for species with a convex to conical pileus, cuboid basidiospores, abundant clamp connections, and often abundant oily contents. They were formerly placed in subgenus Inocephalus Noordel. Most species of the subgenus Cubospora have a tropical to subtropical distribution (Horak 1976, 1977; Romagnesi and Gilles 1979) and few occur in temperate/boreal habitats. Several species of the widely distributed complex of E. quadratum (Berk. \& M.A. Curtis) E. Horak and E. murrayi (Berk. \& M.A. Curtis) Sacc. \& P. Syd. were found in Panama. One of these is described here.

Entoloma aurantiovirescens Reschke, Lotz-Winter, \& Noordel., sp. nov., Figs. 44 and 45

Mykobank number: MB840940.

Typification: PANAMA. CHIRIQUÍ: near Cerro Punta, Entre Ríos, Montaña Azul, PILA, N 08 53'49” W $82^{\circ} 35^{\prime} 03.2^{\prime \prime}, 2330 \mathrm{~m}$ asl., montane forest dominated by Quercus spp., 21 June 2017, K. Reschke, KaiR623, holotype (M).

Etymology: aurantium $($ Latin $)=$ gold, virescent (Latin) = becoming green; refers to colour and staining of the basidiocarps.
Description: Basidiocarps mycenoid. Pileus $2.0-4.0 \mathrm{~cm}$ diameter, conical to broadly conical with distinct, rather acute papilla, with straight, undulating margin, yellowish orange (4A8, 4B8, 4B7), pileal surface appressed fibrillose, almost smooth when wet, not translucently striate when dry, but translucently striate at the margin up to $1 / 3$ of the radius in wet specimens, not hygrophanous, staining greyish green (25C7, 25D7) while ageing or after being touched. Lamellae adnexed, segmentiform to ventricose, medium-spaced to rather distant, slightly transvenose, orange (5A8, 5B8), with uneven, finely fimbriate and somewhat paler edges. Stipe $6.5-10.0 \times 0.25-0.50 \mathrm{~cm}$, cylindrical, slightly broader towards base, solid to stuffed, basically coloured orange-yellow to greyish yellow (4A6, 4A7, 4B6, 4B7), covered by appressed whitish fibrils, which stain greyish green $(25 \mathrm{C} 7,25 \mathrm{D} 7)$ while ageing or touched. Basal mycelium white, with some short rhizomorphs. Odour indistinct, taste not tested.

Basidiospores 8.5-9.5-10.5 ×8.0-9.0-10.0 $\mu \mathrm{m}$, $Q=1.01-1.05-1.13$ ( $n=41$ spores of 2 specimens), cuboid with dièdre basal, with 4 angles in outline, weakly pigmented yellowish pink, somewhat thick-walled. Basidia 48-60×10.0-13.5 $\mu \mathrm{m}$, subclavate, hyaline, 4-spored, sterigmata up to $6.0 \mu \mathrm{m}$ long. Lamellar edge sterile, cheilocystidia clavate, 50-85 (110) ×11.0-18.0, thin walled. Hymenophoral trama regular, formed by rather long, cylindrical cells, 90-350 $\times 6.0-23 \mu \mathrm{m}$. Pileipellis a loose cutis composed of cylindrical cells, $115-250 \times 5.0-17.0 \mu \mathrm{m}$, with intracellular, yellowish pigment. Stipitipellis a cutis composed of long, cylindrical

Fig. 47 Basidiospores of Entoloma cf. indigoferum (KaiR509), bar $=10 \mu \mathrm{m}$

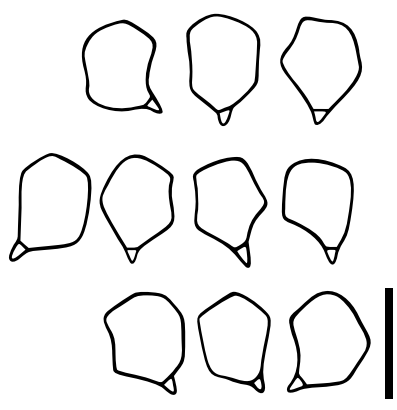


cells, $160-300 \times 5.0-11.0 \mu \mathrm{m}$, with intracellular, yellowish pigment. Caulocystidia absent. Oily contents abundant, especially in hyphae of the lamellae, with yellowish pigment. Clamp connections abundant in all parts of the basidiocarp.

Habitat: Basidiocarps solitary to gregarious in a small group in Quercus-dominated montane forest at about $2300 \mathrm{~m}$ asl. in Chiriquí, Panama.

Additional specimen examined: PANAMA. CHIRIQUÍ: near Cerro Punta, Entre Ríos, Montaña Azul, PILA, about 2300 m asl., montane forest dominated by Quercus spp., 28 July 2015, H. Lotz-Winter, PAN419 (UCH11748, M).

Notes: Entoloma aurantiovirescens belongs to the species complex of E. quadratum and E. murrayi s.l. Its basidiocarps are characterised by salmon colour, a conical, papillate pileus, cuboid spores, and a green staining reaction while ageing or after being touched. The typical habit of basidiocarps of E. quadratum is similar. However, green stains have not been reported for $E$. quadratum and are typical for $E$. virescens and its allies. These differ from E. aurantiovirescens, however, by a blue colour of pileus and stipe and are phylogenetically distant from the E. quadratum complex (Karstedt et al. 2019). A sequence annotated $E$. murrayi is phylogenetically close to those of $E$. aurantiovirescens (Fig. 45), with a p-distance of $4.7-5.0 \%$ in the ITS. However, E. murrayi forms straw yellow basidiocarps which do not stain greenish (Berkeley and Curtis 1859).

\section{Section Calliderma (Romagn.) Noordel}

The section Calliderma in its traditional sense includes species with a hymeniderm to a pallisadic trichoderm and rather robust basidiocarps of various colours (Romagnesi 1974; Romagnesi and Gilles 1979; Noordeloos 2004). Apparently, it is not monophyletic (He et al. 2012). We consider this section here with a narrow concept, only including species with tricholomatoid basidiocarps, blue colours, pileipellis a hymeniderm to trichoderm, iso- to subisodiametrical basidiospores, rather long and narrow basidia, intracellular pigment, and abundant clamp connections. Several species that fit into this concept have been described in recent years, often with a tropical to subtropical distribution (Manimohan et al. 2006; Gates and Noordeloos 2007; Karstedt and Capelari 2010; Aime et al. 2010; Eyssartier et al. 2012; Largent et al. 2014). It is, however, at the moment not possible to give a phylogenetic overview of this group because DNA sequence data of authentical specimens of E. callidermum (Romagn. ex Romagn.) Noordel., the type species of sect. Calliderma, as well as many other species which potentially belong into this section is lacking. The occurrence together with species of Sarcolaeonaceae and Uapaca (Phyllantaceae) in Madagascar (Eyssartier et al. 2012) as well as Podocarpus sp. (Podocarpaceae) in Panama suggests that the species of this clade are ectomycorrhizal.
Entoloma cf. indigoferum (Ellis) Sacc., Sylloge Fungorum 5: 688 (1887), Figs. 46 and 47

三 Agaricus indigoferus Ellis, Bull. Torrey Bot. Club 6: 75 (1876).

Description: Basidiocarps tricholomatoid. Pileus $3.5-7.0 \mathrm{~cm}$ diameter, convex to plane, sometimes irregularly depressed in old basidiocarps, margin incurved in young basidiocarps, long remaining so, becoming straight in old basidiocarps, deep blue (19D8, 19E8), pileal surface velvety, not translucently striate, not hygrophanous. Lamellae emarginate, medium-spaced to rather distant, initially segmentiform, ventricose at expanded pilei, white to cream, becoming pink, with undulating and concolorous edges and transvenose sides. Stipe 3.0-6.0 × 1.0-1.8 cm, cylindrical to clavate or fusiform, solid to somewhat stuffed, deep blue (19D8, 19E8) with white longitudinal striations, appressed fibrillose. Basal mycelium white, cottony with some rhizomorphs in the upper part of the base, densely hirsute from numerous rhizomorphs downwards. Odour indistinct, taste not tested.

Basidiospores $7.0-7.7-8.5 \times 5.5-6.4-7.0 \mu \mathrm{m}$, $Q=1.05-1.20-1.35$ ( $n=51$ spores of 2 specimens), subisodiametrical to broadly heterodiametrical, with predominantly 5 , sometimes 4 , pronounced angles, weakly pigmented yellowish pink, somewhat thick-walled. Basidia (45) 50-60 (70) $\times 10.0-11.5 \mu \mathrm{m}$, clavate, hyaline, 4-spored, sterigmata up to $6.0 \mu \mathrm{m}$ long, with clamp connections. Hymenial cystidia absent. Hymenophoral trama regular, mainly formed by cylindrical cells, $30-100 \times 4.0-7.0 \mu \mathrm{m}$, with some oleiferous hyphae composed of cells of $150-400 \times 5.0-7.0 \mu \mathrm{m}$. Pileipellis a palisadic trichoderm, with blue, intracellular pigment, soluble in $\mathrm{KOH}$. Stipitipellis a cutis composed of rather short, cylindrical cells, $30-60 \times 2.5-6.5 \mu \mathrm{m}$, with subcylindrical, clavate to somewhat lageniform caulocystidia, $15-50 \times 4.5-12.5 \mu \mathrm{m}$. Clamp connections abundant in all parts of the basidiocarp, sometimes degenerated at the base of basidia.

Habitat: Basidiocarps in small groups close to a large Podocarpus sp. in an Alnus acuminata-dominated montane forest at about $2400 \mathrm{~m}$ asl. in Chiriquí, Panama. Possibly ectomycorrhizal with Podocarpus sp.

Specimens examined: PANAMA. CHIRIQUÍ: Cerro Punta, Las Nubes, PILA, Sendero Cascada, N 08 53'58.5" W 82 37'11.1", $2390 \mathrm{~m}$ asl., montane forest dominated by Alnus acuminata, 11 June 2017, K. Reschke and J. Rodríguez, KaiR509 (UCH11739, M); ibid., 27 June 2017, K. Reschke, KaiR678 (M); ibid., 8 July 2015, J. Rodríguez, Y. Castillo, C. Rodríguez, JR59 (M).

Notes: All specimens of this species were collected at the same place and probably belong to the same individual. The basidiocarp of the specimen KaiR678 was immature. This species is characterised by tricholomatoid basidiocarps with a deep blue pileus, rather small basidiospores, and a palisadic 
trichoderm as pileipellis. It is morphologically close or identical to $E$. indigoferum, which was described by Ellis (1876) from a swamp in New Jersey, USA. We have not studied authentical material of this species and molecular sequence data are not available for E. indigoferum. Entoloma callidermum, described by Romagnesi $(1941,1956)$ from Madagascar and Congo, is somewhat similar, but its basidiocarps are slenderer and were found in habitats very different from the one in Panama.

\section{Discussion}

The investigation of species of Entoloma from Panama revealed 17 species new to science; one species could be identified with certainty, and two further species are presented with uncertain identifications. Further specimens representing more than 30 additional species were not thoroughly studied due to limited material. Further fieldwork and investigation of specimens will increase the number of species known for Panama and will lead to many further species new to science.

Most species recorded for Panama belong to the subgenera Cyanula, Entoloma, Alboleptonia, and Nolanea and thereby show a pattern similar to Entoloma species diversity in temperate zones. Species of the section Calliderma as well as the subgenera Cubospora and Inocephalus are unknown from European temperate to boreal regions, but they are present in North America (Hesler 1967; Horak 1976; Largent 1994; Karstedt et al. 2019). This result is not surprising because most collections were made in montane locations around $2000 \mathrm{~m}$ asl. with temperatures similar to subtropical or temperate climate. However, such comparisons based on infrageneric groups of Entoloma are generally difficult to make at this moment, as the infrageneric classification of Entoloma is changing and the position of a large number of species needs to be reassessed. Two specimens representing two species of the subgenus Cyanula were found in lowland habitats at 40 and $120 \mathrm{~m}$ asl., respectively. Thereby, this subgenus is not only the most species rich but also the one with the most widely distributed species in the present study. Species of this subgenus have been reported northwards up to arctic habitats (Noordeloos 1984) and southwards to temperate regions in the southern hemisphere (Horak 2008; Noordeloos and Gates 2012).

The results of fieldwork in 2017 and 2018 show that primary forests in the mountains of Chiriquí harbour a higher diversity and abundance of species of Entoloma than disturbed lowland vegetation. This difference may be explained by different elevations or the degrees of disturbance. In Europe, the diversity and abundance of certain grassland fungi, like Entoloma spp., is used to evaluate the value of locations for nature conservation (McHugh et al. 2001; Newton et al. 2003; Griffith et al.
2013). Horak (1978) reported that in South American virgin forests, Entoloma can outnumber all other agaric genera in species richness at certain times of the year. Diversity of Entoloma spp. may be a promising marker for habitats and locations valuable for nature conservation; however, studies that would examine the possibility of a relationship between disturbance and diversity are needed.

\section{Shape of basidiospores}

Polyhedroid basidiospores are a unique and striking feature of Entoloma spp. The usefulness of their shape and base type for infrageneric classification has been disputed. Pegler and Young (1979) reported a "precise arrangement and order of development" of the facets for a given species. Kühner and Boursier (1929), however, stated that the variability of basidiospore shape rises together with the complexity of the spores. The present study confirmed the latter because a certain variability of the arrangement at the abaxial side was observed as well as there being two species, for which a general basidiospore type could not be determined. In addition to that, Co-David et al. (2009) and Baroni et al. (2011) presented basidiospores with irregular and incomplete facets. Therefore, a fixed number of facets can most likely not be determined for the basidiospores of every species. A possibility to describe such spores may be the use of ranges of numbers of facets, like $x$-hedroid to $(x+a)$-hedroid.

Romagnesi (1941) as well as Pegler and Young (1979) suggested that "simple" basidiospore shapes, like prismatic and cuboid ones, are more primitive than those with many facets. This is contradicted by the fact that molecular phylogenies consistently demonstrate that species with prismatic and cuboid basidiospores are located in several clades, but not in the basal one (Co-David et al. 2009; Karstedt et al. 2019). Considering the relatively large fraction of species with irregular and bumpy basidiospores in the basal clade (CoDavid et al. 2009; Baroni et al. 2011), it is more likely that the basidiospores of the ancestral species of Entoloma had a rather rhodocyboid morphology, as proposed by Mazzer (1976). Cuboid and prismatic basidiospores are most likely derived from "complex" basidiospores through reduction of the number of facets. Entoloma conferendum is nested between species with heterodiametrical hepta- to hendecahedroid basidiospores in subg. Nolanea. Thus, its prismatic basidiospores are most likely derived from these basidiospores, similar to the frequently reduced basidiospores in E. transitionisporum. Regarding the small difference in ITS sequences between $E$. paraconferendum and $E$. conferen$d u m$, such reduction-driven evolution can obviously happen relatively rapidly. The cuboid basidiospore with dièdre basal is shared by all members of the subgenera Cubospora and Cuboeccilia (Karstedt et al. 2019). It remains unknown if this shape evolved more than once. Both subgenera, Cyanula and 
Nolanea, share species with hendecahedroid basidiospores with dièdre basal. Whether this spore type has evolved once or several times is unclear. Diverse basidiospore shapes in species of the subgenus Alboleptonia show that the shape of basidiospores in Entoloma spp. does not reliably reflect systematic relationships. The basidiospore type should thus only carefully be used for infrageneric classification.

In both the subgenera, Entoloma and Nolanea, basidiospores with different base types occur. This is in accordance with the observations of Pegler and Young (1979). Thus, the base type cannot be used as a major character to define subgenera in Entoloma. However, it is possible that this character is consistent in some subgenera or may be useful in subclades at lower rank. More species have to be analysed to assess the phylogenetic value of this character.

\section{Preliminary key to Entoloma spp. in Panama}

Species with comment "not covered" include the one species already reported for Panama and macromorphologically conspicuous species which were not studied in detail.

1 Basidiocarps mycenoid 2

$1 *$ Basidiocarps collybioid to omphalinoid or tricholomatoid 10

2 Basidiospores cuboid

3

2* Basidiospores not cuboid, predominantly with more than 4 angles in outline ... 5 3 Basidiocarps bright yellow, with pronounced papi lla........................................ E. aff. murrayi (not covered) $3^{*}$ Basidiocarps yellowish orange to red-orange, papillate or not ... 4 4 Basidiocarps yellowish orange, staining green with age or upon touch ................................... E. aurantiovirescens 4* Basidiocarps orange to red-orange E. aff. quadratum (not covered) 5 Basidiocarps initially white, often staining yellowish; pileal surface fibrillose .... .. 17

$5^{*}$ Basidiocarps coloured, at least the pileus ..................... 6 6 Stipe with superficial white or whitish fibrils ................ 9 6* Stipe polished or finely pruinose, fibrillose only when contorted

7 Lamellae brownish, pileus rather uniformly brown E. aff. clandestinum (not covered) 7* Lamellae greyish white, pileus paler, yellowish brown

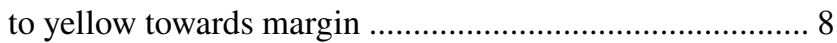
8 Pileus translucently striate at about $1 / 2$ the radius ....... E. flavoconicum 8* Pileus translucently striate almost to the centre E. belouvense 9 Basidiospores 7.5-10.5 $\mu \mathrm{m}$ long, often subcruciform ...... E. transitionisporum
9* Basidiospores 8.5-12 $\mu \mathrm{m}$ long, rarely subcruciform ... E. paraconferendum 10 Basidiocarps tricholomatoid; pileus deep blue, surface velvety E. cf. indigoferum

$10 *$ Basidiocarps tricholomatoid without blue colour or collybioid to omphalinoid ...... .11

11 Basidiocarps tricholomatoid to collybioid; pileal surface smooth, sometimes rugulose or with pruina .................... 12 $11^{*}$ Basidiocarps collybioid to omphalinoid; pileal surface appressed fibrillose to squamulose ....................................... 16 12 Basidiocarps collybioid/omphalinoid to tricholomatoid, rather thin-fleshed; pileus usually translucently striate ... 13

12* Basidiocarps tricholomatoid, robust; pileus not or only slightly translucently striate ..................................... 14 13 Pileus translucently striate almost to the centre; stipe concolorous with pileus ............................ cremeostriatum 13* Pileus translucently striate up to half the radius; stipe white E. nubooccultatum 14 Pileus surface glabrous, somewhat rugulose; pigment intracellular ....................................... E. brunneorugulosum 14* Pileus surface not rugulose, often pruinose; pigment

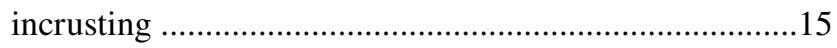
15 Pileus surface pruinose, not hygrophanous; lamellae crowded ....................................................... E. pruinosum 15* Pileus surface sometimes pruinose, hygrophanous; lamellae medium-spaced ......................... . mediorobustum 16 Basidiocarps initially white, often staining yellowish; pileal surface fibrillose .................................................... 17 16* Basidiocarps coloured ............................................. 20 17 Basidiospores small, $6.5-9.0 \times 5.5-7.5 \mu \mathrm{m}$; cheilocystidia long cylindrical-capitate; odour and taste farinaceous E. cylindrocapitatum (not covered) $17^{*}$ Basidiospores larger; cheilocystidia different; odour and taste not farinaceous ........................................................ 18 18 Basidiospores 9.0-12.0 $\mu \mathrm{m}$ long, with 6-9 angles in outline .................................................... E. confusissimum 18* Basidiospores 7.0-10.5 $\mu \mathrm{m}$ long, with 4-6 angles in

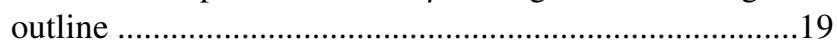

19 Basidiospores $7.0-10.0 \times 6.0-8.0 \mu \mathrm{m}$, with $4-5$ angles in outline, often rhomboid to subcruciform; cheilocystidia 5.0-13.0 $\mu \mathrm{m}$ wide ...................................... E. nubilosilvae 19* Basidiospores $8.5-10.5 \times 6.5-8.5 \mu \mathrm{m}$, with $5-6$ angles in outline, some rhomboid to cruciform; cheilocystidia $10.0-19.0 \mu \mathrm{m}$ wide .................. E. amistadosericellum 20 Lamellar edge dark blue or dark violet-brown, with ser-

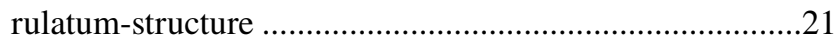
$20^{*}$ Lamellar edge concolorous with faces, without serrulatum-structure ......................................................... 22 21 Pileus violet-brown, up to $1 \mathrm{~cm}$ diam.; lamellar edge violet-brown ........................................ E. microserrulatum $21 *$ Pileus blue, up to $2 \mathrm{~cm}$ diam.; lamellar edge dark blue E. caeruleomarginatum 
22 Basidiocarps bright yellow-green

E. aff. necopinatum (not covered)

$22 *$ Basidiocarps with yellow, brown, grey, blue or violet colours 23

23 Basidiocarps without blue or violet colour, pileus yellowish brown E. mellosquamulosum 23* Basidiocarps with blue or violet colour on stipe and/ or pileus

24 Both, stipe and pileus with blue or violet colour ........ 25

$24 *$ Either stipe or pileus with blue or violet colour ........ 27

25 Pileus bluish grey to violet-grey; stipe dull blue to grey, with white fibrillose floccules

E. cf. violaceobrunneum

$25^{*}$ Pileus and stipe blue

26

26 Pileus blackish blue, fine squamulose; lamellar edge sterile, cheilocystidia $+/$ - fusiform E. arcanum

26* Pileus greyish blue, with rather coarse squamules; lamellar edge heterogeneous, with scattered, broadly clavate to cylindrical cheilocystidia ...... E. griseocaeruleum 27 Stipe bright blue; pileus pale yellow-brown

E. aff. sodale (not covered)

$27 *$ Stipe white; pileus bluish grey to violet-grey

E. cf. violaceobrunneum

Acknowledgements We thank Hermine Lotz-Winter and Felix Hampe for invaluable support. Kenneth Barrera, Christian Fischer, Eike Heinemann, Javier de León, Ruben Valdés, and Björn Wergen are thanked for support in the field and for contributing specimens. Sofia Cáceres is thanked for support in the field and the permission of the use of a picture. Gunnhild Marthinsen and Katriina Bendiksen are thanked for several sequences of the Norwegian Barcode of Life project. We thank Olga Morozova, Ellen Larsson, Irmgard Krisai-Greilhuber, and László Nagy for the permission to use their sequences. Laura GuzmánDávalos and Diégo Montañez, Øyvind Weholt, Jostein Lorås, Matthias Dondl, and Guillaume Eyssartier are thanked for the permission to use sequences of their specimens. Curators and staff of C, L, LE, G, IBUG, O, PC, PDD, and WU are acknowledged for organising loans. Karl-Heinz Rexer is thanked for a piece of DSS and information about SEM preparation. Manlio Cuevas is thanked for organisation and logistics of field trips as well as support in the field. Fernanda Karstedt is thanked for literature. Jesko Kleine is thanked for help with Latin names. Orlando Cáceres is thanked for his support during permit procedures with the Environmental Ministry of Panama (MiAmbiente, corresponding collection permits SE/APH-4-14, SE/APH-2-15, SE/ APH-2-16, SE/AP-17-16, SE/P-13-17, SE/PH-4-18, and export permits SEX/H-4-15, SEX/H-4-17, SEX/H-5-17, SEX/H-2-18). An anonymous reviewer is thanked for valuable comments and suggestions.

Author contribution The study was initially designed by Kai Reschke and Meike Piepenbring. Tina Hofmann, Machiel Noordeloos, and Bálint Dima contributed to the conception. Kai Reschke, Cathrin Manz, José Rodríguez, and Tina Hofmann collected specimens. Kai Reschke did the morphological analyses. Sequencing and molecular phylogenetic analyses were done by Kai Reschke and Bálint Dima. The first draft of the manuscript was written by Kai Reschke and Machiel Noordeloos and all authors commented on previous versions of the manuscript. All authors read and approved the final manuscript.
Funding Open Access funding enabled and organized by Projekt DEAL. The work of Bálint Dima was supported by the ELTE Thematic Excellence Programme 2020 financed by the National Research, Development and Innovation Office (TKP2020-IKA-05).

Data availability Specimens are deposited in M and UCH. DNA sequences have been submitted to GenBank. Alignments can be obtained from the first author.

Code availability Not applicable.

\section{Declarations}

Conflict of interest The authors declare no competing interests.

Open Access This article is licensed under a Creative Commons Attribution 4.0 International License, which permits use, sharing, adaptation, distribution and reproduction in any medium or format, as long as you give appropriate credit to the original author(s) and the source, provide a link to the Creative Commons licence, and indicate if changes were made. The images or other third party material in this article are included in the article's Creative Commons licence, unless indicated otherwise in a credit line to the material. If material is not included in the article's Creative Commons licence and your intended use is not permitted by statutory regulation or exceeds the permitted use, you will need to obtain permission directly from the copyright holder. To view a copy of this licence, visit http://creativecommons.org/licenses/by/4.0/.

\section{References}

Agerer R (1997) Entoloma sinuatum (Bull.: Fr.) Kummer + Salix spec. Descr Ectomyc 2:13-18

Aime MC, Largent DL, Henkel TW, Baroni TJ (2010) The Entolomataceae of the Pakaraima Mountains of Guyana IV: new species of Calliderma, Paraeccilia and Trichopilus. Mycologia 102:633649. https://doi.org/10.3852/09-162

Antibus RK, Croxdale JG, Miller OK, Linkins AE (1981) Ectomycorrhizal fungi of Salix rotundifolia III. Resynthesized mycorrhizal complexes and their surface phosphatase activities. Can J Bot 59:2458-2465. https://doi.org/10.1139/b81-297

Baroni T, Hofstetter V, Largent DL, Vilgalys R (2011) Entocybe is proposed as a new genus in the Entolomataceae (Agaricomycetes, Basidiomycota) based on morphological and molecular evidence. N Am Fungi 6:1-19. https://doi.org/10.2509/naf2011.006.012

Baroni TJ, Halling RE (2000) Some Entolomataceae (Agaricales) from Costa Rica. Brittonia 52:121-135

Baroni TJ, Lodge DJ (1998) Alboleptonia from the Greater Antilles. Mycologia 90:680-696. https://doi.org/10.2307/3761227

Berkeley MJ, Curtis MA (1859) On new species of North American fungi. Ann Mag Nat Hist 3:284-296

Bjorbækmo MFM, Carlsen T, Brysting A et al (2010) High diversity of root associated fungi in both alpine and arctic Dryas octopetala. BMC Plant Biol 10:244. https://doi.org/10.1186/1471-2229-10-244

Brandrud TE, Bendiksen E, Jordal JB et al (2018) Entoloma species of the rhodopolioid clade (subgenus Entoloma; Tricholomatinae, Basidiomycota) in Norway. Agarica 38:21-46

Co-David D, Langeveld D, Noordeloos ME (2009) Molecular phylogeny and spore evolution of Entolomataceae. Persoonia 23:147176. https://doi.org/10.3767/003158509X480944

Coimbra VRM (2014) Checklist of Central and South American Agaricales (Basidiomycota) I: Entolomataceae. Mycosphere 5:475-487 
Coimbra VRM, Wartchow F, Gibertoni TB (2013) Studies on Entoloma (Agaricales, Basidiomycota) in the Atlantic Forest, Northeast Brazil. Nova Hedwigia 97:139-157. https://doi.org/10.1127/ 0029-5035/2013/0100

Crous PW, Carnegie AJ, Wingfield MJ et al (2019) Fungal Planet description sheets: 868-950. Persoonia 42:291-473

Crous PW, Cowan DA, Maggs-Kölling G et al (2021) Fungal Planet description sheets: 1182-1283. Persoonia 46:313-528

Crous PW, Wingfield MJ, Burgess TI et al (2018) Fungal planet description sheets: 716-784. Persoonia 40:240-393

Crous PW, Wingfield MJ, Burgess TI et al (2017) Fungal planet description sheets: 625-715. Persoonia 39:270-467. https:// doi.org/10.3767/persoonia.2017.39.11

Dennis RWG (1953) Les Agaricales de l'Ile de la Trinité. Rhodosporae-Ochrosporae. Bull Soc Mycol Fr 69:145-198

Dentinger BTM, Didukh MY, Moncalvo J-M (2011) Comparing COI and ITS as DNA barcode markers for mushrooms and allies (Agaricomycotina). PLoS ONE 6:e25081. https://doi.org/10. 1371/journal.pone.0025081

Dima B, Brandrud TE, Corriol G et al (2021) Fungal systematics and evolution: FUSE 7. Sydowia 73:271-340. https://doi.org/ 10.12905/0380.sydowia73-2021-0271

Ellis JB (1876) New fungi found at New Field, New Jersey (Continued). Bull Torrey Bot Club 6:75-77

Erbar C (1995) On the floral development of Sphenoclea zeylanica (Sphenocleaceae, Campanulales)-SEM-investigations on herbarium material. Bot Jahrb Syst 117:469-483

Eyssartier G, Randrianjohany É, Buyck B (2012) Trois Entolomes (Entolomatales, Basidiomycota) à épicutis Hyméniforme de la Réserve Spéciale d'Ambohitantely, Madagascar. Cryptogam, Mycol 33:157166. https://doi.org/10.7872/crym.v33.iss2.2012.157

Felsenstein J (1985) Confidence limits on phylogenies: an approach using the bootstrap. Evolution 39:783-791. https://doi.org/10. $2307 / 2408678$

Franco-Molano AE, Uribe-Calle E (2000) Hongos Agaricales y Boletales de Colombia. Biota Colombiana 1:25-43

Gardes M, Bruns TD (1993) ITS primers with enhanced specificity for basidiomycetes-application to the identification of mycorrhizae and rusts. Mol Ecol 2:113-118. https://doi.org/10. 1111/j.1365-294X.1993.tb00005.x

Gates GM, Noordeloos M (2007) Preliminary studies in the genus Entoloma in Tasmania - I. Persoonia 19:157-226

Geml J, Timling I, Robinson CH et al (2012) An arctic community of symbiotic fungi assembled by long-distance dispersers: phylogenetic diversity of ectomycorrhizal basidiomycetes in Svalbard based on soil and sporocarp DNA. J Biogeogr 39:74-88

Griffith GW, Camarra JGP, Holden EM et al (2013) The international conservation importance of Welsh "waxcap" grasslands. Mycosphere Online 4:969-984

Halling RE, Mueller GM (2005) Common mushrooms of the Talamanca Mountains, Costa Rica. New York Botanical Garden, New York

Hay CR, Thorn RG, Jacobs CR (2018) Taxonomic survey of Agaricomycetes (Fungi: Basidiomycota) in Ontario tallgrass prairies determined by fruiting body and soil rDNA sampling. Can Field Nat 132:407-424

He X-L, Horak E, Li T-H et al (2015a) Two new cuboid-spored species of Entoloma s. 1. (Agaricales, Entolomataceae) from Southern China. Cryptogam, Mycol 36:237-249. https://doi. org/10.7872/crym/v36.iss2.2015.237

He X-L, Horak E, Wang D et al (2019) Descriptions of five new species in Entoloma subgenus Claudopus from China, with molecular phylogeny of Entoloma sl. MycoKeys 61:1

He X-L, Li T-H, Jiang Z-D, Shen Y-H (2012) Four new species of Entoloma s.l. (Agaricales) from southern China. Mycol Progr 11:915-925. https://doi.org/10.1007/s11557-012-0807-0
He X-L, Li T-H, Xi P-G et al (2013) Phylogeny of Entoloma s.l. subgenus Pouzarella, with descriptions of five new species from China. Fungal Divers 58:227-243. https://doi.org/10. 1007/s 13225-012-0212-7

He X-L, Peng W-H, Gan B-C (2015b) Morphological and molecular evidence for a new species in Entoloma subgenus Claudopus from Sichuan Province, southwest China. Mycoscience 56:326-331. https://doi.org/10.1016/j.myc.2014.10.001

He X-L, Wang D, Peng W-H, Gan B-C (2017) Two new Entoloma s.L. species with serrulatum-type lamellar edge from Changbai Mountains, Northeast China. Mycol Progr 16:761-768. https:// doi.org/10.1007/s11557-017-1313-1

He X-L, Ye X-J, Li T-H et al (2015) New and noteworthy species of white Entoloma (Agaricales, Entolomataceae) in China. Phytotaxa 205:99-110. https://doi.org/10.11646/phytotaxa.205.2.3

Hesler LR (1967) Entoloma in southeastern North America. J. Cramer, Leutershausen

Hofmann TA, Piepenbring M (2021) Checklist of fungi in Panama 2020. Dataset. The Smithsonian Institution. https://doi.org/10. 25573/data.13341605.v2

Hongo T (1957) Notes on Japanese larger fungi (11). J Jap Bot $32: 208-214$

Hooghiemstra H (2006) Immigration of oak into Northern South America: a paleo-ecological document. In: Kappelle M (ed) Ecology and conservation of neotropical montane oak forests. Springer, Berlin, Heidelberg, pp 17-28

Horak E (1978) Entoloma in South America. I. Sydowia 30:40-111 Horak E (1982) Entoloma in South America. II. Sydowia 35:75-99

Horak E (2008) Agaricales of New Zealand 1: Pluteaceae-Entolomataceae. Fungal Diversity Press, Hong Kong

Horak E (1980) Entoloma (Agaricales) in Indomalaya and Australasia. J. Cramer, Vaduz

Horak E (1976) On cuboid spored species of Entoloma (Agaricales). Sydowia 28:171-236

Horak E (1977) Additions to "On cuboid-spored species of Entoloma". Sydowia 29:289-299

Janssen JAM, Rodwell JS, García Criado M et al (2016) European red list of habitats part 2. Terrestrial and freshwater habitats. European Commission

Kappelle M, Cleef AM, Chaverri A (1992) Phytogeography of Talamanca montane Quercus forests, Costa Rica. J Biogeogr 19:299-315. https://doi.org/10.2307/2845453

Karich A, Kellner H, Schmidt M, Ullrich R (2015) Ein bemerkenswertes Mykotop im Zittauer Gebirge mit Microglossum rufescens als Erstnachweis für Deutschland. Boletus 36:151-163

Karstedt F, Bergemann SE, Capelari M (2020) Five Nolanea spp. nov. from Brazil. Mycotaxon 135:589-612

Karstedt F, Capelari M (2013) Inocephalus (Entolomataceae, Agaricales) from São Paulo State, Brazil. Nova Hedwigia 96:279-308

Karstedt F, Capelari M (2010) New species and new combinations of Calliderma (Entolomataceae, Agaricales). Mycologia 102:163173. https://doi.org/10.3852/09-019

Karstedt F, Capelari M, Baroni TJ et al (2019) Phylogenetic and morphological analyses of species of the Entolomataceae (Agaricales, Basidiomycota) with cuboid basidiospores. Phytotaxa 391:1-27. https://doi.org/10.11646/phytotaxa.391.1.1

Katoh K, Standley DM (2013) MAFFT Multiple Sequence Alignment Software Version 7: improvements in performance and usability. Mol Biol Evol 30:772-780. https://doi.org/10.1093/molbev/mst010

Kim CS, Jo JW, Kwag Y-N et al (2015) Mushroom flora of Ulleunggun and a newly recorded Bovista species in the Republic of Korea. Mycobiology 43:239-257

Kinoshita A, Sasaki H, Nara K (2012) Multiple origins of sequestrate basidiomes within Entoloma inferred from molecular phylogenetic analyses. Fungal Biol 116:1250-1262. https://doi.org/10. 1016/j.funbio.2012.09.006 
Koch JA, Fischer A, Manz C, Rexer K-H (2021) Rehydration of dried mushroom specimens with Aerosol® OT for scanning electron microscopy. Mycol Progr 20:747-754. https://doi.org/10.1007/ s11557-021-01697-6

Kokkonen K (2015) A survey of boreal Entoloma with emphasis on the subgenus Rhodopolia. Mycol Progr 14:116. https://doi.org/ 10.1007/s11557-015-1135-y

Kondo K, Nakamura K, Ishigaki T et al (2017) Molecular phylogenetic analysis of new Entoloma rhodopolium -related species in Japan and its identification method using PCR-RFLP. Sci Rep 7:14942. https://doi.org/10.1038/s41598-017-14466-x

Kornerup A, Wanscher JH (1967) Methuen handbook of colour, 2nd. Methuen \& Co., Ltd., London

Kühner R, Boursier J (1929) La forme des spores chez les Agarics rhodo-goniosporés. Bull Soc Mycol Fr 45:264-277

Kühner R, Romagnesi H (1953) Flore analytique des champignons superieurs. Masson, Paris

Kühner R, Romagnesi H (1954) Espèces nouvelles ou critiques de Rhodophyllus. Revue De Mycologie 19:3-46

Largent DL (1994) Entolomatoid fungi of the western United States and Alaska. Mad River Press, Eureka, California

Largent DL, Aime MC, Henkel TW, Baroni TJ (2008) The Entolomataceae of the Pakaraima Mountains of Guyana 2: Inocephalus dragonosporus comb. nov. Mycotaxon 105:185

Largent DL, Benedict RG (1970) Studies in the rhodophylloid fungi II: Alboleptonia, a new genus. Mycologia 62:437-452. https:// doi.org/10.2307/3757517

Largent DL, Bergemann SE, Abell-Davis SE (2014) Entoloma species from New South Wales and northeastern Queensland, Australia. Mycotaxon 129:329-359. https://doi.org/10.5248/129.329

Largent DL, Henkel TW, Aime MC, Baroni TJ (2008b) The Entolomataceae of the Pakaraima Mountains of Guyana I: four new species of Entoloma s. str. Mycologia 100:132-140. https://doi. org/10.3852/mycologia.100.1.132

Largent DL, Henkel TW, Siegel N et al (2019) New species of Entolomataceae from Cameroon. FUSE 5:151-167

Largent DL, Kluting KL, Anderson NM, Bergemann SE (2016) New leptonioid species from New South Wales and northeastern Queensland, Australia. Mycotaxon 131:153-176

Larsson A (2014) AliView: a fast and lightweight alignment viewer and editor for large datasets. Bioinformatics 30:3276-3278. https:// doi.org/10.1093/bioinformatics/btu531

Loree MAJ, Lumme I, Niemi M, Tormala T (1989) Inoculation of willows (Salix spp.) with ectomycorrhizal fungi on mined boreal peatland. Plant Soil 116:229-238

Manimohan P, Leelavathy KM (1988) Two new species of Alboleptonia (Agaricales, Entolomataceae) from southern India. Trans Br Mycol Soc 91:710-712

Manimohan P, Noordeloos ME, Dhanya AM (2006) Studies on the genus Entoloma (Basidiomycetes, Agaricales) in Kerala State, India. Persoonia 19:45-93

Manimohan P, Vijaya Joseph A, Leelavathy KM (1995) The genus Entoloma in Kerala state, India. Mycol Res 99:1083-1097. https://doi.org/10.1016/S0953-7562(09)80777-6

Matheny PB (2005) Improving phylogenetic inference of mushrooms with RPB1 and RPB2 nucleotide sequences (Inocybe; Agaricales). Mol Phylogenet Evol 35:1-20. https://doi.org/10.1016/j. ympev.2004.11.014

Mazzer SJ (1976) A monographic study of the genus Pouzarella: a new genus in the Rhodophyllaceae, Agaricales, Basidiomycetes. J. Cramer, Vaduz

McHugh R, Mitchel D, Wright M, Anderson R (2001) The fungi of Irish grasslands and their value for nature conservation. Biol Environ 101B:225-243

Montañez D, Noordeloos ME, Rodríguez O et al (2016) Notes on the genus Entoloma (Basidiomycota, Agaricales) in two volcanic areas of Jalisco, Mexico. Phytotaxa 277:211-236. https://doi. org/10.11646/phytotaxa.277.3.1

Morgado LN, Noordeloos ME, Lamoureux Y, Geml J (2013) Multigene phylogenetic analyses reveal species limits, phylogeographic patterns, and evolutionary histories of key morphological traits in Entoloma (Agaricales, Basidiomycota). Persoonia 31:159-178. https://doi.org/10.3767/003158513X673521

Morozova OV, Noordeloos ME, Popov ES, Alexandrova AV (2017) Three new species within the genus Entoloma (Basidiomycota, Agaricales) with clamped basidia and a serrulatum-type lamellae edge, and their phylogenetic position. Mycol Progr 1-12.https:// doi.org/10.1007/s11557-017-1364-3

Morozova OV, Noordeloos ME, Vila J (2014a) Entoloma subgenus Leptonia in boreal-temperate Eurasia: towards a phylogenetic species concept. Persoonia 32:141-169. https://doi.org/10.3767/ 003158514 X681774

Morozova OV, Voronina EY, Arslanov SN (2014b) Entoloma piceinum, a new lignicolous species of Entolomataceae (Agaricales) from the European Russia. Nov Sist Nizs Rast 48:181-187

Murrill WA (1944) New Florida fungi. Proc Fla Acad Sci 7:107-127

Murrill WA (1917) North American Flora. Vol. 10. Part 2. New York Botanical Garden

Myers N, Mittermeier RA, Mittermeier CG et al (2000) Biodiversity hotspots for conservation priorities. Nature 403:853-858. https:// doi.org/10.1038/35002501

Newton AC, Davy LM, Holden E et al (2003) Status, distribution and definition of mycologically important grasslands in Scotland. Biol Conservat 111:11-23. https://doi.org/10.1016/S00063207(02)00243-4

Noordeloos ME (1981) Introduction to the taxonomy of the genus Entoloma sensu lato (Agaricales). Persoonia 11:121-151

Noordeloos ME (1992) Entoloma s.1., Fungi Europaei 5. Libreria editrice Giovanna Biella, Saronno, Italy

Noordeloos ME (2004) Entoloma s.l., Fungi Europaei, 5A. Edizioni Candusso, Alassio, Italy

Noordeloos ME (1982) Notes on Entoloma. New and rare species of Entoloma from Scandinavia. New names and combinations. Nord J Bot 2:155-162. https://doi.org/10.1111/j.1756-1051.1982.tb01176.x

Noordeloos ME (1988) Entoloma in North America. Gustav Fischer Verlag, Stuttgart, New York

Noordeloos ME (1980) Entoloma subgenus Nolanea in the Netherlands and adjacent regions with a reconnaissance of its remaining taxa in Europe. Persoonia 10:427-534

Noordeloos ME (1984) Entolomataceae (Agaricales, Basidiumycetes) in Greenland-I. The Genus Entoloma. Persoonia 12:263-305

Noordeloos ME (1987) Entoloma (Agaricales) in Europe. J. Cramer, Berlin-Stuttgart

Noordeloos ME, Gates GM (2012) The Entolomataceae of Tasmania. Springer Science \& Business Media

Noordeloos ME, Hausknecht A (2007) The genus Entoloma (Basidiomycetes, Agaricales) of the Mascarenes and Seychelles. Fungal Divers 27:111-144

Noordeloos ME, Hausknecht A (2016) Die Gattung Entoloma von den Maskarenen und Seychellen. Z Mykol 82:295-347

Noordeloos ME, Hausknecht A (2009) New and interesting Entoloma species from Central Europe. Österr Z Pilzk 18:169-182

Noordeloos ME, Hausknecht A (2002) Weitere neue Entoloma-Arten aus Südeuropa. Österr Z Pilzk 11:117-131

Noordeloos ME, Lorås JA, Eidissen SE et al (2021) Three new Entoloma species of the Cyanula clade from (sub)alpine habitats in Northern Norway and Sweden. Sydowia 73:185-196. https://doi. org/10.12905/0380.sydowia73-2020-0185

Noordeloos ME, Weholt $\emptyset$, Bendiksen E et al (2018) Entoloma aurorae-borealis sp. nov. and three rare Entoloma species in the Sinuatum clade (subg. Entoloma) from northern Europe. Sydowia 70:199-210 
O’Donnell K (1992) Ribosomal DNA internal transcribed spacers are highly divergent in the phytopathogenic ascomycete Fusarium sambucinum (Gibberella pulicaris). Curr Genet 22:213-220

Osorio CAP, Osorio JP (2016) Primer reporte de Entoloma hochstetteri (Entolomataceae, Agaricales, Basidiomycota) para el departamento de Santander, Colombia. Revista Biodiversidad Neotropical 6:126-130. https://doi.org/10.18636/bioneotropical.v6i2.181

Ovrebo CL, Baroni TJ (2007) New taxa of Tricholomataceae and Entolomataceae (Agaricales) from Central America. Fungal Divers 27:157-170

Papp V, Dima B (2018) New systematic position of Aurantiporus alborubescens (Meruliaceae, Basidiomycota), a threatened oldgrowth forest polypore. Mycol Progress 17:319-332. https://doi. org/10.1007/s11557-017-1356-3

Pegler DN, Young TWK (1979) Spore form and phylogeny of Entolomataceae (Agaricales). Beih Sydowia 8:290-303

Raj KNA, Latha KPD, Kumar TKA, Manimohan P (2014) A new species of Entoloma from India. Mycoscience 55:400-404. https:// doi.org/10.1016/j.myc.2014.01.003

Rambaut A (2014) FigTree v1. 4. University of Edinburgh, Edinburgh, UK. Version v1.4.2URL http://tree.bio.ed.ac.uk/software/figtree/

Romagnesi H (1974) Essai d'une classification des Rhodophylles. Bull Mens Soc Linn Lyon 43:325-332. https://doi.org/10.3406/linly. 1974.10142

Romagnesi H (1941) Les Rhodophylles de Madagascar:(Entoloma, Nolanea, Leptonia, Eccilia, Claudopus). Laboratoire de cryptogamie du Museum national d'histoire naturelle, Paris

Romagnesi H (1956) Les Rhodophylles du Congo belge d'apres les recoltes de $\mathrm{M}^{\wedge} \mathrm{me}$ Goossens-Fontana. Bull Jard Bot Brux 26:137-182

Romagnesi H, Gilles G (1979) Les Rhodophylles des forêts côtières du Gabon et de la Côte d'Ivoire: avec une introduction générale sur la taxinomie du genre. Cramer
Stamatakis A (2014) RAxML version 8: a tool for phylogenetic analysis and post-analysis of large phylogenies. Bioinformatics 30:1312-1313. https://doi.org/10.1093/bioinformatics/btu033

Stevenson G (1962) The Agaricales of New Zealand: III. Kew Bull 16:227-237. https://doi.org/10.2307/4118823

Truong C, Mujic AB, Healy R et al (2017) How to know the fungi: combining field inventories and DNA-barcoding to document fungal diversity. New Phytol 214:913-919

Varga T, Krizsán K, Földi C et al (2019) Megaphylogeny resolves global patterns of mushroom evolution. Nat Ecol Evol 3:668. https://doi.org/10.1038/s41559-019-0834-1

Vasco-Palacios AM, Franco-Molano AE (2013) Diversity of Colombian macrofungi (Ascomycota-Basidiomycota). Mycotaxon 121:499

Vidal JM, Bellanger J-M, Moreau P-A (2016) Tres nuevas especies gasteroides del género Entoloma halladas en España. Boletín Micológico De FAMCAL 11:53-78

Vila J, Carbó J, Caballero F et al (2013) A first approach to the study of the genus Entoloma subgenus Nolanea sensu lato using molecular and morphological data. Fungi Non Delineati 66:3-62

Vilgalys R, Hester M (1990) Rapid genetic identification and mapping of enzymatically amplified ribosomal DNA from several Cryptococcus species. J Bacteriol 172:4238-4246

Weholt Ø, Lorla as J, Eidissen SE (2014) One new and one rare species of Entoloma from the Norwegian nature reserve Holmvassdalen. Österr Z Pilzk 23:55-60

White TJ, Bruns T, Lee S, Taylor JW (1990) Amplification and direct sequencing of fungal ribosomal RNA genes for phylogenetics. In: Innis MA, Gelfand DH, Sninsky JJ, White TJ (eds) PCR protocols: a guide to methods and applications. pp 315-322

Publisher's note Springer Nature remains neutral with regard to jurisdictional claims in published maps and institutional affiliations. 